RICE UNIVERSITY

\title{
Developing a Radar-based Flood Alert System \\ For Sugar Land, Texas
}

by

Andrew Juan

A THESIS SUBMITTED

IN PARTIAL FULFILLMENT OF THE

REQUIREMENTS FOR THE DEGREE

\section{Master of Science}

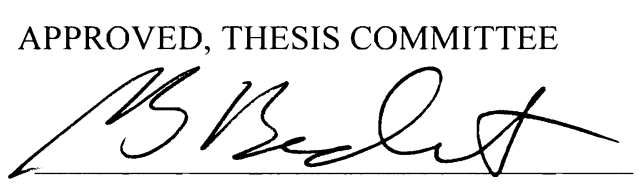

Philip Bedient, Herman and George R.

Brown Professor of Civil Engineering

Civil and Environmental Engineering

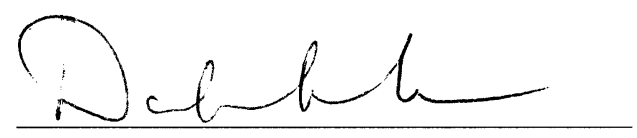

Dale Sawyer, Professor

Earth Science

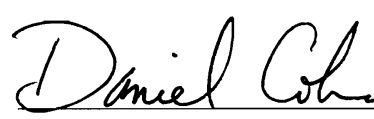

Daniel Cohan, Assistant Professor

Civil and Environmental Engineering

HOUSTON, TEXAS

APRIL 2011 


\begin{abstract}
Developing a Radar-based Flood Alert System for Sugar Land, Texas

by
\end{abstract}

\begin{abstract}
Andrew Juan
This thesis presents a framework for a radar-based flood alert system (FAS) for the Oyster Creek Watershed to aid the City of Sugar Land in flood forecasting. The motivation for using this particular system stems from a radar's ability to provide flood warning lead-time when calibrated with available gauge information. This study follows a typical workflow in analyzing watersheds, which involves converting excess rainfall to runoff, then converting the resulting flow rates to polygons that show water levels.

This thesis also introduces the Flood Warning Indicator (FWI) as a component of Sugar Land's FAS. FWI only uses radar rainfall to portray potential flooding problems within the watershed through GIS mapping, which is helpful when gauge information is unavailable. Having a significant role in the communication of flood information, FWI may be applied in other areas that lack the resources to build extensive gauge networks for flood monitoring and radar calibration.
\end{abstract}




\section{Acknowledgements}

First of all, I will like to thank my advisor Dr. Philip Bedient, for providing me with much support, guidance, and instruction, not only in this thesis but also throughout my two years at Rice. I will also like to thank my committee members Dr. Daniel Cohan and Dr. Dale Sawyer for their input and advice.

Special thanks to Mr. Shashi Kumar and the City of Sugar Land for their continuous support in this project.

I will like to thank everyone in the Hydrology and Water Resources Group from the Civil and Environmental Engineering Department at Rice: Jason Christian, Emilia Stepinski, Heather Winter, Antonia Sebastian, Frances Kellerman, and Roni Deitz. Special thanks to Dr. Nick Fang for his invaluable insights and help in this project. Many thanks to my office mates Brandon Duncan and Aarin Teague for all their help, support, and ideas in these two years.

Finally, but most importantly, I will like to thank God for giving me the passion, opportunity, and ability to pursue my interests, and also providing me with parents that constantly give words of wisdom and encouragement. 


\section{Table of Contents}

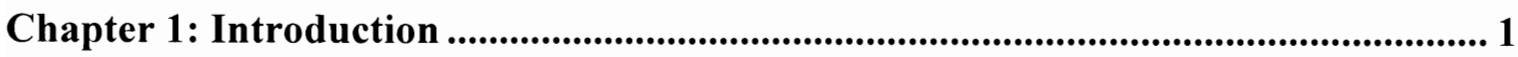

1.1 Motivation and Study Area ...................................................................... 1

1.2 Research Objectives............................................................................... 5

Chapter 2: Literature Review .................................................................................. 7

2.1 Floodplain and the Need for Flood Control ................................................... 7

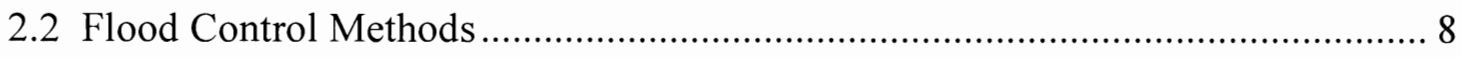

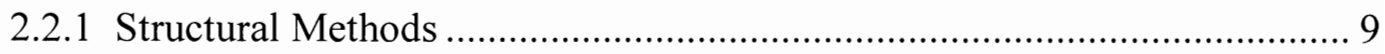

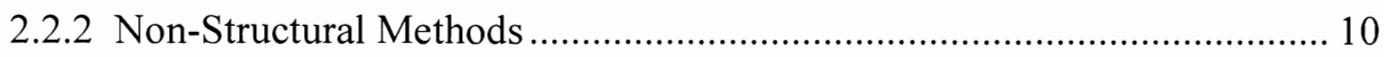

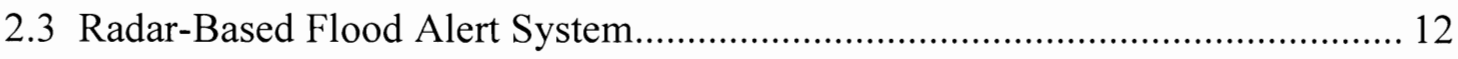

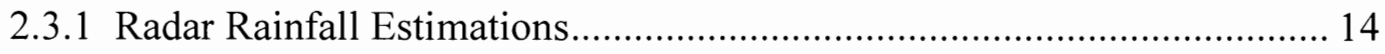

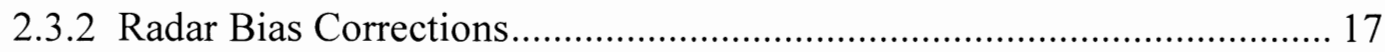

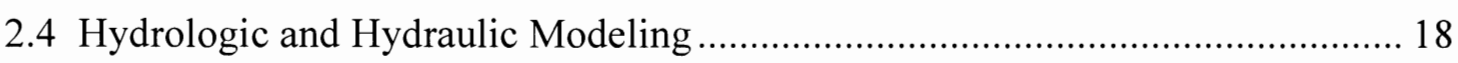

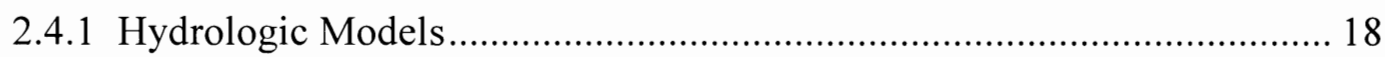

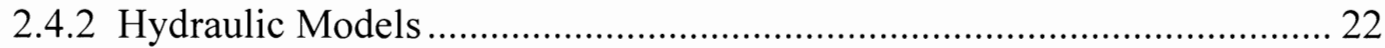

2.5 The Role of GIS and Remote Sensing in Hydrology .................................. 22

Chapter 3: Model Development and Calibration ........................................................ 26

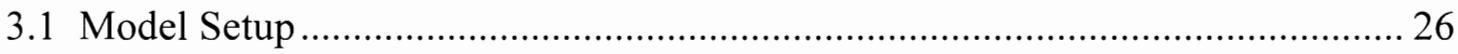

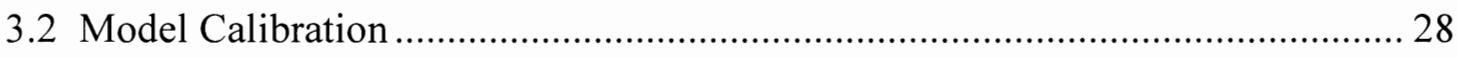

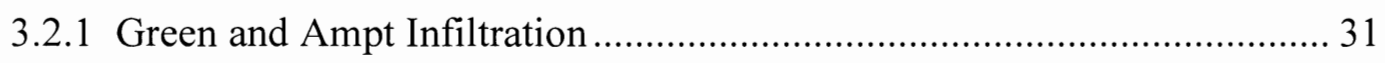

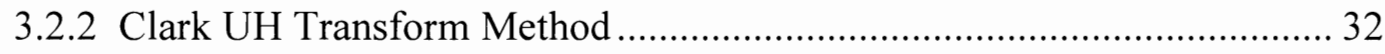

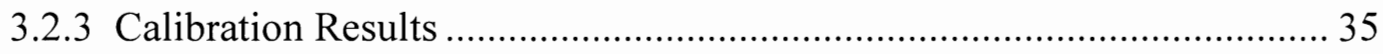

Chapter 4: Flood Vulnerability Assessment................................................................... 39

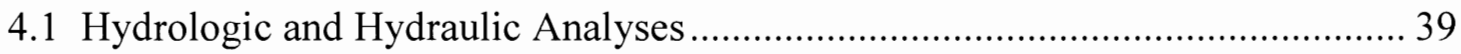

4.2 Identification of Flood Prone Areas................................................................... 42

4.3 Assessment of Structural Flood Control Scenarios .......................................... 44 
Chapter 5: Sugar Land Flood Alert System (FAS)........................................................ 50

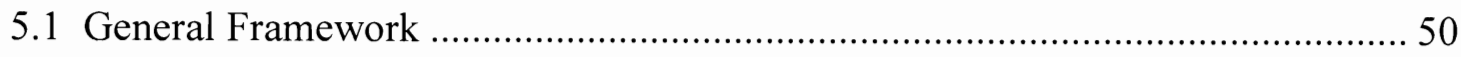

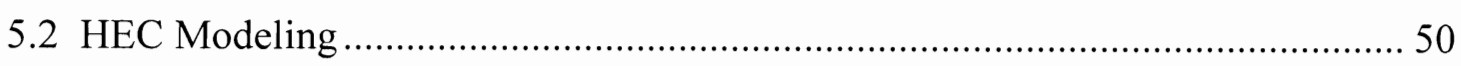

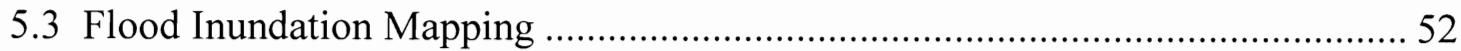

5.4 Floodplain Map Library (FPML) …………………………………………..... 55

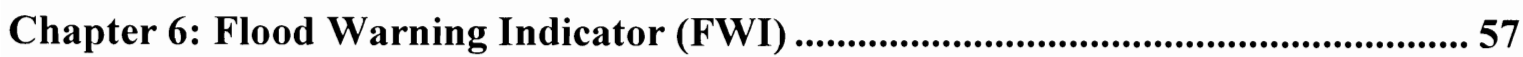



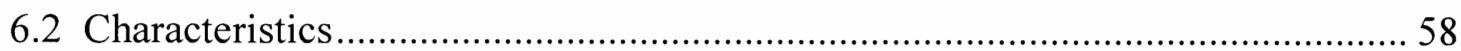

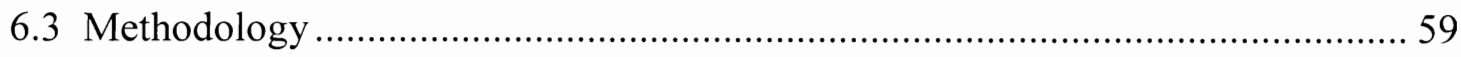



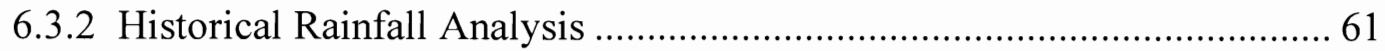

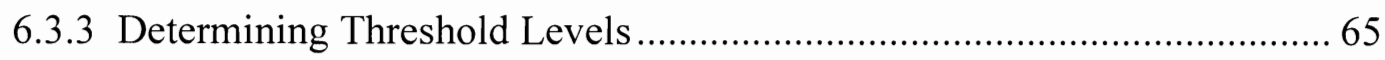

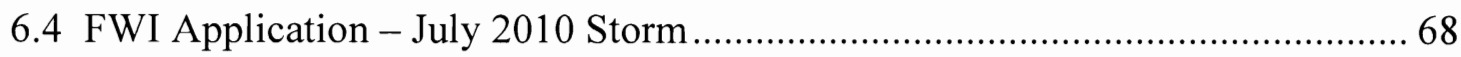

Chapter 7: Conclusions and Recommendations ........................................................... 71

7.1 Objective 1: Create and calibrate the hydrologic models of Oyster Creek

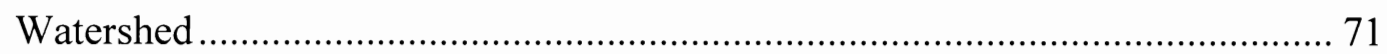

7.2 Objective 2: Determine the flood vulnerability of the watershed and assess the effectiveness of structural flood control options .................................................. 71

7.3 Objective 3: Develop a framework for a real-time radar-based flood warning

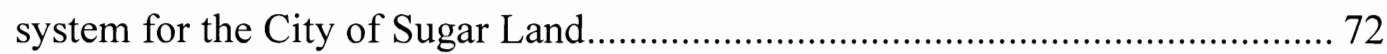

7.4 Objective 4: Introduce the radar-based Flood Warning Indicator (FWI) as a flood

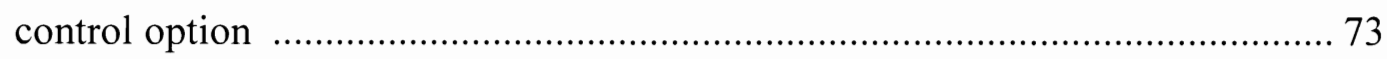

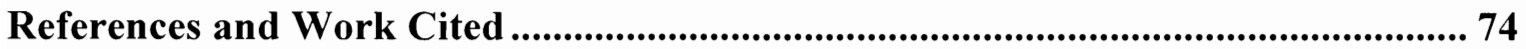

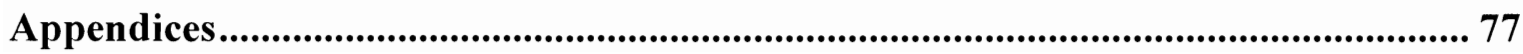




\section{List of Figures}

Figure 1.1: Oyster Creek Watershed and Sugar Land, TX ........................................ 2

Figure 1.2: Sugar Land's rain gauge locations .......................................................... 4

Figure 2.1: Schematic of a 100-year floodplain ......................................................... 7

Figure 2.2: Typical workflow of a radar-based flood alert system............................... 12

Figure 2.3: Completed WSR-88D installations in the contiguous U.S. ........................ 15

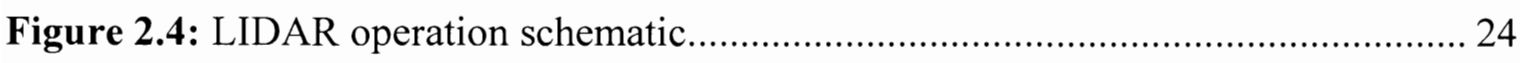

Figure 3.1: HEC-HMS 3.3 basin model of Oyster Creek Watershed ............................ 27

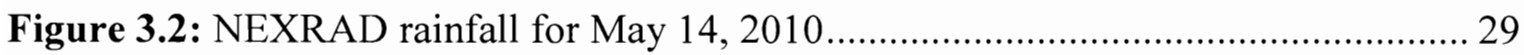

Figure 3.3: Stream gauge locations along Oyster Creek .............................................. 30

Figure 3.4: K variations vs. original HEC-HMS model .............................................. 32

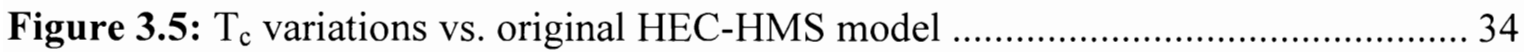

Figure 3.6: R variations vs. original HEC-HMS model ............................................. 35

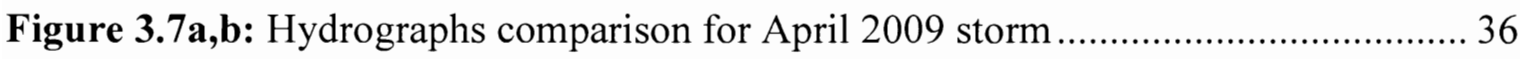

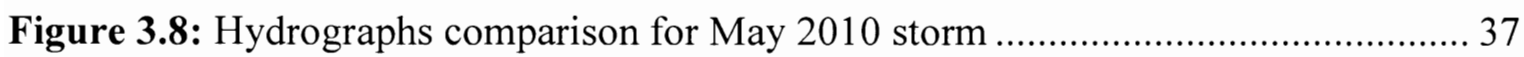

Figure 4.1: Steady-state HEC-RAS 10-year 3D profile of Oyster Creek ........................ 41

Figure 4.2: 100-year outflows at selected junctions from HEC-HMS $3.3 \ldots \ldots \ldots \ldots \ldots \ldots . . . . . . . . . .42$

Figure 4.3: Steady-state HEC-RAS 100-year 3D profile of Oyster Creek showing flood-

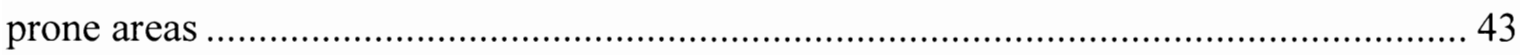

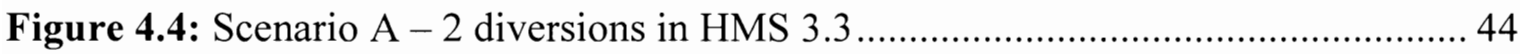

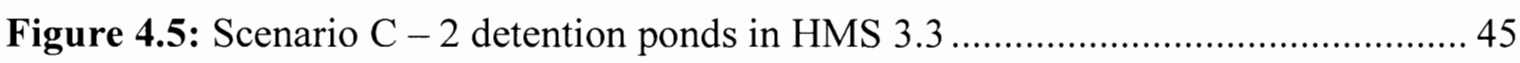

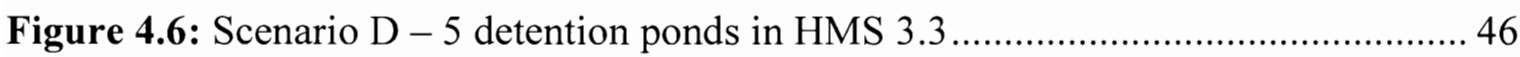

Figure 4.7: Scenario E - 3 detention ponds with channel modifications ...................... 46

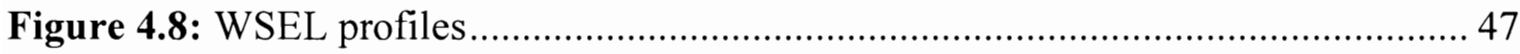

Figure 5.1: Sugar Land Flood Alert System ............................................................... 51

Figure 5.2: Calibrated 10-year floodplain map of Oyster Creek .................................. 53

Figure 5.3: Calibrated 100-year floodplain map of Oyster Creek ............................... 53

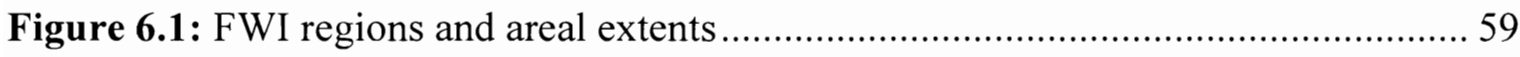

Figure 6.2: Total rainfall distribution comparison for July 2010 storm ....................... 60

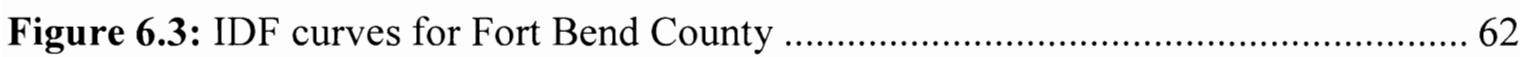


Figure 6.4: Fort Bend County Rainfall Depth Duration - Frequency Curves ................ 63

Figure 6.5: Historical max.24-hr rainfall at Sugar Land Regional Airport ................... 64

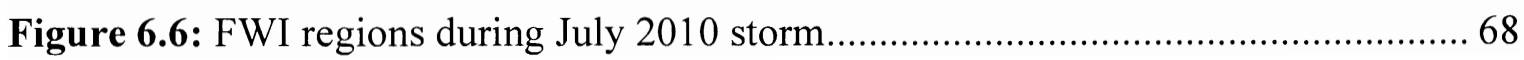




\section{List of Tables}

Table 1.1: Top 10 U.S. flood disasters.................................................................... 1

Table 3.1: Analyzed storms for model calibration..................................................... 29

Table 3.2: Error comparisons for April 2009 storm................................................ 38

Table 3.3: Error comparisons for May 2010 storm at Location $F$.............................. 38

Table 4.1: HEC-RAS river stations with corresponding HEC-HMS junctions .............. 40

Table 4.2: WSEL comparison for varying flood control scenarios .............................. 48

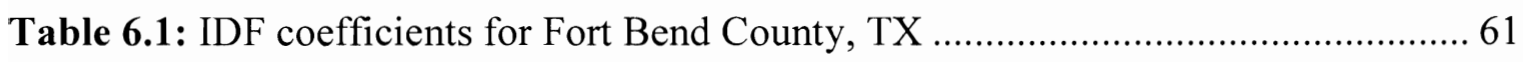

Table 6.2: FWI threshold levels for the rainfall intensity procedure ............................. 66

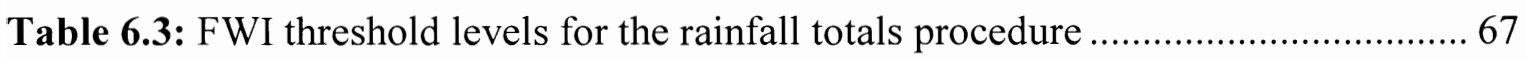

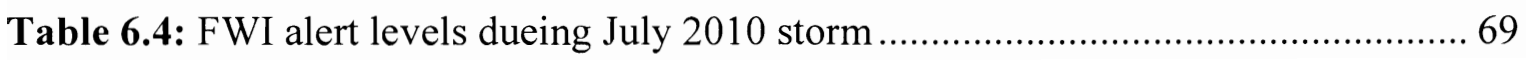




\section{Chapter 1: Introduction}

\subsection{Motivation and Study Area}

Flooding occurrences and their devastating effects have become increasingly common in the United States over the last few decades. Floods are considered as the most damaging natural hazard in the United States (Pielke Jr., Downton et al. 2002). The table below shows the top ten U.S. flood disasters from early 1990s to 2004.

\begin{tabular}{|lcc|}
\hline Event & Date & Paid Losses (in millions) \\
\hline TS Allison & Jun-01 & $\$ 1,095$ \\
\hline Hurricane Ivan & Sep-04 & $\$ 648$ \\
\hline Louisiana flood & May-95 & $\$ 584$ \\
\hline Hurricane Isabel & Sep-03 & $\$ 449$ \\
\hline Hurricane Floyd & Sep-99 & $\$ 439$ \\
\hline Hurricane Opal & Oct-95 & $\$ 400$ \\
\hline Nor'easter & Dec-92 & $\$ 342$ \\
\hline Midwest floods & Jun-93 & $\$ 271$ \\
\hline Texas flood & Oct-94 & $\$ 217$ \\
\hline Hurricane Fran & Sep-96 & $\$ 214$ \\
\hline
\end{tabular}

Table 1.1: 10 U.S. flood disasters (adapted from www.fema.gov)

Recorded by the National Oceanic and Atmospheric Association (NOAA) as the worst urban flood in U.S. history, Tropical Storm Allison brought widespread flooding to Houston and its surrounding areas. After Allison occurred in 2001, the region completely overhauled its flood control schemes. This major overhaul resulted in the Tropical Storm Allison Recovery Project (TSARP), a joint flood recovery project between the Harris County Flood Control District (HCFCD) and the Federal Emergency Management Association (FEMA). One of the goals of TSARP is to increase public awareness regarding the dangers and risks of flooding. As a result of TSARP, many cities surrounding Houston have realized the importance of implementing flood mitigation 
strategies in their own communities. Such city is Sugar Land, a vibrant city located approximately 20 miles southwest of downtown Houston.

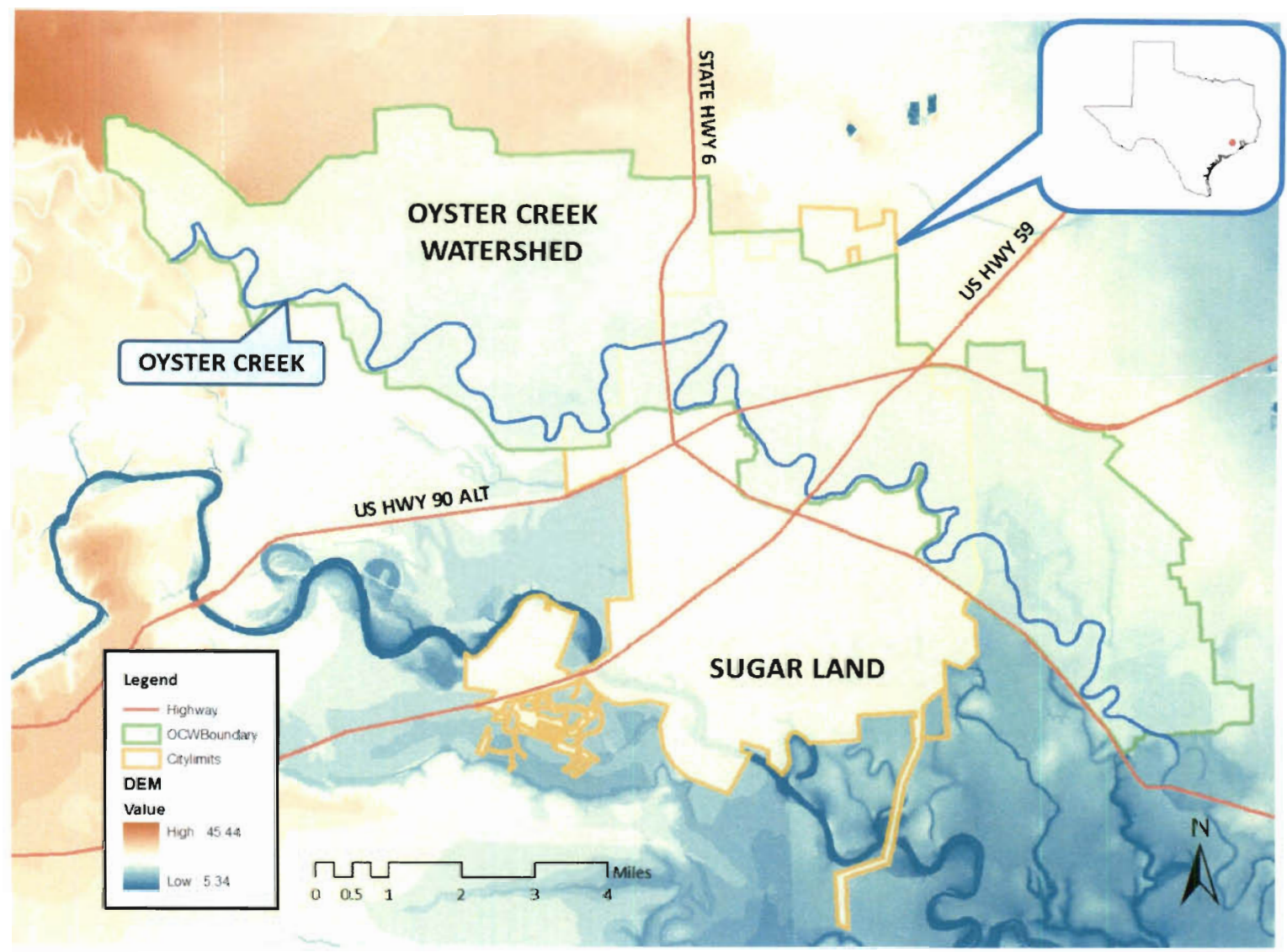

Figure 1.1: Oyster Creek Watershed and Sugar Land, TX

This thesis focuses on the establishment of a reliable flood warning system for the Oyster Creek Watershed in Fort Bend County, Texas to aid the City of Sugar Land in flood forecasting and management. Sugar Land is one of the fastest-growing cities in Texas, having grown nearly 160 percent from 24,529 in 1990 to 63,328 in 2000 . The U.S. Census Bureau estimated that the city's population was 84,511 in January 2010. The above figure shows the Oyster Creek Watershed, a major drainage area that covers approximately 46 square miles with 33 sub-basins. It is a complex watershed, due to the presence of numerous flood control structures, such as dams and diversions. The main 
channel, Oyster Creek, runs southeast through Sugar Land and discharges to the Brazos River.

Topographically, the Oyster Creek Watershed sits on a relatively flat region. Ground slopes throughout the watershed are generally less than 10 feet per mile. Clay and silt-loam soil dominate the soil type of the watershed, resulting in low permeability and high runoff potential. Land uses encompass single-family residential, commercial, and industrial establishments, mostly concentrated in the center portion of the watershed.

A few hydrologic and hydraulic studies over the past three decades on Oyster Creek have been conducted. The earliest study was the Flood Insurance Study conducted in 1977, which was updated in 2001. Other studies included the Missouri City Master Drainage Plan and its update (1987 and 2001), the Implementation Program and Impact Fee for Upper Oyster Creek Watershed $(1989,1992)$, and the most recent flood insurance study, the DFIRM update (2006), conducted by Michael Baker Jr., Carter Burgess, CDM, and Moffatt Nichols. The results of these studies served as a framework to update existing datasets and models. This update was necessary, since previous studies were calibrated with design storms, while the updated models have been calibrated to actual storm events in addition to design storms.

Currently, the city's flood monitoring system includes fifteen operational gauges that relay precipitation information (see Fig.1.2) to emergency personnel. Although the gauge network is useful for general hydrologic and hydraulic analyses, it is insufficient to provide any lead time for flood warning - as is true for most flood warning systems that solely rely on gauges. To address this limitation, a radar-based flood alert system was proposed in 2009 for the City of Sugar Land. According to Bedient et al. (2003), the main 
advantage of using a radar-based flood alert system over traditional gauge-based systems is the increased lead time for flood warning. Depending on the size of the watershed, rainfall amount, and channel characteristics, radar can often provide up to three hours of flood warning lead time. Precipitation data obtained from radar are generally more accurate than those recorded by rain gauges, due to radar having denser spatial and temporal coverage. When radar rainfall is calibrated with available rain gauges to correct any systematic or instrumentation bias, it can provide accurate real-time rainfall estimates for use in hydrologic models.

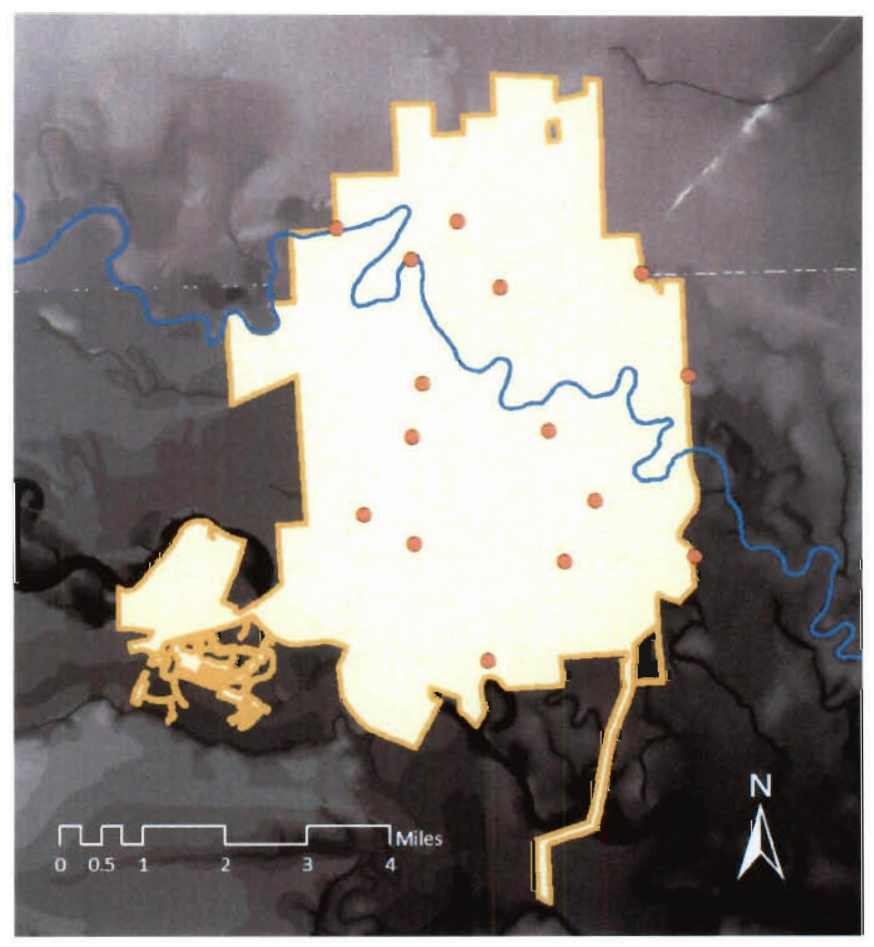

Figure 1.2: Sugar Land's Rain Gauge Locations

A hydrologic model that accurately depicts the drainage and characteristics of the watershed is an important prerequisite for a reliable radar-based flood warning system. The hydrologic models used in this research are HEC-1 and HEC-HMS. The hydrologic inputs include calibrated radar rainfall information delivered by Vieux and Associates, 
Inc. based in Oklahoma as well as local precipitation and stream gauges data obtained from the city of Sugar Land. Hydrographs that are produced from the hydrologic models were then imported into a hydraulic model, HEC-RAS, to generate water surface profiles of various cross sections along the channel. This particularly useful feature of HEC-RAS may be converted to floodplain maps in ArcGIS, which illustrate real time visualizations of the flooding extents in the watershed during a storm event. The floodplain maps, along with the created hydrologic outputs would then be communicated to emergency personnel to plan for any necessary actions.

As part of Sugar Land's flood alert system, the Flood Warning Indicator (FWI) is also presented. Unlike a typical radar-based flood warning system, the FWI mainly utilizes radar rainfall to show potential flooding problems within the watershed through GIS mapping. This technique is especially useful when data from gauges are unavailable. Although it does not provide detailed information regarding the extents of flooding at specific locations throughout the watershed, it holds a significant role in the communication of flood information for the City of Sugar Land. This unique capability of FWI may potentially be applied in other areas that lack the resources to build extensive gauge networks for flood monitoring and radar calibration.

\subsection{Research Objectives}

The research objectives of this thesis are outlined as follows:

1. Develop an accurate hydrologic model of the Upper Oyster Creek Watershed.

- Compare existing models with historical design storms.

- Calibrate models with actual storms by utilizing radar rainfall estimates. 
2. Evaluate the overall flooding vulnerability of the watershed and assess the effectiveness of structural flood control options.

3. Develop a framework for an operational radar-based flood alert system for the City of Sugar Land.

4. Develop and implement the radar-based Flood Warning Indicator (FWI) as a flood control option for areas that lack sufficient gauge networks. 


\section{Chapter 2: Literature Review}

\subsection{Floodplain and the Need for Flood Control}

Flood is defined by the U.S. Executive Office of the President (USEOP, 1994) as "a general and temporary condition of partial or complete inundation of normally dry land areas from the overflow of river and/or tidal waters and/or the unusual accumulation of waters from any source that may be associated with undesirable effects to life and property." According to the Federal Emergency Management Agency (FEMA), flood is one of the most dangerous and common natural disasters in the United States (FEMA 2006a). In 2005, the National Climatic Data Center stated that hurricanes and floodrelated disasters account for most of the natural disasters occurring between 1980 and 2005 that resulted in damages exceeding one billion dollars. The majority of these disasters occurred in highly urbanized and coastal floodplains, and therefore increased the overall flooding damages (Correia et al. 1999).

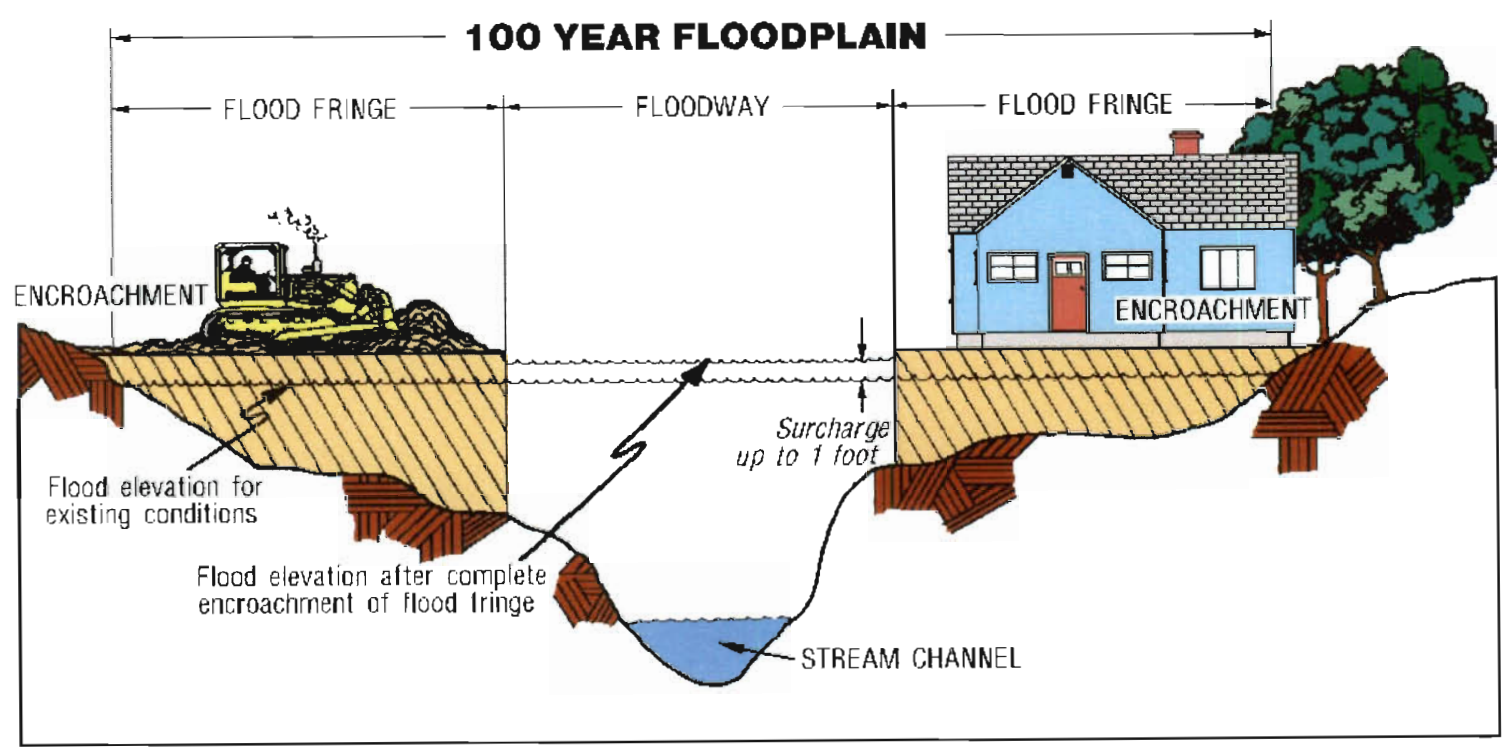

Fig.2.1. Schematic of a 100-year floodplain (Source: www.dnr.ne.gov) 
According to Bedient, Huber, and Vieux (2008), a floodplain is defined as lowland surfaces that connect to a water body (i.e. rivers and lakes) that are prone to flooding. Floodplains are often categorized based on various flood return periods. A 100year floodplain, shown in Figure 2.1, means that the area would be inundated by a 100year flood, also known as a $1 \%$ annual exceedance probability flood. History shows that many civilizations have prospered in areas close in proximity with water bodies. From the ancient Egypt civilization that originated over 5,000 years ago to the present, communities have chosen to live near rivers, lakes, or at coastal regions due to the need of water to support life. Due to explosive population growths in the past century, increasingly more people have migrated from rural to urban areas. Unfortunately, many of these urban areas are located in floodplains where they are most susceptible to flooding damages.

\subsection{Flood control methods}

To reduce potential flooding damages, it is imperative that floodplain characteristics be well understood. Recognizing the importance of having sufficient floodplain data to minimize associated flood losses, FEMA and the U.S. Army Corps of Engineers (USACE) have identified and delineated most major channels and floodplains in the United States through the National Flood Insurance Program (NFIP). Building on

their work, other studies such as TSARP (2006) were able to collect more region-specific floodplain information, which resulted in the formulation of various flood control strategies. There are a number of approaches that one may choose for flood control: structural, nonstructural, or a combination of both. Structural methods may include 
detention ponds, channel modifications, or diversions; while nonstructural methods may consist of flood insurance policies, home buyouts, or flood warning systems.

\subsubsection{Structural Methods}

Structural flood control strategies are usually applied to a watershed or a catchment. A watershed is an area where all its water drains into a single outlet (Bedient, Huber, and Vieux 2008). These flood control strategies may include detention ponds, channel modifications, and diversion channels.

- Detention ponds: Detention ponds are used to hold runoff for a short period before releasing the water back into the main channel. Since detention ponds (especially small ones) can be integrated into existing landscapes such as golf courses and parks, this option is more likely to be accepted by the general public than other structural options due to aesthetic considerations and minimal environmental impacts.

Generally, detention ponds are placed in the upper or middle portions of the watershed to protect the areas downstream.

- Channelization: Channel modifications are used to improve the conveyance of a channel. This can be done by modifying channel slope, depth, width, or roughness. The goal of channel modification is to increase hydraulic efficiency, which increases channel velocity, resulting in reduced flood stage or water elevation during a storm event. A downside to the improved conveyance, however, is the increased possibility of flooding at the downstream portion of the channel. Therefore, it is imperative that modifications to the channel be done properly. Also, though channel modifications have been widely used in meandering streams of the South and Southeastern coastal 
plains, one needs to carefully assess the potential environmental impacts caused by those modifications, such as the possibility of increased erosion of stream banks and the increased downstream deposition of silt and sedimentation.

- Diversions: Diversions are mainly used to reroute a portion of water flow away from a flood-prone area. This option may be feasible if another channel or basin exists within the vicinity of the flood-prone area to which the diversion can be routed to. For this option, it is important that the target channel or basin where the diversion is routed to not be located too far from the main channel. Another consideration is to properly size the diversion so that it would not cause flooding in the diverted areas. In addition, right-of-ways must be considered when diverting flows into adjacent channels or basins.

\subsubsection{Nonstructural Methods}

Nonstructural approaches were often overlooked in past flood control projects. However, disasters such as the Midwest floods in 1993 and Hurricane Katrina in 2005 have shown that pure structural methods are insufficient to provide protection from flood damage. After Katrina, the USACE established the National Flood Risk Management Program (NFRMP) to coordinate flood management efforts both internally and externally with other agencies. One of NFRMP's goals is to promote nonstructural approaches for flood control (USACE 2010). The purpose of nonstructural approaches is to carefully manage flood prone areas such as those that lie within the floodplain to minimize overall damage. This approach differs from structural methods in that it does not attempt to alter 
outflows and/or flow directions. Examples of nonstructural methods include flood insurance programs, buyouts of flood prone properties, and flood warning systems.

- Flood insurance programs: The most prominent flood insurance program in the U.S. is the National Flood Insurance Program (NFIP). This program aims to protect property owners from flooding losses in participating flood prone areas, while at the same time reduce post-disaster government's assistance. The program was a result of the National Flood Insurance Act of 1968, as a response to prevent future losses such as those experienced by Florida and Louisiana due to Hurricane Betsey in 1965 .

- Voluntary property buyouts: Buyouts of flood prone properties, as the name implies, attempts to reduce flood damage by removing any houses or other types of property in locations that are most susceptible to flooding. This option may be selected when structural alternatives such as channelization or building detention ponds are considered not to be cost effective.

- Flood alert systems: Various forms of flood alert systems have been used in the United States after World War II to reduce flood damages in susceptible areas (Bedient, Huber, and Vieux 2008), from conventional tables that showed water elevations linked to precipitation amounts to sophisticated models that had the capabilities to predict the likelihood of flooding. Conventional flood alert systems employ a series of rain and stream gauges to provide the necessary precipitation and stream elevation data. Newer flood alert systems (e.g. a radar-based flood alert system that will be discussed in the next section) often utilize high definition weather radar to collect rainfall information in addition to those recorded by the gauge network. 


\subsection{Radar-based Flood Alert System}

Hoblit et al. (1999) stressed the importance of having a reliable flood warning system, especially in urban areas, which are usually more vulnerable compared to rural regions since they have denser populations and have limited spaces for flood control structures. In recent years, increasing usage of radar-based flood warning systems was observed. As mentioned in the last section, a radar-based flood alert system uses weather radar to collect rainfall data calibrated with available gauge recordings. Generally, as shown in Figure 2.2, the calibrated radar rainfall data are input and processed in hydrologic and hydraulic models which result in floodplain maps that communicate flood risk information. This information may then be disseminated to the public or be used for other purposes such as evacuation planning and future development designs.

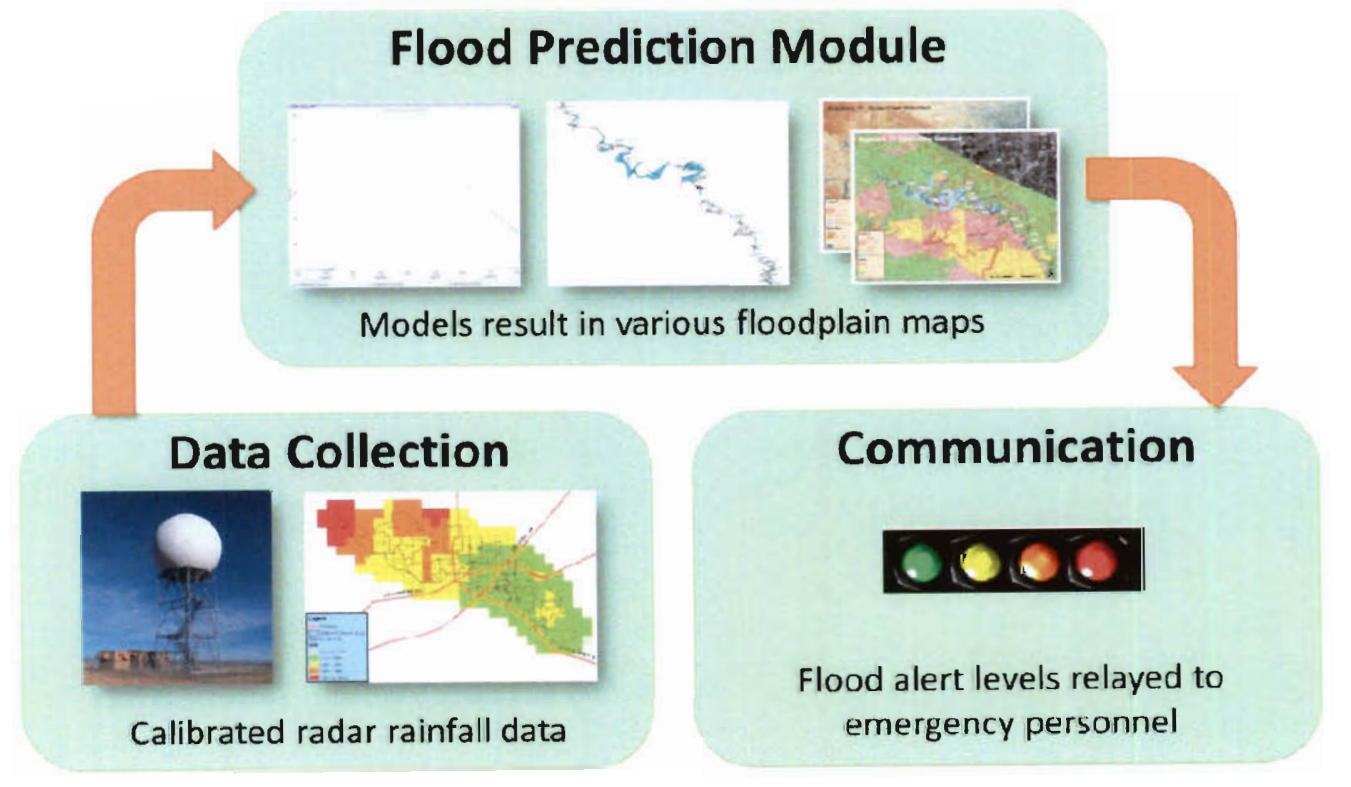

Fig.2.2. Typical workflow of a radar-based flood alert system

The major impetus of using a radar-based flood alert system as opposed to a conventional gauge-based flood alert system is the increased flood warning lead-time 
provided by radars. Since the 1970s, the U.S. had been relying on rain and stream gauge networks for flood warning systems developed by NWS, called the Automated Local Evaluation in Real-Time (ALERT). Bedient et al. (2003) claimed that apart from their inferior spatial and temporal coverages, the ALERT systems require huge maintenance and operating costs since they rely on widely-spread mechanical instruments. Other factors such as debris obstructions or faulty data transmissions may also adversely affect the performances of the gauges during a storm event.

Furthermore, Fang et al. (2008) pointed out that the effects of limited spatial and temporal coverages were especially apparent in highly urbanized areas. This sentiment was supported by Berne et al. (2004), who analyzed rainfall data collected in Marseille, a large city located in the southeast of France. Due to the Mediterranean climate, the city often experiences heavy rainfall, especially during the summer. By investigating various spatial-temporal scales of urban watersheds and rainfall data collected from gauge networks, Berne et al. (2004) were able to determine the gauge densities required for effective hydrologic analyses in urban settings. Their results show that urban watersheds require an extensive gauge network to fulfill the spatial requirements. For example, Marseille requires that every gauge be able to cover a $12 \mathrm{~km}^{2}$ area with a recording time interval of 6 minutes. As a comparison, a typical urban watershed has 1 rain gauge that covers approximately 100 square miles $\left(\sim 259 \mathrm{~km}^{2}\right)$. Houston fares much better in this regard. The Harris County Office of Emergency Management (HCOEM) has a gauge density of one gauge for every 16 square miles. However, other urban and suburban areas are unlikely to have this level of coverage. This condition leads to the stipulation that reliance on gauges alone is both impractical and ineffective. 
When a rain gauge network is used as the sole method of recording rainfall information at a watershed, rainfall amounts are distributed based on rain gauge readings. Otherwise, uniform rainfall averaged by all gauges has to be assumed for the entire watershed. Although it provides a quick and easy way to input rainfall information in hydrologic models, assuming a uniform rainfall over the entire watershed may very likely lead to inaccurate hydrographs responses (Bedient, Huber, and Vieux 2008).

Studies by Bedient et al. (2003) as well as other scholars (Vieux and Bedient 2004; Neary, Habib, and Fleming 2004) have proven that the hydrographs' rising limbs and peak flows produced from calibrated radar data were more accurate than those produced from rain gauges alone when input into hydrologic models. One particular study by (Bedient et al. 2003) showed that a radar-based flood alert system is superior to stand-alone gauge-based systems. Bedient et al. had developed a flood alert system (FAS) to monitor and forecast flooding events for Brays Bayou located in Houston, Texas. They used rainfall data collected by radar, which provided real-time precipitation information for every 6 square mile grid cells. The original FAS had color-coded alert levels that were based on rainfall intensities, duration and peak flows. The resulting FAS allowed for 2-3 hours of flood warning lead time and also showed that the simulated models had hydrographs that compared well with observed stream flows.

\subsubsection{Radar Rainfall Estimations}

High-definition weather radar provides real-time rainfall tracking up to $230 \mathrm{~km}$ away from its installation location. The advantages of this instrument prompted its use for large and small-basin flood warning systems as well as water resources management 
(James, Robinson, and Bell 1993; Krajewski and Smith 2002; Vieux, Park, and Kang 2009; Villarini et al. 2010). The radar mentioned in this context is NEXRAD, which stands for next-generation radar. It is technically known as WSR-88D, which operates in the 10-cm wavelength (S-band), and has the capability to record reflectivity, radial Doppler velocity, and the broad spectrum width of reflected signals.



Fig.2.3. Completed WSR-88D installations in the contiguous U.S. (Source: www.roc.noaa.gov)

There are currently approximately 160 WSR-88D radars installed throughout United States (see Fig. 2.3). NEXRAD operates by transmitting microwave pulses to the target and then detects the returned pulse, also known as the radar reflectivity. Several factors affect radar rainfall detection: atmospheric conditions between radar and target rainfall, distance from radar to the target, and characteristics of both the radar and the target (Bedient, Huber, and Vieux 2008). Radar reflectivity data is collected at $1 \mathrm{~km}$ in 
range from the radar station and at 1 degree radial resolution, therefore producing a radial coordinate system of reflectivities for each tilt angle.

The reflectivity data can be obtained through volume scans of the entire watershed, which includes sweeps for increasing antenna elevation angles, usually occurring every 5-15 minutes. A specific reflectivity-rainfall (Z-R) relationship can then be determined by using two different approaches: drop size distribution (DSD) and the optimization approach. According to Bedient, Huber, and Vieux (2008), the standard Z-R relationship used at the time of deployment of WSR-88D was:

$$
Z=300 R^{1.4}
$$

where $Z$ indicates radar reflectivity and $R$ denotes rainfall. The Houston-Galveston NWS Forecast Office, however, viewed that the standard Z-R relationship did not accurately reflect the warm tropical drop distributions caused by underestimation of rainfall totals in that particular region. Therefore, the following tropical Z-R relationship was established:

$$
Z=200 R^{1.2}
$$

According to Krajewski and Smith (2002), the DSD method derived Z-R relationships from raindrop size distribution that are usually observed at the surface representing a sample volume of $1 \mathrm{~m}^{3}$. Via statistical methods, Z-R relations can be determined and selected for a given major rainfall event. Problems associated with the DSD approach include reliance of said parameters on statistical methods, sample size of the data used, and instruments used to collect the data. Since instrumental errors were generally disregarded in this approach, difficulties such as bias and nonlinear transformation of radar-reflectivity measurements may arise. For the optimization 
approach, radar reflectivity measured in the atmosphere is related to surface observations of rainfall rate (i.e. from rain gauges). This approach tends to reduce errors that may be caused by sampling properties that relate surface radar reflectivity to atmospheric radar reflectivity.

\subsubsection{Radar Bias Corrections}

Krajewski and Smith (2002) define bias as the "systematic departure from the true, unknown rainfall." Since bias is an inevitable result of radar reflectivity conversion to rainfall, they emphasized the importance of identifying and quantifying bias to understand the error structure of radar-rainfall estimates. For this purpose, Bedient et al (2000) calculated bias by the following relationship:

$$
\text { Bias }=\frac{(\text { Radar measurement }- \text { Gauge measurement })}{\text { Gauge measurement }}
$$

A negative bias means that the radar under-predicted the rainfall values and a positive bias indicates over-prediction of precipitation amount. Bias can be caused by various factors, including miscalibration of radar, overshooting of cloud systems, improper applications of Z-R relationships, and subcloud evaporation of raindrops. Therefore, calibrating radar rainfall data with rain gauge data is imperative to minimize systematic errors in rainfall data collections by radar and to improve accuracies of the hydrologic models used.

The attempts to correct systematic errors in radar began with the work of Wilson and Brandes (1979), in which they proposed the following two methods: ratio of the means and mean of the ratios in numerous gauge recordings. Stemming from their work, other scholars were able to use various methods to further reduce errors from radar 
rainfall. For example, Seo and Breidenbach (2002) were able to conduct real-time correction of non-uniform radar rainfall bias using rain gauge measurements. In another study, Ciach et al. (2000) showed that reducing conditional bias resulted in improved radar rainfall accuracies. Due to the advances in radar technologies, results achieved in other studies (Brandes, Vivekanandan, and Wilson 1999; Vivekanandan, Yates, and Brandes 1999; Krajewski, Villarini, and Smith 2010) have generally shown significant improvements of radar rainfall estimates. In light of this, bias-corrected radar rainfall data used in this thesis were acquired from Vieux and Associates, Inc. based in Oklahoma for two storm events that occurred in April 2009 and May 2010.

\subsection{Hydrologic and Hydraulic Modeling}

Besides having gauge-calibrated radar rainfall data, a successful flood prediction system also requires accurate hydrologic and hydraulic models, both of which will be discussed in the following sections.

\subsubsection{Hydrologic Models}

Hydrologic models take the characteristics of the watershed and precipitation information to simulate their hydrologic responses. Over the years, the use of hydrologic models has vastly improved the accuracy and reliability of flood prediction methods. This improvement is attributed to the models' capabilities to process the increasing quality and quantity of datasets used.

Hydrologic models are categorized based on how they handle spatial variability. These models are lumped, distributed, and semi-distributed models. Lumped parameter 
models transform uniform rainfall into the watershed and convert it to runoff and stream flow, without considering the spatial variability of the model inputs. An example of a lumped model is the HEC-1 model developed by USACE in the 1960s, which is one of the most widely used lumped parameter models for hydrologic prediction and has seen extensive uses in Texas for local hydrographs and peak flows determination. HEC-1 simulates the runoff response of a river basin to rainfall by representing a watershed as a series of inter-connected systems of hydrologic and hydraulic elements. The updated version of HEC-1 is HEC-HMS, which was also developed by USACE, released in 1998. According to Bedient, Huber, and Vieux (2008), unless extensive spatial and temporal watershed information is available, performing hydrologic analysis using a lumped model is generally recommended.

On the other hand, distributed models attempt to account for spatial variability in the watershed by assigning specific hydrological parameters at certain points in the basin and therefore minimizing the need for data extrapolation between those points. Distributed models typically employ mass, momentum, and energy conservation equations to simulate the hydrologic processes in numerous small, interconnected grid cells. Therefore, distributed models require much more extensive and detailed hydrological inputs compared to lumped models. These models have been used in various watershed studies (Dutta et al., 2000, Ogden et al., 2001, Vieux et al., 2009, and Sharif et al., 2010). Examples of distributed models include the TOPMODEL developed by Beven and Kirkby in 1979, SWAT (Arnold et al. 1998), and Vflo ${ }^{\mathrm{TM}}$ (Vieux and Bedient 2004).

There has been much debate regarding the efficacy of distributed models over their lumped counterparts. Although distributed models are theoretically more accurate 
since they account for spatial variability, their simulation results often showed no significant improvements compared to lumped models. Bates (2004) claimed that conventional distributed models had two weaknesses: insufficient amount of distributed data to be input into the models and the uncertainties associated with converting the parameters designed for point-based scales to grid scales. However, according to Bates, recent advances in remote sensing technologies such as Light Detection and Ranging (LiDAR) have the ability to alleviate these weaknesses. Using remote sensing technologies, Mason et al. (2003) were able to calculate the time and space distributed friction coefficients directly from LiDAR to be input into distributed models. According to Bates, this achievement would lead to fulfilling grid-scale parameter requirements in distributed models as well as to minimizing the needs for model calibration.

Besides the lumped and the distributed models, another type of hydrologic model is the semi-distributed model, which attempts to combine features from both the lumped and the distributed model. In essence, semi-distributed models try to account for spatial variability in the watershed by partitioning the watershed into smaller sub-basins with varying input parameters. Similar to the lumped versus distributed model dilemma, there has also been much discussion whether a semi-distributed hydrologic model holds any advantage compared to a traditional lumped model. To address this issue, Ajami et al. (2004) performed a study on the Illinois River Basin at Watts, Oklahoma. By comparing results from a lumped model provided by the National Weather Service (NWS) and several semi-distributed models, they found that the semi-distributed models with their data averaged over each sub-basin with non-varying model parameters showed improved simulation results. 
Sharing similar sentiments with Ajami et al., Delrieu et al. (2009) also viewed a semi-distributed approach as a good compromise between lumped and distributed model. As stated by Ajami et al. (2004), using a distributed model may potentially increase the number of model inputs and therefore subsequently increase the uncertainties in their results. The problem of over-parameterization are also present in lumped models, since the nature of those models allows multiple changes in input parameters to produce identical results during model calibration (Freer, Beven, and Ambroise 1996). Regardless of the type of models one chooses, Ajami et al. (2004) advised performing the calibration procedures with caution to prevent propagating more uncertainties in the process. These uncertainties may originate from the NEXRAD rainfall data used, assumptions behind routing methods, as well as the estimations of various input parameters; all of which need to be addressed to reduce errors in the simulated outputs.

Agreeing with both Ajami and Delrieu, this thesis uses a semi-distributed approach for hydrologic analyses performed on the Oyster Creek Watershed. While the use of a semi-distributed model does not eliminate the over-parameterization problems, its capabilities in better addressing the heterogeneities of inputs in the watershed without requiring extensive amount grid-scale data parameters was the underlying reason for the selection.

\subsubsection{Hydraulic Models}

The outputs of hydrologic models result in flow rates and hydrographs that are then processed in hydraulic models. The primary purpose of hydraulic models is to convert these flow rates into water surface elevations, which are useful to show the 
flooding extents at certain locations within the watershed. Most hydraulic models assume a gradually varied and steady flow river system, which means that the velocity and depth of the river do not change with time. Instead, they vary with slight incremental changes in distances. Although this assumption is not thoroughly realistic, it does provide one with conservative water level estimates.

Among the many hydraulic models that adopt the gradually varied and steady flow assumption, one of the most prominent models used in the U.S. was the River Analysis System (HEC-RAS) released in 1995. Since it is available to the public for free, HEC-RAS and its iterations have been widely used in various hydraulic applications including floodplain delineation, bridge and levee designs, and flood insurance studies (Knebl et al. 2005; Whiteaker et al. 2006). The availability and versatility of HEC-RAS are the main reasons it was selected for hydraulic analyses in this thesis; the use of HECRAS in this research will be discussed in more detail in Chapter 4.

\subsection{The Role of Geographic Information Systems and Remote Sensing in Hydrology}

One of the major features of hydraulic models is their ability to create floodplain polygons from the simulated water surface elevations. The resulting polygons can then be used to create floodplain maps that portray flood inundations in the watershed. This ability is further enhanced with the advances in Geographic Information System (GIS) packages. GIS is an organized amalgam of computer hardware and software, network, data, and procedures that have the ability to collect, classify, and process large amounts of geospatial information. GIS has been used in a wide range of applications from civil and environmental engineering to the social sciences. 
Over the years, GIS has played an increasingly significant role in hydrology, partly due to technological improvements in the power and capabilities of personal computers and remote sensing equipment. The applications of GIS in hydrology include basin or watershed delineation, runoff computations, hydrologic and hydraulic analyses, and floodplain maps creation. Input parameters in hydrologic models such as precipitation data, topography, land use, and imperviousness can also be processed and enhanced in GIS.

Besides its data processing prowess, GIS also “provides a framework for integrating data from disparate sources," as stated by Gurnell and Montgomery (1998). This allows the researcher to freely choose whichever hydrologic and/or hydraulic model that he or she views as appropriate, since GIS has the potential to serve as a data bridge to link data transfer between those models.

The data structure in GIS is usually split between two categories: vector and raster. Vector data are points, lines, or polygons that may represent or connect certain features. For instance, points may be associated with rain or stream gauges; lines with rivers or streets; and polygons with watersheds or lakes. In contrast, raster data comprise rectangular grid cells with each cell containing specific information such as spatial data and their associated attributes. Vector data differs from raster data in that multiple attributes can be associated with any points, lines, or polygons, while in raster data, only a single attribute is associated with each grid cell. Examples of raster data include the digital elevation model (DEM) and radar rainfall information. DEM consists of specific integers that represent the spatial distribution of elevations. It usually represents the 
average elevation over a specified segment of the landscape. Applications in hydrology often combine both vector and raster data.

To increase the quality of data collection, various remote sensing techniques (i.e. lasers and satellite imageries) have been utilized and improved. Among the results of these improvements are more complete and extensive databases of land use and higher resolution DEMs. The United States Geological Survey (USGS) has made available 90meter resolution DEMs for most areas in the United States. However, 30-meter, and even 10-meter resolution DEMs have become increasingly common. A raster DEM can be used to automatically delineate the watershed boundaries and stream network, draining to a selected point or for an entire region. Since many watershed boundaries are delineated in GIS using DEM (Ogden et al. 2001), these improvements are most welcomed.

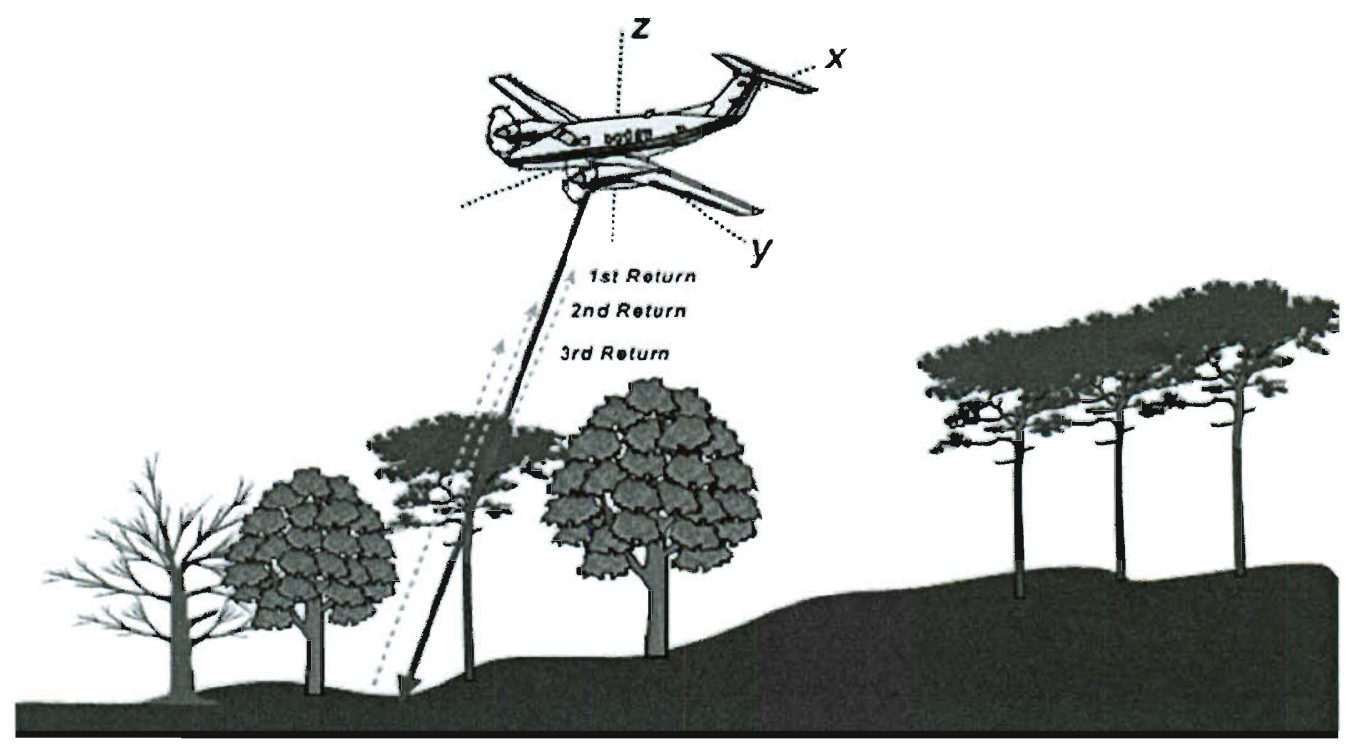

Fig.2.4. LiDAR operation schematic (adapted from www. fugroearthdata.com)

Another application of remote sensing technologies is the use of Light Detection and Ranging (LIDAR), as shown in Fig. 2.4. In the U.K., LIDAR with a $\sim 0.3 \mathrm{~m}$ spatial 
resolution has been used to survey the topography (Bates, 2004). In essence, LIDAR operates by emitting high frequency lasers $(\sim 5-33 \mathrm{KHz})$ to the surface from an aircraft or a helicopter, and recording the travel time for the laser to return to the sensor. When the laser hits vegetation, a portion of the laser will be reflected from the canopy while the other portion will continue until it reaches the surface before returning to the sensor. The difference between the two can then be calculated and the heights of the vegetation be determined. This ability is extremely useful to approximate floodplain resistances used in distributed hydrologic models. The use of GIS and remote sensing applications in this thesis will be discussed and demonstrated further in the next few chapters. 


\section{Chapter 3: Model Development and Calibration}

To address the research objectives presented in Chapter 1, the first step is to have an operational hydrologic model of the study area. This chapter discusses the development and calibration of the hydrologic model for the Oyster Creek Watershed. The general procedures for the hydrologic model development and calibration in this thesis are as follows:

1. Export existing hydrologic model from HEC-HMS 2.2 to HEC-HMS 3.3.

2. Acquire rainfall data, both theoretical (design storms) and actual (rain gauges, NEXRAD).

3. Convert rainfall to direct runoff using a hydrologic model, HEC-HMS that produces hydrographs of flow versus time.

4. Compare the resulting flow rates with available stream gauges data.

5. Calibrate model by adjusting hydrologic parameters to match observed flow rates.

\subsection{Model Setup}

Since existing hydrologic models of the Oyster Creek Watershed were already available in HEC-HMS, it was natural to continue using HEC-HMS for this study, albeit with a newer version. The HEC-HMS 3.3 model was chosen due to its more intuitive user interface as well as better compatibility with the hydraulic model, HEC-RAS. There are three distinct model sections for a project in HEC-HMS: the Basin Model, the Meteorologic Model, and Control Specifications. The Basin Model stores information pertaining to the basin or watershed, such as sub-basin areas, loss parameters, as well as 
routing and connectivity data. In the Meteorologic Model, one can input precipitation data. This precipitation information can be either design storms or actual rainfall events. It is important to point out that the software also has the capability to model gridded rainfall data, for example radar rainfall that is estimated by NEXRAD. Finally, the Control Specifications allow users to input timing information regarding the model, such as start time, end time, and time intervals used in simulations.

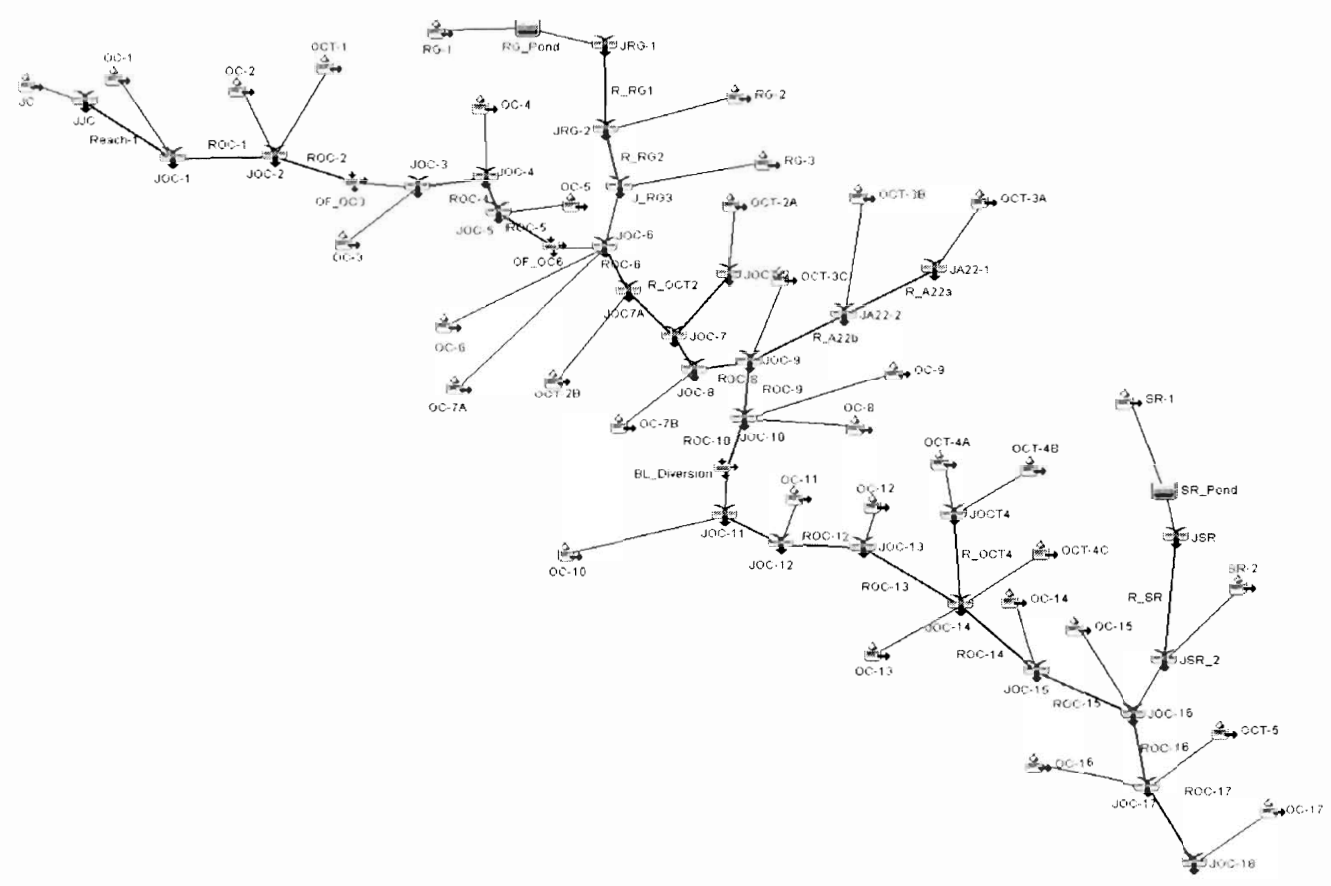

Fig.3.1. HEC-HMS 3.3 Basin Model of Oyster Creek Watershed

In HEC-HMS, rainfall excess can be converted to surface runoff via a number of methods: Clark UH, Snyder, SCS UH, or user-specified UH. Since the software has the capability to model gridded rainfall information as mentioned previously, it allows for a quasi-distributed linear transformation to calculate runoff at a spatially-distributed watershed. A number of flood routing options are also available to users in HEC-HMS: the Muskingum method, the lag method, the Modified Puls method, the kinematic wave 
method, and the Muskingum-Cunge method. The Muskingum method is used for general routing; the lag method is used for routing where no attenuation is necessary; the Modified Puls method allows one to input specific storage-discharge relationships in the model; and both the kinematic wave and the Muskingum-Cunge methods allow different channel cross-section shapes to be modeled. In this thesis, the Clark UH transform method and the Modified Puls routing method were used.

After exporting the hydrologic model of Oyster Creek from HMS 2.2 to HMS 3.3, the performances of the latter model were tested. Both 10-year and 100-year design storms were used to compare the hydrological responses of the two models at several junctions along the watershed. The hydrographs produced by the newer HEC-HMS 3.3 model compared well with the older HEC-HMS 2.2 model. Posing no significant differences between the two models, calibration efforts were continued in HMS 3.3.

\subsection{Model Calibration}

The existing HEC-HMS model was created based on a number of design storms, ranging from a 10 -year storm to a 500-year storm. To test the performance of the model, actual storm events were needed. In order to achieve this goal, several storm events that occurred in Sugar Land and its surrounding vicinity were considered. An important factor of consideration was the availability of stream and precipitation gauges information during those storm events. Recent events that occurred in 2009 and 2010 were selected to be analyzed. From those events, two storms from April 2009 and May 2010 were selected for calibration (see Table 3.1). 


\begin{tabular}{cccc}
\hline Start & End & Gauges (in) & Radar (in) \\
$4 / 27 / 2009$ & $4 / 29 / 2009$ & 2.6 & 2.4 \\
$5 / 14 / 2010$ & $5 / 15 / 2010$ & 3.5 & 2.7 \\
\hline
\end{tabular}

Table 3.1. Analyzed storms for model calibration

(Note: Values for both gauges and radar are total rainfall averages of the entire watershed)

An important source of rainfall data was gauge-calibrated radar rainfall, obtained from Vieux and Associates. Although a few events in prior to 2009 were considered, based on the poor agreement between information obtained from rain gauges and radar, those storms were ultimately not analyzed. Furthermore, the discarded storms were not substantial enough to be selected, since the total rainfall during these events did not exceed 2 inches, and would therefore not be a good fit for proper calibration.

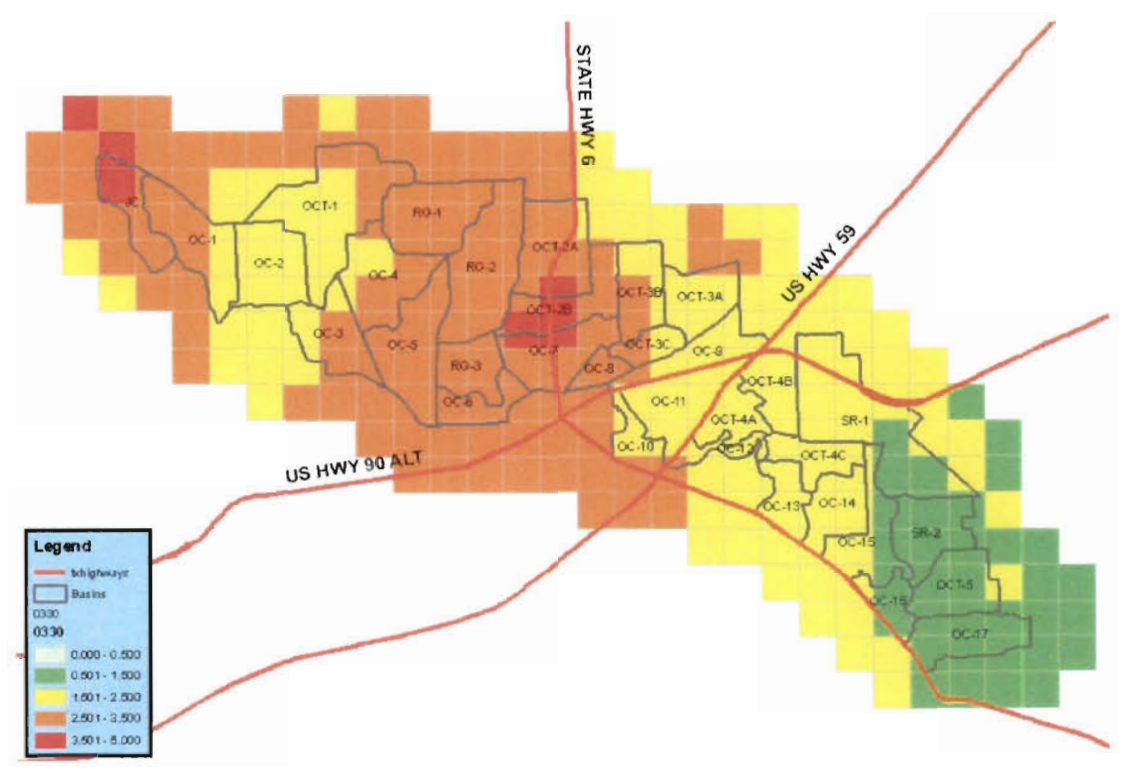

Fig. 3.2 NEXRAD rainfall for May 14, 2010

Radar rainfall data were chosen to be input into HEC-HMS 3.3 instead of rain gauges information since NEXRAD provided specific rainfall information for each of the 33 sub-basins in the watershed, whereas rain gauges were only available at a few 
particular locations and hence the results would not be representative of the entire watershed. Another advantage of NEXRAD over rain gauges is that radar rainfall data was recorded consistently every 5 minutes. In contrast, rain gauges information was generally not recorded on regular intervals, causing gaps between recorded data points over a significant period of time during a storm event. A major disadvantage of rain gauges is that they require regular maintenance to ensure that they operate properly. Severe weather, vandalism, and other problems may prevent rain gauges from working properly. In contrast, radar is less susceptible to these problems. Therefore, the availability of radar rainfall data is crucial to perform accurate hydrologic analyses of the watershed. After running the hydrologic model with these two storms, the resulting flow rates were compared to observed flows from available stream gauges (see figure below).

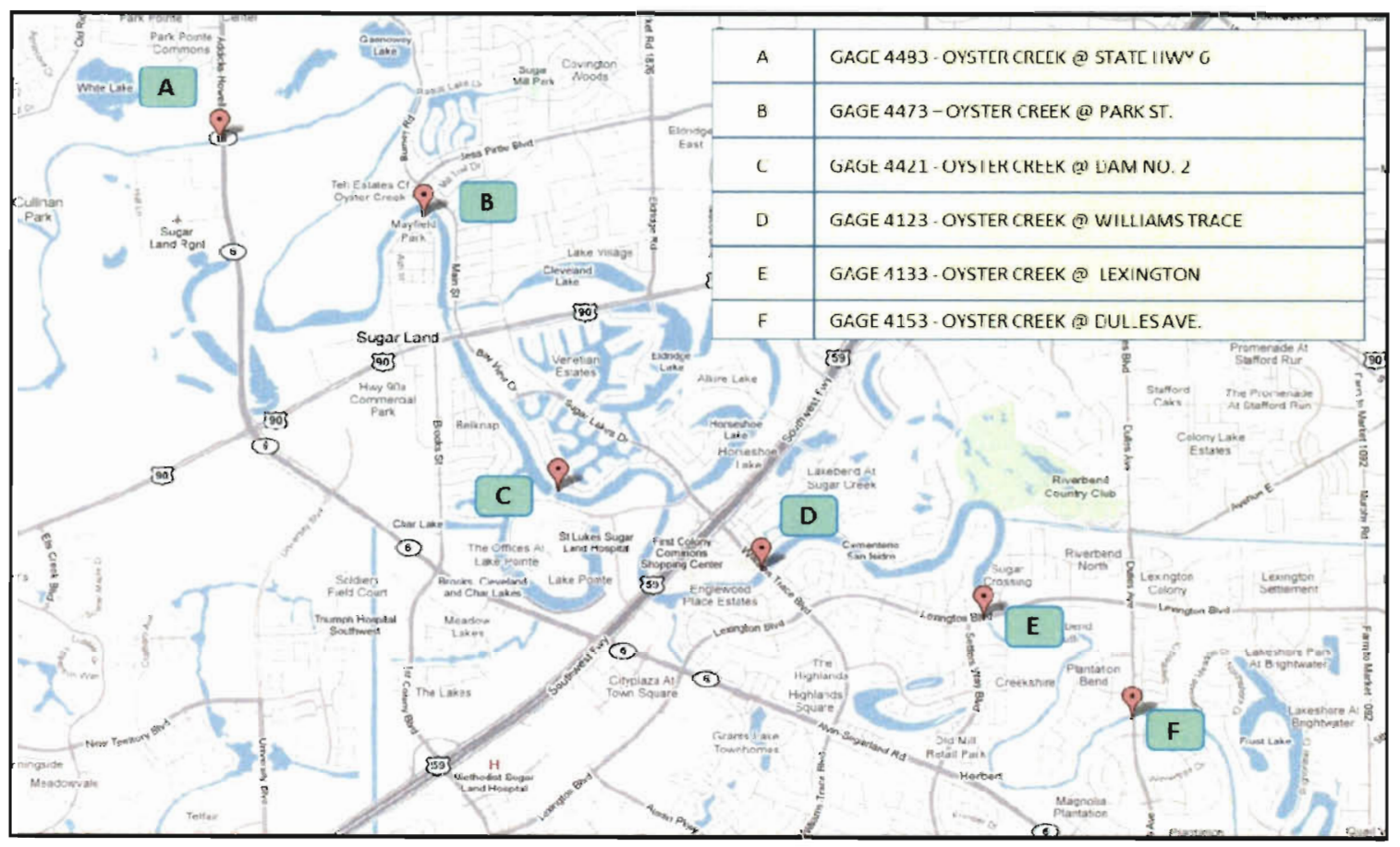

Fig.3.3. Stream gauge locations along Oyster Creek 


\subsubsection{Green and Ampt Infiltration}

One significant factor that affects the accuracy of hydrologic modeling is infiltration, because it can influence runoff volume, especially in areas with higher conductivity soils. According to Bedient et al. (2008), the Green and Ampt method, which originated in 1911, has been widely used due to its ability to forecast "cumulative infiltration as a function of time and readily available soil parameters." As evidence, this method was used in various Houston watersheds after Tropical Storm Allison in 2001. It was also adapted in the Fort Bend County Drainage Criteria Manual, which was the basis of existing hydrologic studies performed for Sugar Land. The original Green and Ampt equation is as follows:

$$
f=K s\left(1-M_{d} \psi / F\right)
$$

where $f$ is the infiltration rate, $F$ is the cumulative depth of water infiltrated into soil, $K s$ is the saturated hydraulic conductivity, $M_{d}$ is the moisture deficit, and $\psi$ indicates wetting front suction head.

Since the Green and Ampt infiltration method was used in existing hydrologic models, the various parameters that influence the Green and Ampt equation were considered for calibration. These parameters are the hydraulic conductivity (Ks), the moisture deficit $\left(\mathrm{M}_{\mathrm{d}}\right)$, and the wetting front suction head $(\psi)$. Among the three parameters, the hydraulic conductivity is the limiting factor of water transmission rate (Bedient et al. 2008). Therefore, various values of hydraulic conductivities were used to see their effects on the hydrographs simulated by the model for a 10-year design storm on a particular sub-basin, as shown in the Figure 3.4 below: 


\section{Hydraulic Conductivity (K) Variations}

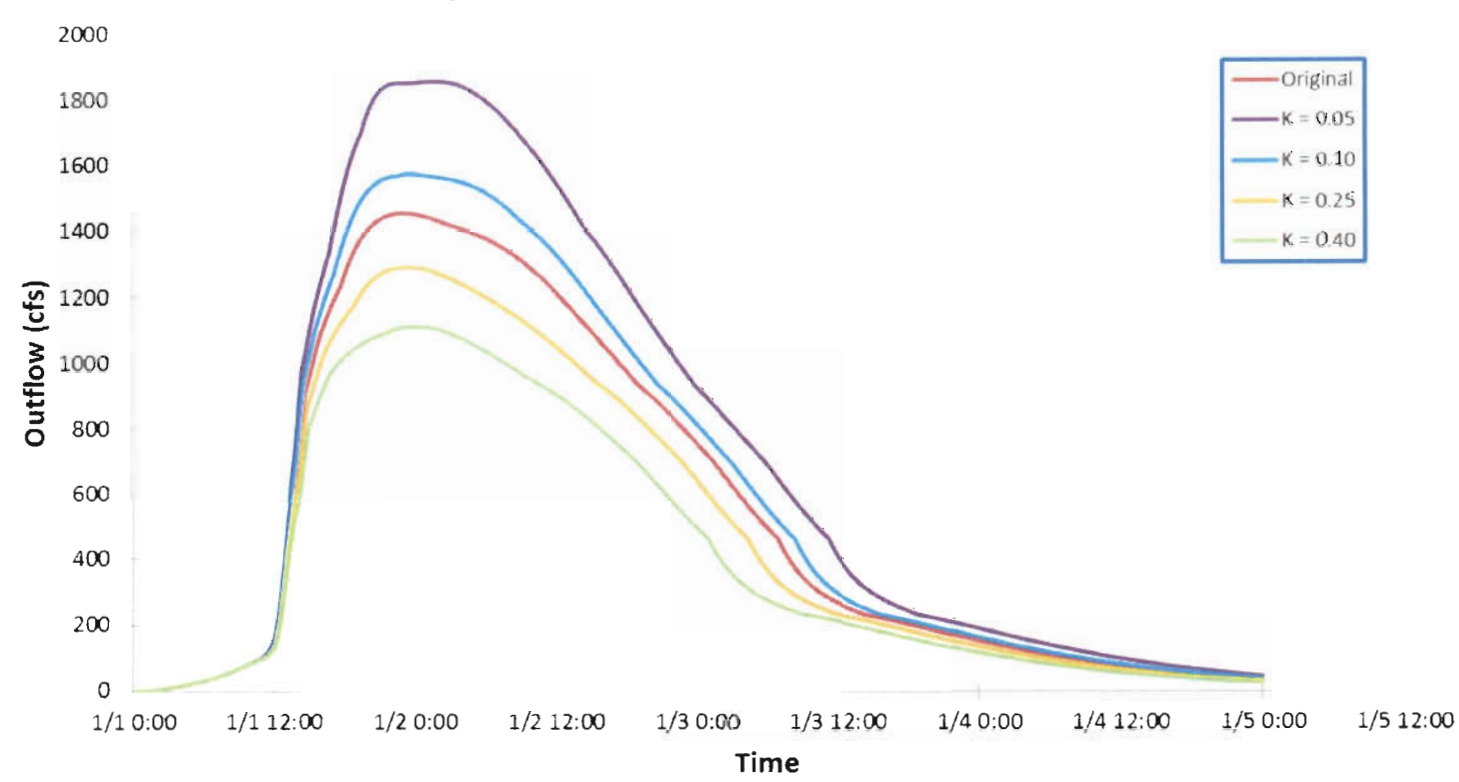

Fig.3.4. K variations vs. Original HEC-HMS Model

The original model has a uniform hydraulic conductivity $(\mathrm{K})$ value of 0.15 . When the $\mathrm{K}$ values were decreased, increasing peak flows as well as overall volume (the area under the curves) were observed. Likewise when $\mathrm{K}$ values are increased, the peak flows as well as the volume decrease. Another observation that can be made from this figure is that variations of hydraulic conductivities also result in changes in time to peak. $\mathrm{K}$ values that are smaller than the original model have longer time to peaks, while the opposite were observed for the larger $\mathrm{K}$ values.

\subsubsection{Clark UH Transform Method}

The Clark UH method models a watershed as a linear channel that is linked with a linear reservoir to account for hydrograph translation and peak flow attenuation based on time-area relationships. This method differs from other synthetic unit hydrograph 
methods such as the Snyder and the SCS methods in that it is an instantaneous unit hydrograph (IUH). This means that although the Clark UH theory follows the fundamental principle of a unit hydrograph (the series of runoff is the result of one inch of excess rainfall applied uniformly over a watershed), the excess rainfall duration is infinitesimally small. Another unique characteristic of the Clark UH method is the assumption that the volume of runoff generated from each time-area increment is directly proportional to the areal extent of that particular increment.

Two major parameters in the Clark UH method are the time of concentration, $\mathrm{T}_{\mathrm{c}}$, and the storage coefficient, $R . T_{c}$ is defined as the runoff travel time between the most hydraulically remote portion of a sub-basin and the outlet, whereas $\mathrm{R}$ represents the slope of the storage-discharge relationship for a linear reservoir (Bedient, Huber, and Vieux 2008). These parameters are important because they affect how hydrographs are routed from one location in the channel to the next. Both $T_{c}$ and $R$ values are usually determined from observed hydrographs in gauged basins. In ungauged basins, these values are determined from region-specific regression equations.

The $T_{c}$ and $R$ values used in existing hydrologic models were determined based on the following equations (3.2 through 3.4) set by the Fort Bend County Drainage Criteria Manual:

$$
\begin{aligned}
& T_{c}+R=128 \frac{(L / \sqrt{S})^{57}(N)^{.8}}{\left(S_{o}\right)^{.11}(10)^{I}} \\
& T_{c}=\left(T_{c}+R\right) \times 0.38\left(\log S_{o}\right) \\
& R=\left(T_{c}+R\right)-T_{c}
\end{aligned}
$$


where $T_{c}$ denotes Clark's time of concentration, $R$ is the storage coefficient, $L$ is the length of the longest watercourse within the drainage area in miles, $S$ is the average slope along the area's longest watercourse in feet/mile, $N$ is Manning's weighted roughness coefficient along the longest watercourse, $S_{o}$ is the average basin slope of overland draining into the longest watercourse in feet/mile, and $I$ is the effective impervious ratio. The effects of varying $\mathrm{T}_{\mathrm{c}}$ and $\mathrm{R}$ on the resulting flow rates from a 10 -year storm at a particular sub-basin can be seen on the following figures:

\section{Time of Concentration (TC) Variations}

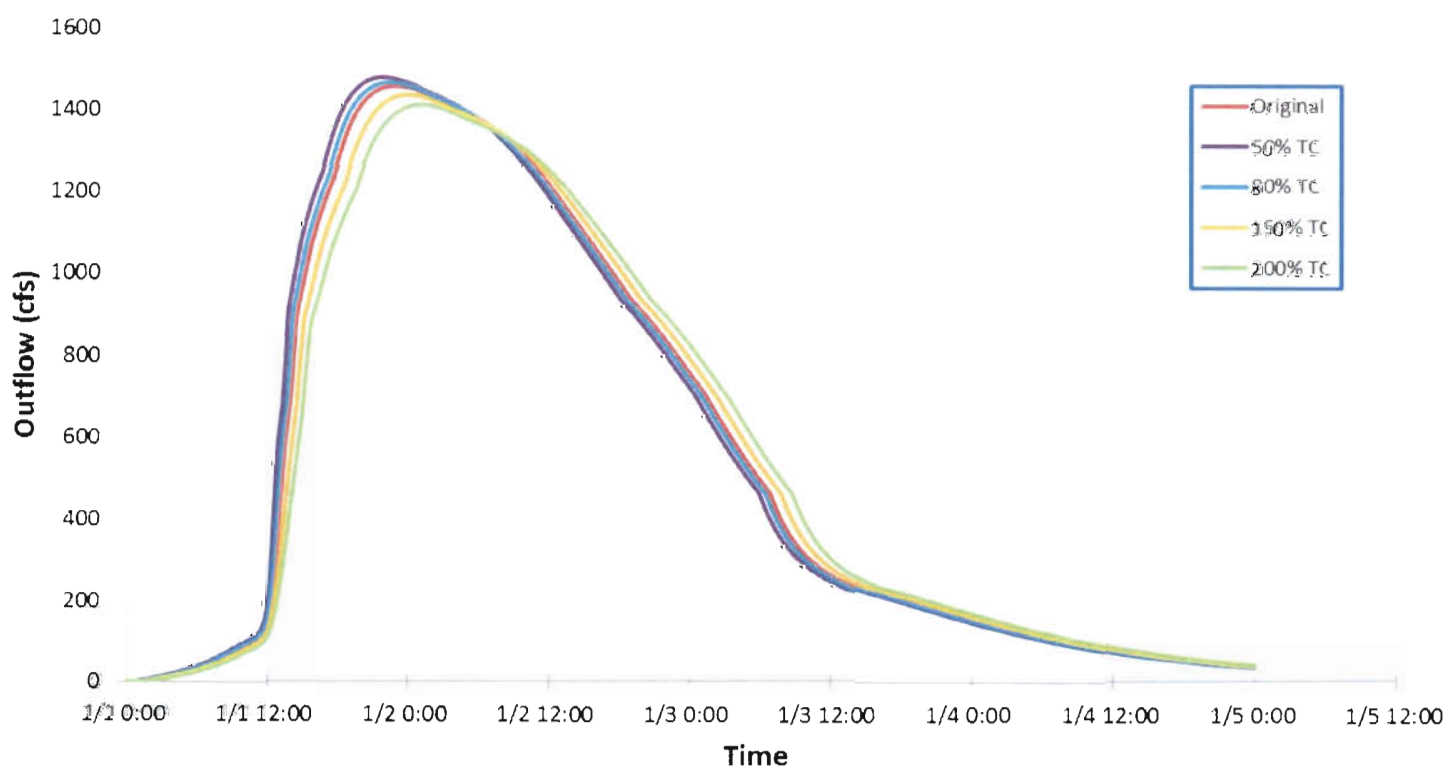

Fig.3.5. $T_{C}$ Variations vs. Original HEC-HMS Model

Figure 3.5 shows the effects of varying time of concentrations $\left(\mathrm{T}_{\mathrm{c}}\right)$ on flow rates. It appears that although the times to peak changed slightly with varying $T_{c}$ values, the peak flows and the overall volume remained relatively constant with respect to the 
original model. While $\mathrm{T}_{\mathrm{c}}$ variations did not produce significant changes in outflows, storage coefficient variations $(\mathrm{R})$ behaved differently.

As can be seen in Fig. 3.6, varying $\mathrm{R}$ values affected peak flows, time to peaks, and the overall volume and shape of the hydrographs. By performing sensitivity analyses of $\mathrm{K}, \mathrm{T}_{\mathrm{c}}$, and $\mathrm{R}$ values, it was evident that it would be difficult to match the model with the observed flow recorded by stream gauges by adjusting a single parameter. With this knowledge in mind, combinations of $\mathrm{K}, \mathrm{T}_{\mathfrak{c}}$, and $\mathrm{R}$ values were adjusted.

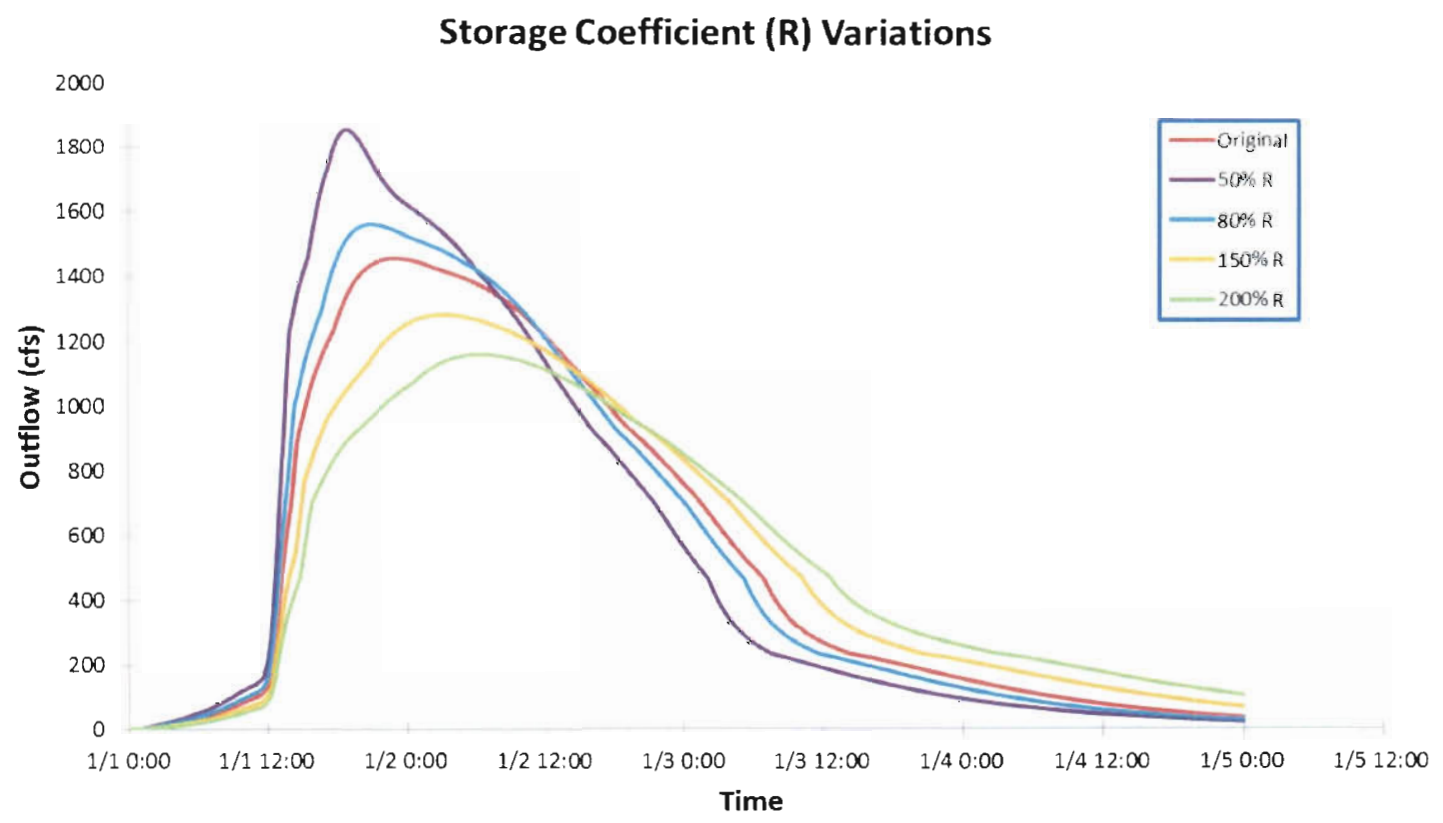

Fig.3.6. $R$ Variations vs. Original HEC-HMS Model

\subsubsection{Calibration Results}

Due to limited stream gauge data availability, hydrographs could only be compared at two locations: JOC-7A (Location A) and JOC-14 (Location F), the results of which can be seen in the following graphs: 


\section{4/2009 Storm at HW 6 (Location A)}

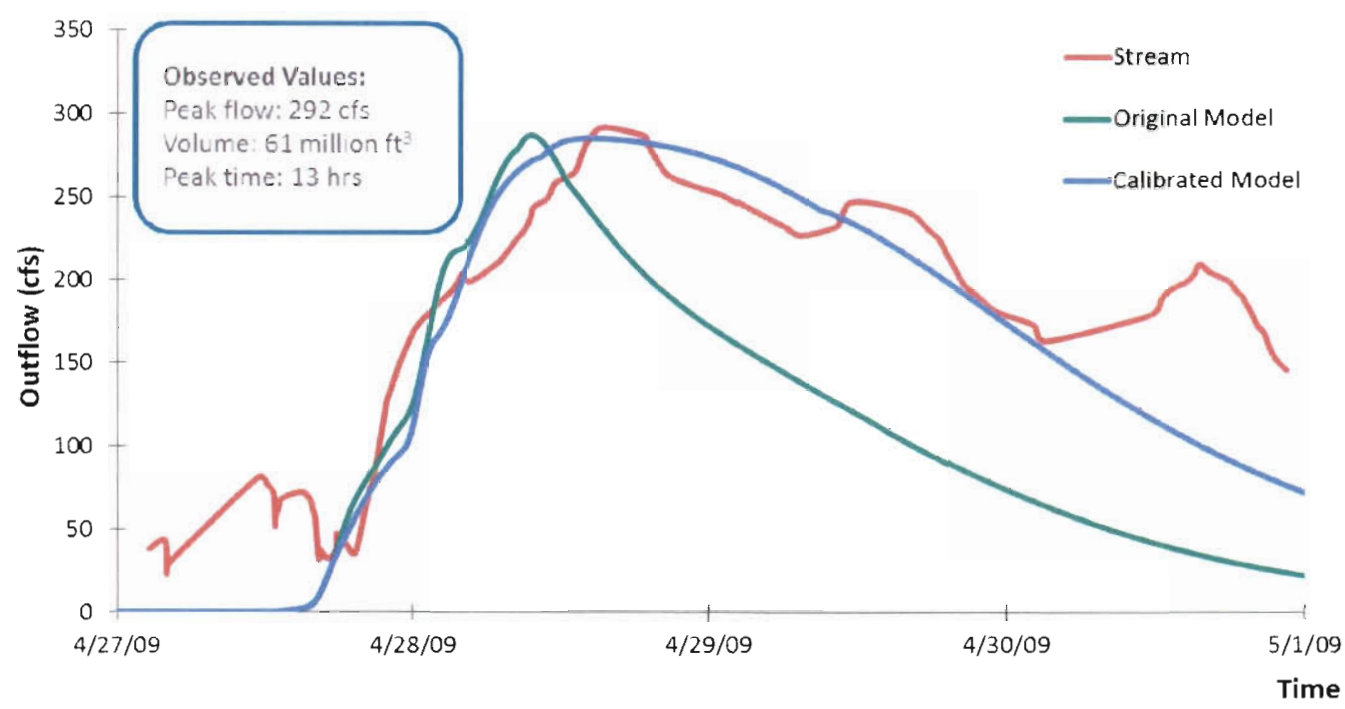

(a)

04/2009 Storm at Dulles Ave. (Location F)



(b)

Fig.3.7(a) and (b). Hydrographs Comparison for April 2009 Storm 


\section{5/2010 Storm at Dulles Ave. (Location F)}

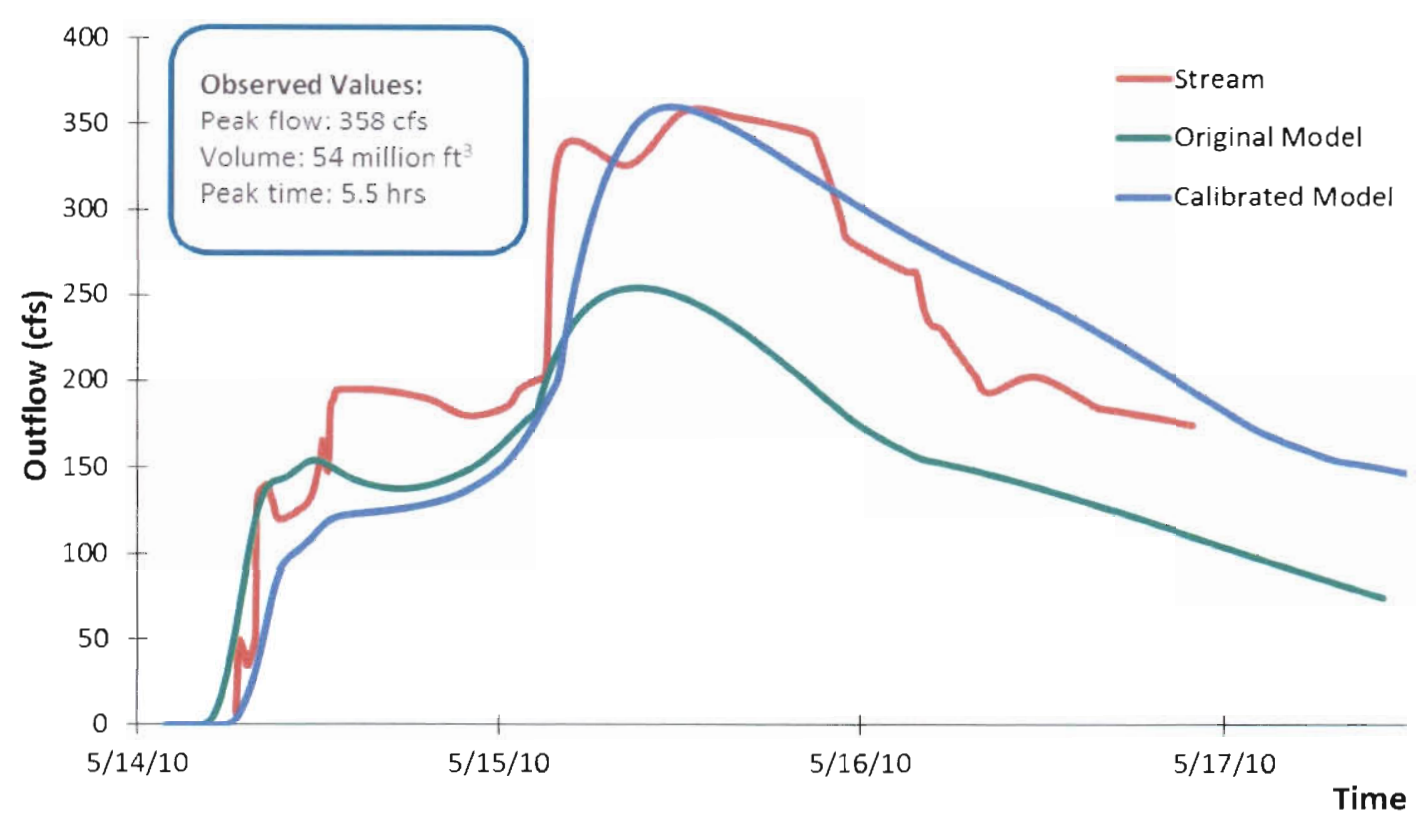

Fig.3.8. Hydrographs Comparison for May 2010 Storm

Initial hydrograph comparisons between the simulated model and the observed flow data showed significant discrepancies in peak flows and volumes for both storms (refer to Tables 3.2 and 3.3). To alleviate this, a number of parameters in the model were adjusted, including infiltration loss values and the Clark UH transformation parameters. These were adjusted both manually by performing sensitivity analyses on various parameters as well as automatically from the optimization tool available in HEC-HMS. Generally, the calibrated model had lower hydraulic conductivities, slightly lower $\mathrm{T}_{\mathrm{c}}$ values, and higher $\mathrm{R}$ values compared to the original model (refer to Appendix A for details on the calibrated model parameters). The error comparisons of the original and calibrated model for the two storms are as follows: 


\begin{tabular}{|l|c|c|c|c|}
\hline \multirow{2}{*}{} & \multicolumn{2}{|c|}{ Location A } & \multicolumn{2}{c|}{ Location F } \\
\cline { 2 - 5 } & $\begin{array}{c}\text { Original } \\
\text { Model }\end{array}$ & $\begin{array}{c}\text { Calibrated } \\
\text { Model }\end{array}$ & $\begin{array}{c}\text { Original } \\
\text { Model }\end{array}$ & $\begin{array}{c}\text { Calibrated } \\
\text { Model }\end{array}$ \\
\hline Peak Error (\%) & 1.54 & 2.12 & 17.27 & 0.39 \\
\hline Volume Error (\%) & 41.48 & 11.78 & 16.13 & 1.95 \\
\hline Peak time error (hrs) & -5.8 & 1.5 & 5 & 6 \\
\hline
\end{tabular}

Table 3.2. Error comparisons for April 2009 storm

\begin{tabular}{|l|c|c|}
\hline & Original Model & Calibrated Model \\
\hline Peak Error (\%) & 28.89 & 0.81 \\
\hline Volume Error (\%) & 28.20 & 1.53 \\
\hline Peak time error (hrs) & -1.2 & -0.7 \\
\hline
\end{tabular}

Table 3.3. Error comparisons for May 2010 Storm at Location F

Although the results of calibration showed better fit in terms of peak flows and volumes between the observed stream flows and the simulated model (see Tables 3.2 and 3.3 above), the calibrated model was only validated for two relatively small storms. The limited calibration results might suggest that the same parameter adjustments may not be applicable to larger storms (Freer, Beven, and Ambroise 1996). Furthermore, the peak time error of 6 hours in the calibrated model for the April 2009 at Location F might be related to manual operations of dams and/or flood gates. The operation procedures for these flood control structures need to be well documented and understood to improve the hydrologic model performance. Therefore, it is imperative that the current model be continually updated and compared with more storms in the future and updated as deemed necessary to improve its accuracy and reliability. 


\section{Chapter 4: Flood Vulnerability Assessment}

\subsection{Hydrologic and Hydraulic Analyses}

The next step after the hydrologic model is set up and calibrated is to assess the flood vulnerability of the Oyster Creek Watershed. This is done by performing both hydrologic and hydraulic analyses of the watershed. First, the hydrologic model was run under two design storms: 10 year (10\% frequency rainfall) and 100 year $(1 \%$ frequency rainfall), and their respective outcome models were compared. After obtaining hydrographs from HEC-HMS, the next step was to input peak flows into the hydraulic model, HEC-RAS.

HEC-RAS is a hydraulic model that has the capability to compute water surface profiles for steady, gradually varied flow in natural or manmade channels based on onedimensional energy equation. The main purpose of this program is to calculate water surface elevations at channel cross sections of interest for any given flow rate. HEC-RAS is also used for a wide range of applications, such as floodplain management, flood insurance studies, and determination of flood-prone areas.

HEC-RAS is often used in conjunction with HEC-HMS to determine flow rates and flood elevations at the basin of interest. HEC-HMS calculates flow rates at various points or junctions along the channel during a storm event. The resulting peak flows are then imported to HEC-RAS to perform steady-state calculations at corresponding river stations along the channel to determine water surface elevations (see table and figure below). 


\begin{tabular}{|c|c|c|}
\hline & HEC-RAS & HEC-HMS \\
\hline 1 & 169403.5 & JOC-1 \\
\hline 2 & 160826.7 & JOC-2 \\
\hline 3 & 150620.6 & JOC-3 \\
\hline 4 & 147098.7 & JOC-4 \\
\hline 5 & 136677.1 & JOC-5 \\
\hline 6 & 121766.7 & JOC-6 \\
\hline 7 & 110964.3 & JOC-7 \\
\hline 8 & 103528.9 & JOC-8 \\
\hline 9 & 97425.13 & JOC-9 \\
\hline 10 & 94648.5 & JOC-10 \\
\hline 11 & 89264.64 & JOC-11 \\
\hline 12 & 83250.36 & JOC-12 \\
\hline 13 & 70154.9 & JOC-13 \\
\hline 14 & 56630.27 & JOC-14 \\
\hline 15 & 51916.07 & JOC-15 \\
\hline 16 & 39834.86 & JOC-16 \\
\hline 17 & 32828.75 & JOC-17 \\
\hline 18 & 27761 & JOC-18 \\
\hline
\end{tabular}



Table 4.1. HEC-RAS river stations with corresponding junctions from HEC-HMS

In steady flow calculations, time-dependent parameters are not included in the energy equation. Therefore, several conditions are assumed: flow is steady and gradually varied, flow is one-dimensional, and the river channels have slopes less than 1:10.

Violations in any of these assumptions would result in error. On situations where steadystate assumptions cannot be made, HEC-RAS has the ability to perform unsteady-state calculations based on a simplified form of St. Venant equation. A flow is characterized as unsteady when flow varies with time at a particular location. An unsteady-state model allows for a more accurate depiction of the watershed's hydraulic characteristics compared to a steady-state model due to the additional time component. One would be able to track the channel's water surface elevations during a storm event in user-specified time intervals. To perform the necessary unsteady-state calculations, HEC-RAS incorporates the Unsteady NET (UNET) simulator. In this case, entire hydrographs 
instead of peak flows are imported from HEC-HMS. One advantage of using HEC-RAS as means for hydraulic analyses is its ease of data transfer between HEC-RAS and HECHMS. For example, HEC-RAS is able to calculate storage-discharge relationships by correlating a series of water surface profiles with their corresponding discharges. The storage-discharge relationships, which are also known as rating curves, can then be transferred back to HEC-HMS to be used for model calibration.

Existing steady-state HEC-RAS models of Upper Oyster Creek basin were available. However, since the existing models used flow data from HEC-HMS 2.2, the models were updated using information obtained from HEC-HMS 3.3. Steady-state runs with 10-year and 100-year design storms were initially conducted. Peak flows from HECHMS were inputted into HEC-RAS, instead of entire hydrographs.

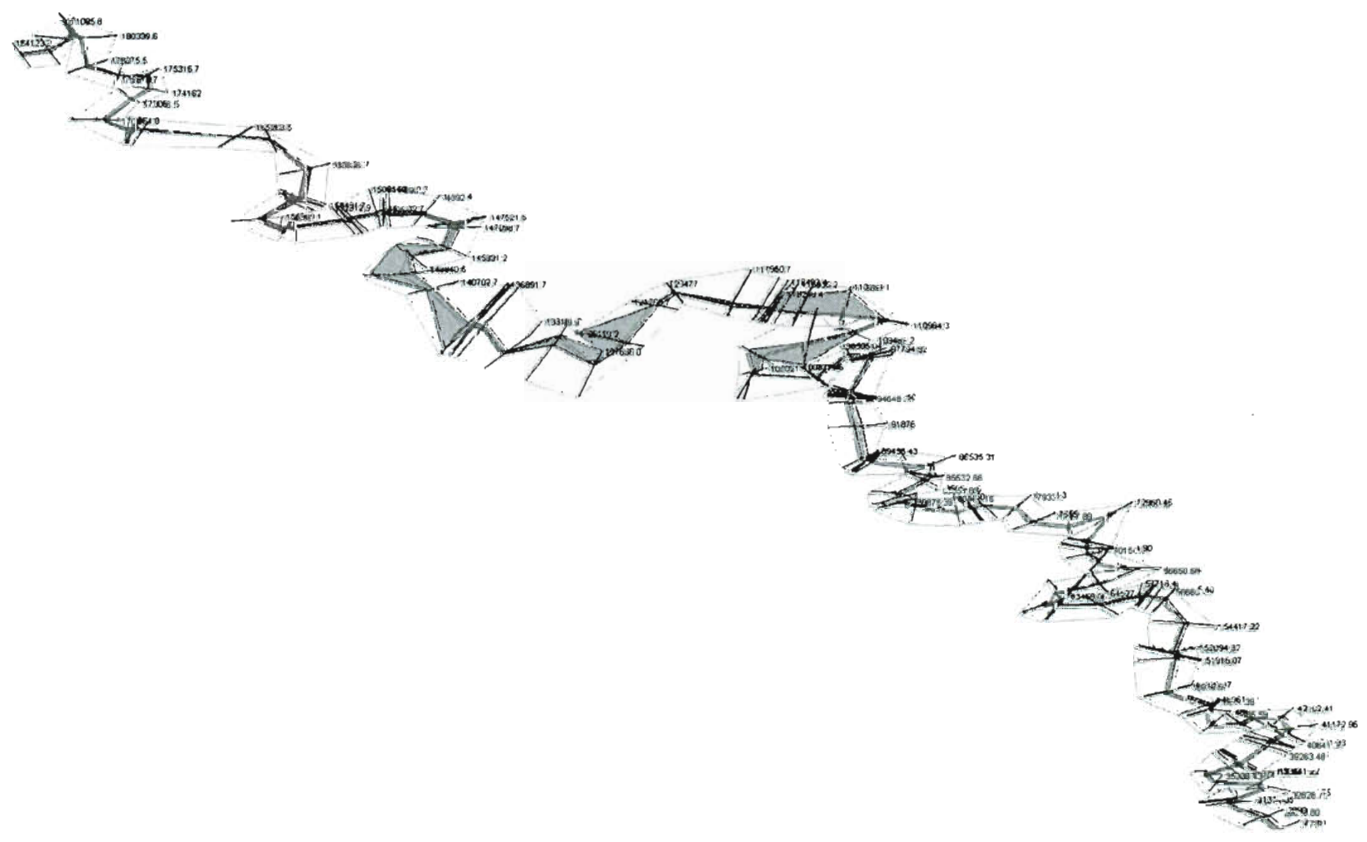

Fig.4.1. Steady-state HEC-RAS 10-Year 3D Profile of Oyster Creek

While steady-state results do not provide realistic depictions of how the water elevations in the watershed vary with time, they do provide conservative results showing 
worst case scenarios that are useful for floodplain mapping, development strategies, and evacuation planning purposes. Steady-state, as opposed to unsteady-state runs were chosen since they are based on hypothetical design storms that do not depict real storm events. Moreover, unsteady-state models require significant geometry preprocessing times before the models can be run. Therefore, for the purposes of this thesis, only steady-state analyses in HEC-RAS were performed.

\subsection{Identification of Flood Prone Areas}

In order to identify flood prone areas along Oyster Creek, locations with high flow rates were identified in the HEC-HMS 3.3 model for 10 and 100 year design storms and inundated areas were identified using the HEC-RAS model.

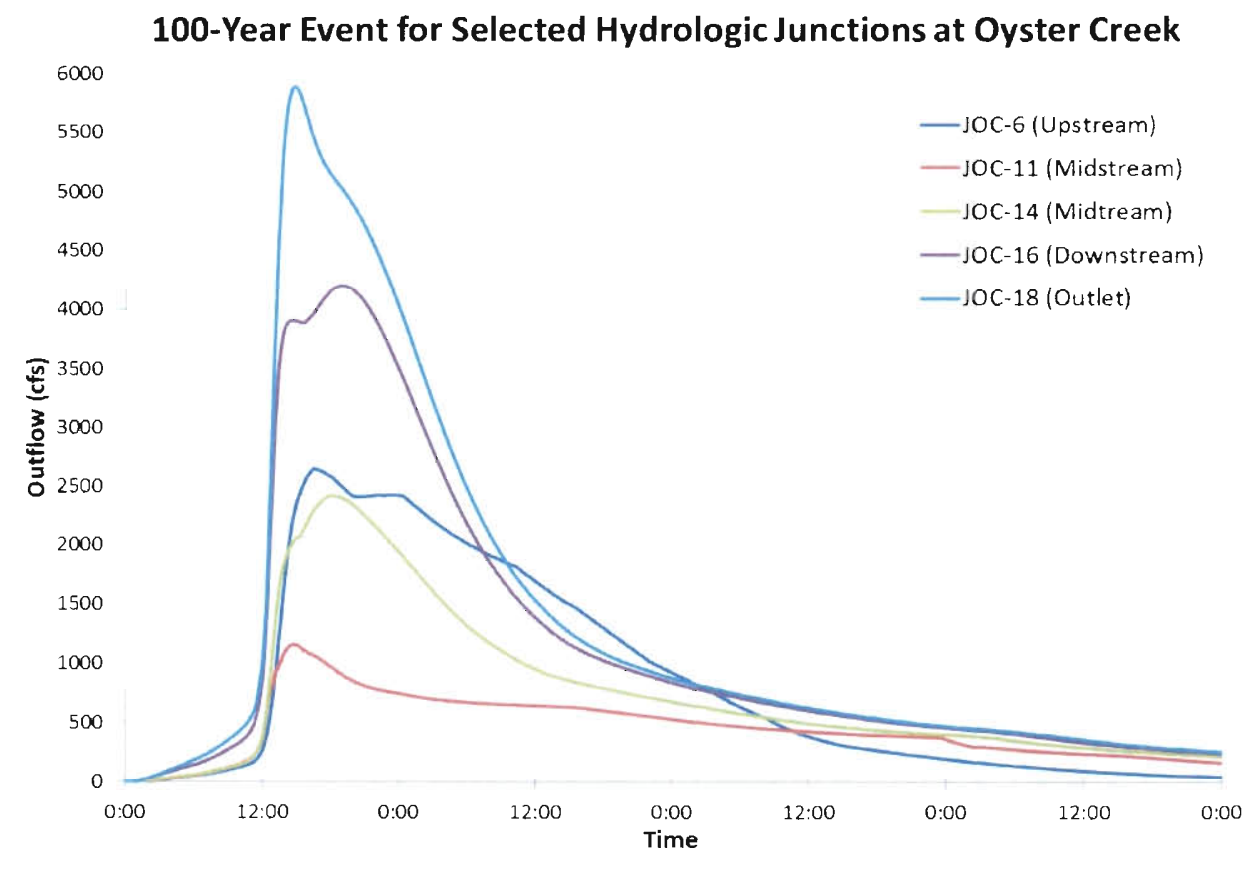

Fig.4.2. 100-year outflows at selected junctions from HEC-HMS 3.3

High flow rates within HEC-HMS 3.3 were determined by tabulating and graphing flows in Microsoft Excel for all junctions along the main channel of Oyster 
Creek, going back and identifying peak flows at each junction, and finally selecting the junctions with the highest flow rates. Generally, the highest flow rates were observed at downstream junctions along Oyster Creek (JOC-15 and beyond).

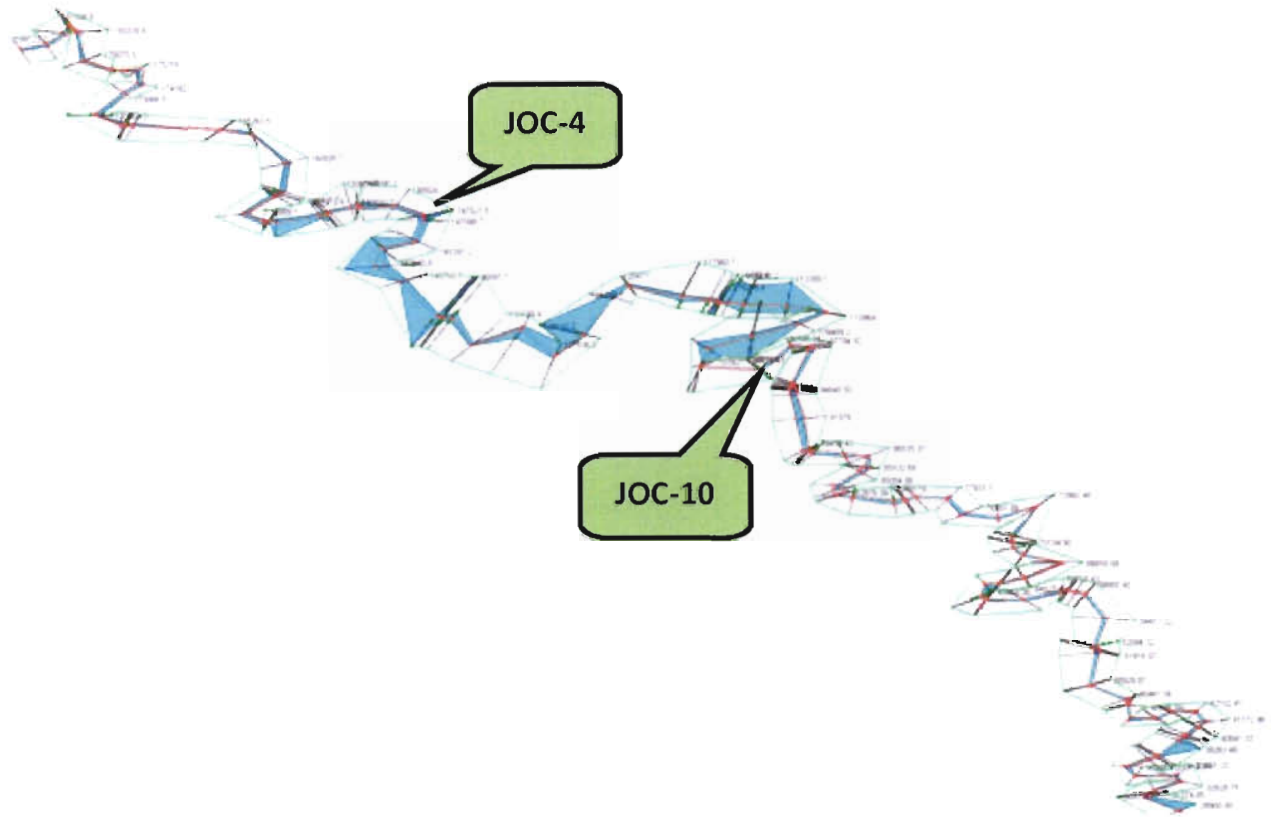

Fig.4.3. HEC-RAS Steady-State 100-year 3D Profile showing areas of flooding concern

Areas prone to flooding were determined in HEC-RAS by noting areas where water overtopped the main channel. It is worth pointing out that high-flow areas identified in HEC-HMS did not necessarily coincide with water-inundated areas observed in HEC-RAS outputs. In HEC-HMS, areas with high flows generally occurred in the downstream portion of Oyster Creek (JOC-15 onwards). However, HEC-RAS outputs showed that flooding mostly occurred between JOC-4 and JOC-10 shown in Fig. 4.3. This discrepancy may be attributed to the varying hydrologic and hydraulic capacities of channel cross sections along Oyster Creek. Based on these results, several structural flood control scenarios were analyzed to see their effectiveness for flood mitigation. 


\subsection{Assessment of Structural Flood Control Scenarios}

As shown in Fig. 4.3, it appeared that varying degrees of flooding would occur along Oyster Creek for a 100-year storm. A number of flood control scenarios were then simulated in both HEC-HMS and HEC-RAS to see the effects of structural solutions on flood mitigation. These scenarios involve adding diversions and detention ponds in HECHMS, as well as performing channel modifications in HEC-RAS with a 100-year design storm. The flood control scenarios are as follows:

- Scenario A - Diversion: In this option, two diversions were inserted prior to JOC-4 and JOC-10.

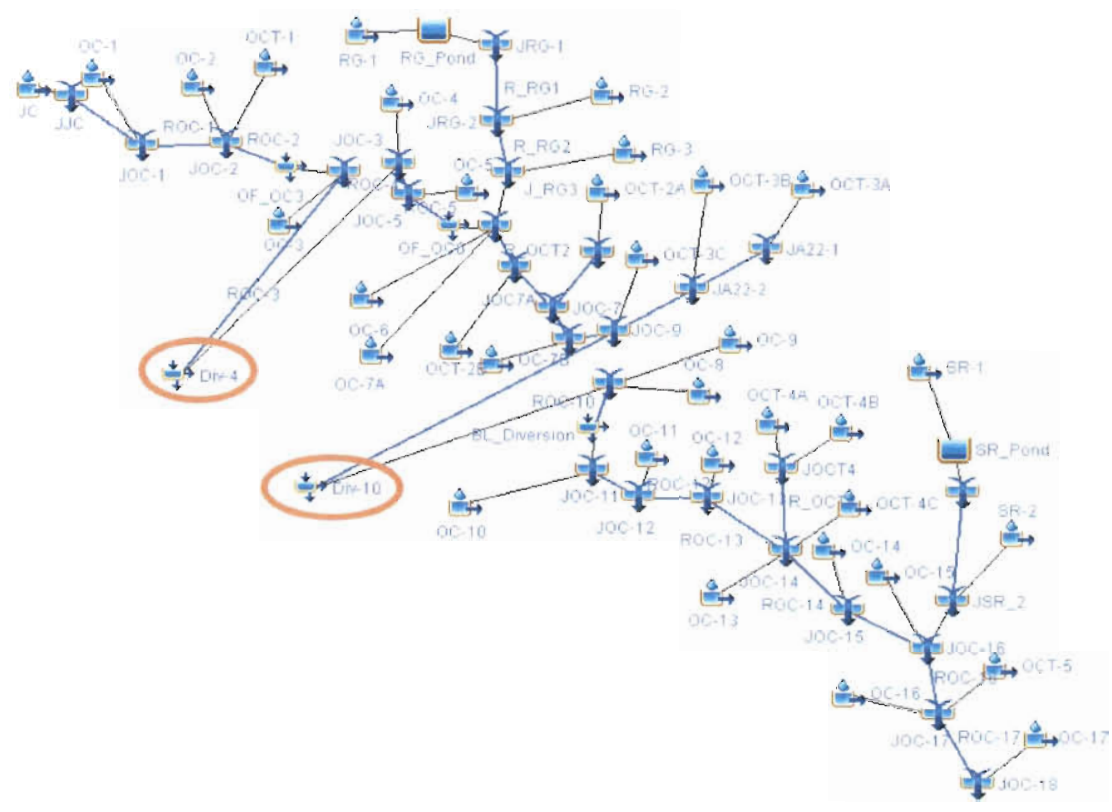

Figure 4.4: Scenario A - 2 diversions in HMS 3.3

- Scenario B - Channel modification: To assess the effects of channel modifications on water surface elevations, the values of Manning's roughness were modified in HEC-RAS. The existing models had channel roughness values of 0.04 , which was 
typical for a well-maintained natural channel. These values were then modified to 0.02, which represented smooth, concrete-lined channels.

- Scenario C - 2 detention ponds: Two detention ponds were inserted prior to JOC-4 and JOC-10 in the HEC-HMS 3.3 Basin Model. The elevation-storage-discharge relationships of the new ponds were adapted and extrapolated from an existing upstream detention pond (RG_Pond).

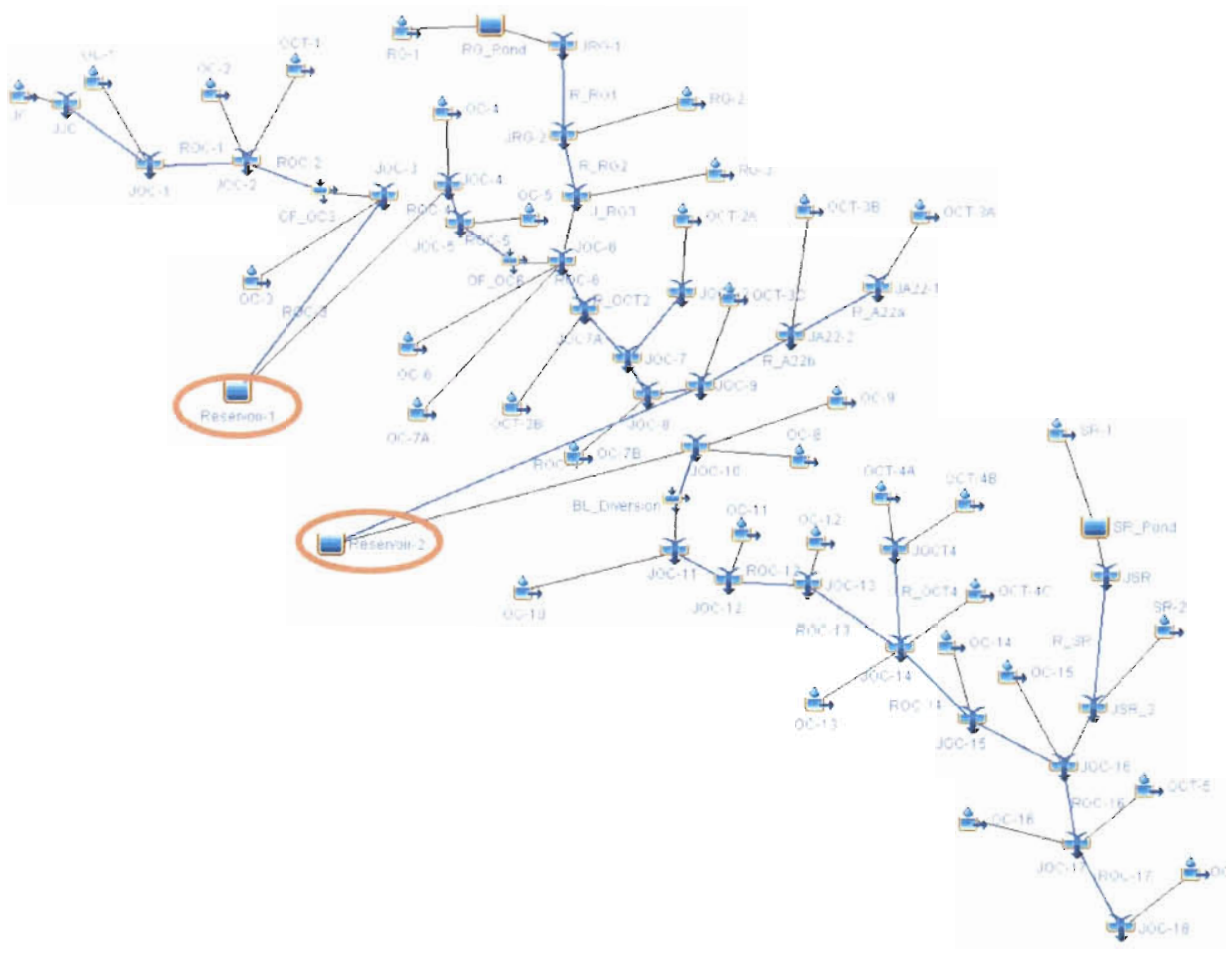

Figure 4.5: Scenario $C-2$ detention ponds in HMS 3.3

- Scenario D - 5 detention ponds: Similar to Scenario C, five detention ponds were placed throughout the watershed instead of two. The detention ponds were placed upstream from JOC-4, 6, 7, 9, and 10. 


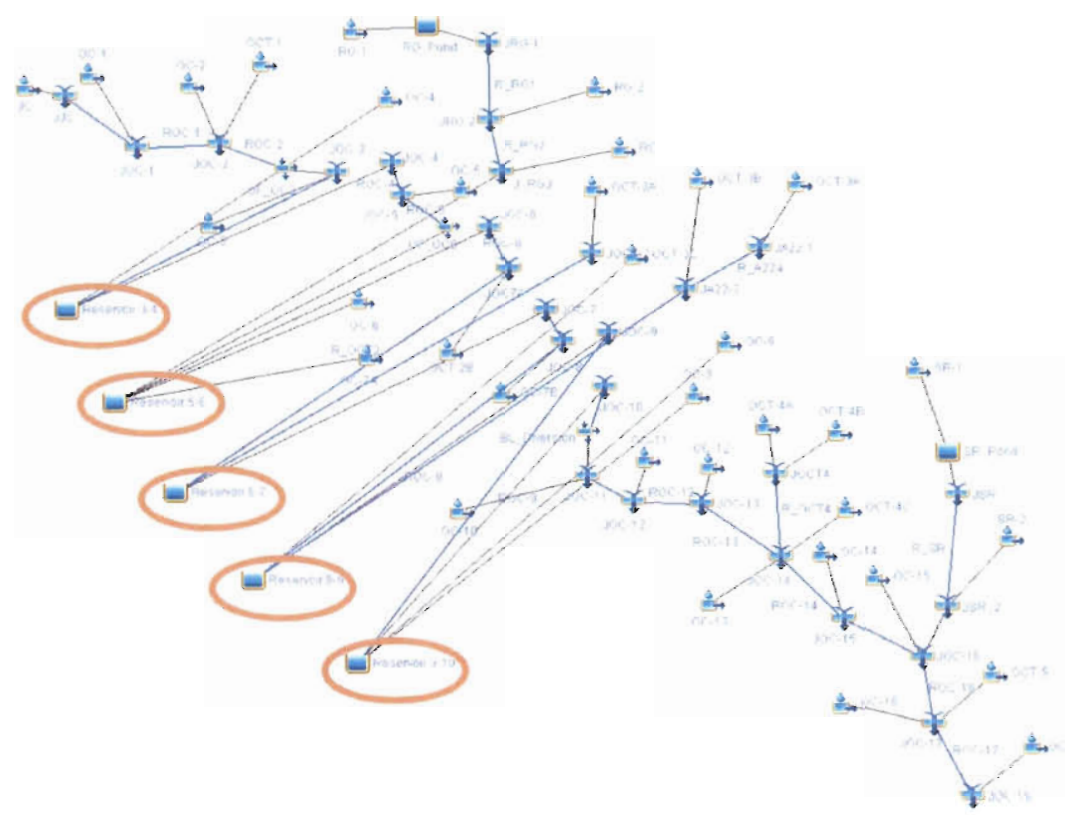

Figure 4.6: Scenario D-5 detention ponds in HMS 3.3

- Scenario E - 3 detention ponds with channel modifications: A combination of 3 detention ponds with modified channel roughness values were used to assess the effects on flood mitigation.

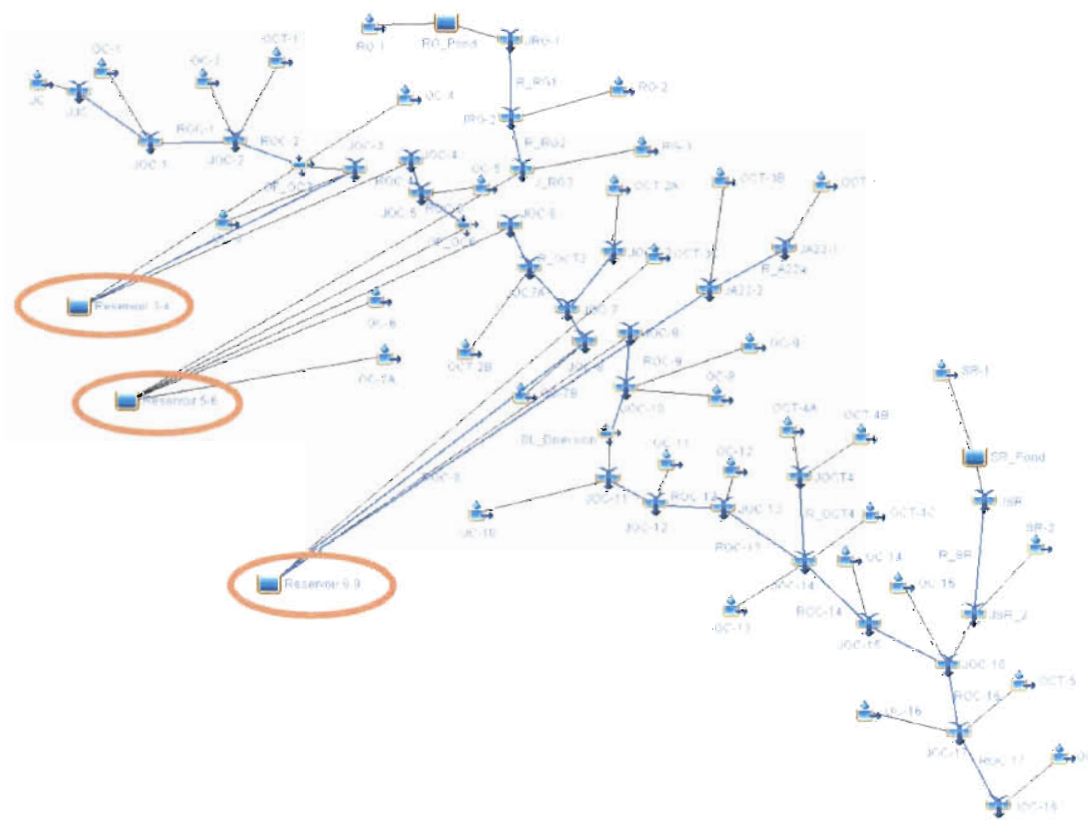

Figure 4.7: Scenario $E-3$ ponds with channel modifications 
'The structural options considered in this study resulted in varying degree of success in reducing water surface elevations from JOC-4 to JOC-9, with the most significant reduction observed in Scenario E (refer to Fig. 4.8). However, three of the five scenarios (Scenarios A, D, and E) failed to provide significant flood protection downstream of JOC-10 (i.e. JOC-11 to JOC-13).

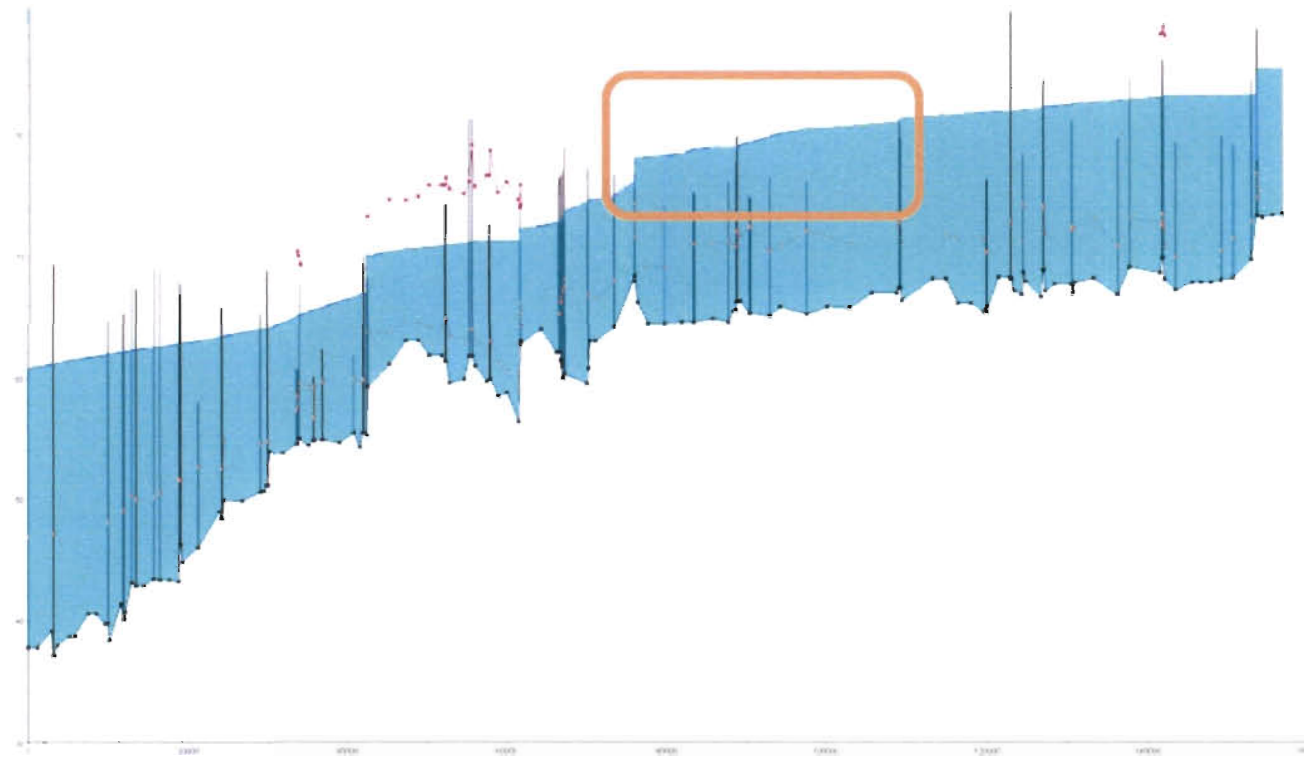

b.

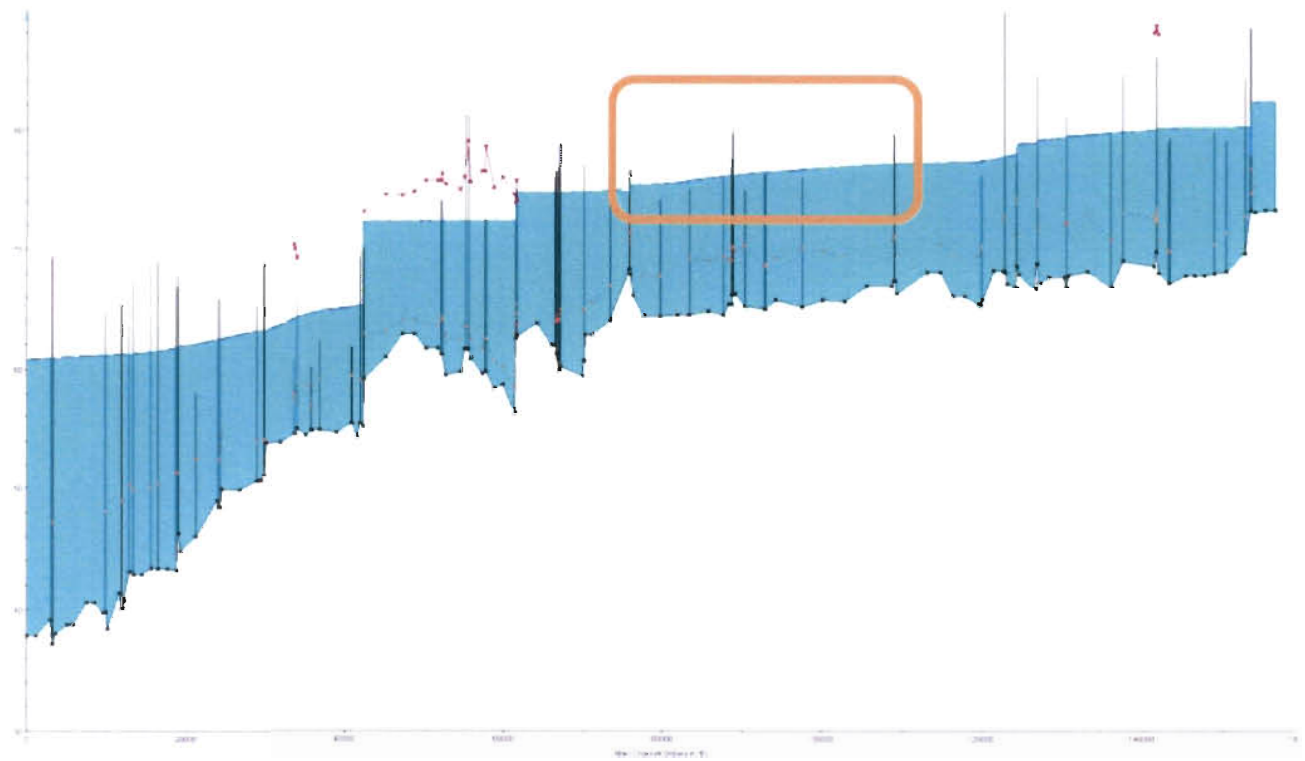

Figure 4.8: WSEL profiles of a) Existing 100-year and b) Scenario $E$ 
Table 4.2 shows water surface elevations (WSEL) along Oyster Creek in feet with the different flood control scenarios. All these scenarios were performed with a 100-year design storm.

\begin{tabular}{|ccccccc|}
\hline Locations & Existing 1\% & A & B & C & D & E \\
\hline JJC & 85.31 & 84.87 & 83.21 & 84.86 & 84.45 & 82.41 \\
\hline JOC-1 & 83.09 & 82.61 & 81.01 & 82.61 & 82.15 & 80.15 \\
\hline JOC-2 & 82.67 & 82.11 & 80.69 & 82.1 & 81.53 & 79.66 \\
\hline JOC-3 & 81.9 & 81.03 & 79.81 & 81.02 & 79.69 & 77.83 \\
\hline JOC-4 & 81.7 & 80.77 & 79.66 & 80.77 & 79.15 & 77.44 \\
\hline JOC-5 & 81.24 & 80.67 & 79.32 & 80.65 & 78.84 & 77.23 \\
\hline JOC-6 & 80.02 & 80.21 & 78.6 & 80.16 & 78.01 & 76.63 \\
\hline JOC-7A & 78.95 & 78.93 & 78.09 & 78.74 & 77.4 & 76.29 \\
\hline JOC-7 & 78.77 & 78.73 & 77.96 & 78.52 & 76.8 & 75.87 \\
\hline JOC-8 & 77.99 & 77.91 & 77.67 & 77.53 & 75.94 & 75.5 \\
\hline JOC-9 & 74.39 & 75.3 & 73.36 & 73.18 & 75.02 & 74.93 \\
\hline JOC-10 & 73.67 & 75.2 & 72.82 & 72.57 & 74.95 & 74.89 \\
\hline BL-Div & 72.34 & 75.14 & 72.34 & 71.63 & 74.87 & 74.87 \\
\hline JOC-11 & 71.34 & 72.71 & 70.48 & 70.28 & 72.74 & 72.55 \\
\hline JOC-12 & 71.25 & 72.68 & 70.47 & 70.21 & 72.71 & 72.54 \\
\hline JOC-13 & 70.04 & 72.45 & 70.04 & 69.17 & 72.47 & 72.47 \\
\hline JOC-14 & 63.98 & 63.76 & 63.98 & 63.78 & 63.77 & 63.77 \\
\hline JOC-15 & 63.38 & 63.25 & 63.38 & 63.26 & 63.25 & 63.25 \\
\hline JOC-16 & 62.13 & 62.1 & 62.13 & 62.1 & 62.1 & 62.1 \\
\hline JOC-17 & 61.39 & 61.4 & 61.39 & 61.4 & 61.4 & 61.4 \\
\hline JOC-18 & 60.9 & 60.9 & 60.9 & 60.9 & 60.9 & 60.9 \\
\hline
\end{tabular}

Table.4.2. WSEL Comparison for Varying Flood Control Scenarios (all results in feet) (Note: Values in red indicate increased WSEL compared to the existing $1 \%$ storm)

The WSEL results from the different scenarios imply that structural solutions alone are insufficient to provide the necessary protection from flood damage. This statement is especially true when considering a number of man-made flood control structures such as dams and diversions are already present in the watershed. These structures might not be 
able to withstand the hydrologic and hydraulic demands associated with future development within the city and the watershed. Therefore, to address the sustainability issues, conjunctive use of a structural option with other non-structural flood mitigating strategies should be considered. An example of the non-structural solution would be a reliable and operational flood warning system, which would be discussed in the next chapter. 


\section{Chapter 5: Sugar Land Flood Alert System (FAS)}

\subsection{General Framework}

A framework for a real-time flood alert system (FAS) has been developed by Bedient et al. (2003) to provide advanced flood warning information for the Texas Medical Center in Brays Bayou (Houston, TX). This system uses basin-averaged, realtime radar rainfall in a lumped hydrologic model, HEC-1 to convert rainfall intensities and durations to peak flows at particular points of interest. Different alert levels are assigned to specific rainfall intensities, durations, and flow rates. These alerts are delivered automatically through the internet to the Texas Medical Center personnel. FAS has been tested on several occasions, and the results have shown that it was successful in

providing flood warning lead time up to 2-3 hours. Using the same framework of the Rice University-Texas Medical Center FAS, the real-time flood warning system for Sugar Land is developed.

\subsection{HEC Modeling}

In order to provide real-time hydrologic flood forecasting, a HEC-1 model of the Oyster Creek Watershed is built (refer to Appendix F for the HEC-1 scripts of the Oyster Creek Watershed), using the parameters that have been calibrated from HEC-HMS 3.3. The decision to choose HEC-1 over HEC-HMS 3.3 is strictly due to scripting compatibility issues. The performances of the HEC-1 model are compared to the HECHMS 3.3 model by simulating both the 10 -year and the 100 -year design storms, the results of which can be viewed in Appendices B1 and B2. 
The HEC-1 model generally produced similar results with the HEC-HMS 3.3 model, with average peak flow differences of $2.5 \%$ and $1.1 \%$ for the 10 -year and 100 year design storms. Based on these results, the HEC-1 model is considered ready to be used in real-time hydrologic flood forecasting. At the time of this writing, the HEC-1 model is on the process of being uploaded to a server to be implemented in Sugar Land's FAS. Real-time sub-basin averaged radar rainfall data will be input into the model during a storm event. The results of the hydrologic computations will then be shown on the Sugar Land's FAS website (see Fig. 5.1), which will be updated every 15 minutes as the storm progresses. The performances of this model will have to be assessed and validated in future storm events.

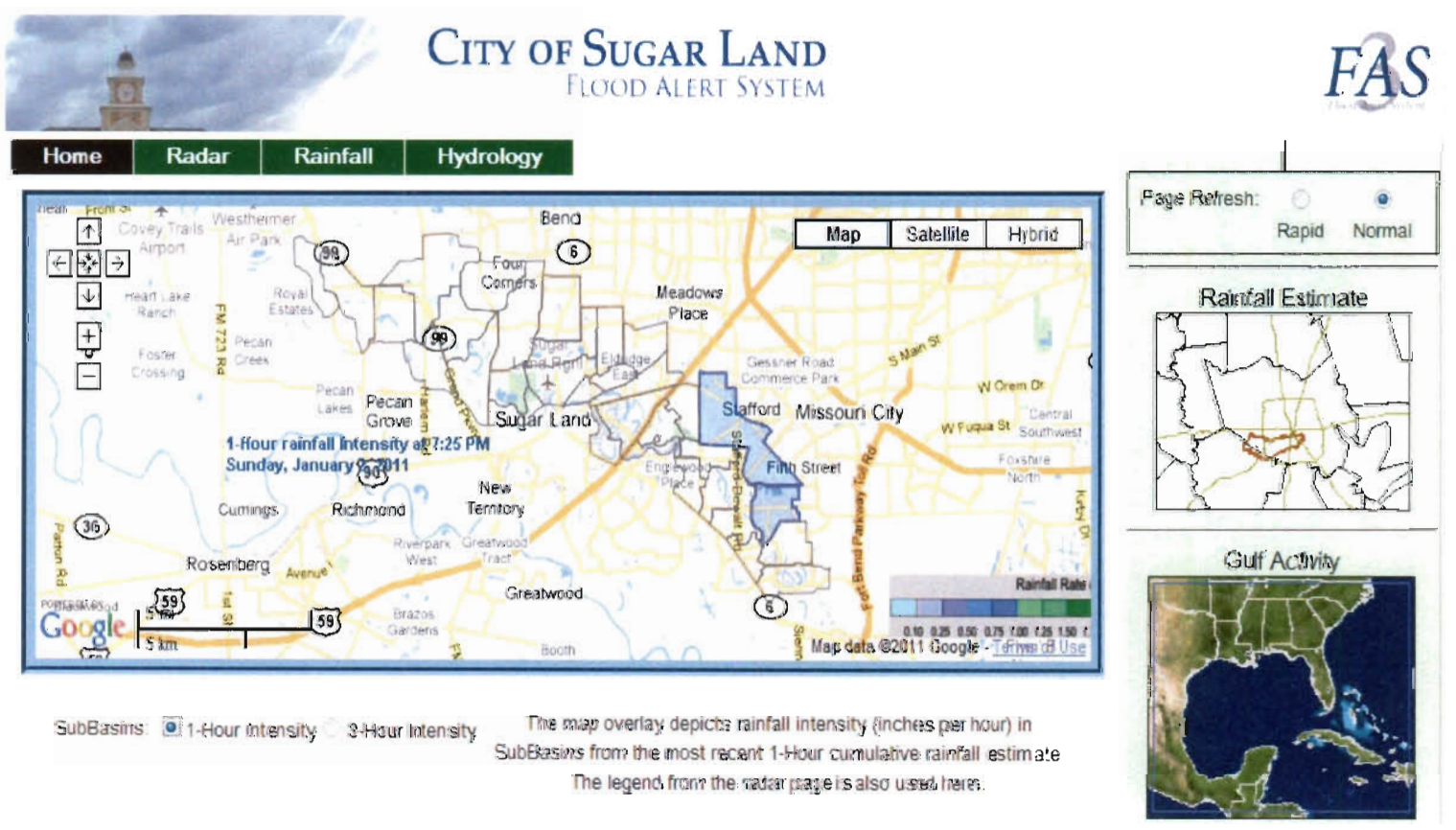

Figure 5.1: Sugar Land Flood Alert System (http://ike.oystercreek.flood-alert.org) 


\subsection{Flood Inundation Mapping}

The next step in Sugar Land's FAS is the creation of floodplain maps to visualize flooding inundation during storm events. One particularly useful feature of HEC-RAS is generating water surface profiles by running hydraulic simulations that can then be exported into a GIS software (i.e. ArcGIS). When elevation data are available (for example LiDAR and USGS DEM), ArcGIS can process the water surface profiles to create floodplain maps of that watershed. A plug-in tool, HEC-Geo-RAS, is required to activate this floodplain map generation feature in ArcGIS. In this thesis, the elevation dataset are obtained from the United States Geological Survey (USGS) National Map Seamless Server (http://seamless.usgs.gov/website/seamless/viewer.htm). The 32-feet resolution elevation data from Fort Bend County are processed to produce the watershed DEM.

Using generated water surface profiles based on the calibrated hydrologic and hydraulic models, the resulting 10-year and 100-year floodplain maps were created (Figure 5.2 and Figure 5.3). Comparing both maps, it appears that the upstream portions of the watershed are generally more prone to flooding, as evidenced by the depicted water levels. It is important to mention that the water levels shown in the figures might not accurately represent the actual conditions of the watershed. There are three major factors that may cause this occurrence: the use of a steady-state hydraulic model, the inherent limitation of a one-dimensional (1D) hydraulic model, and the resolution of the elevation dataset. 


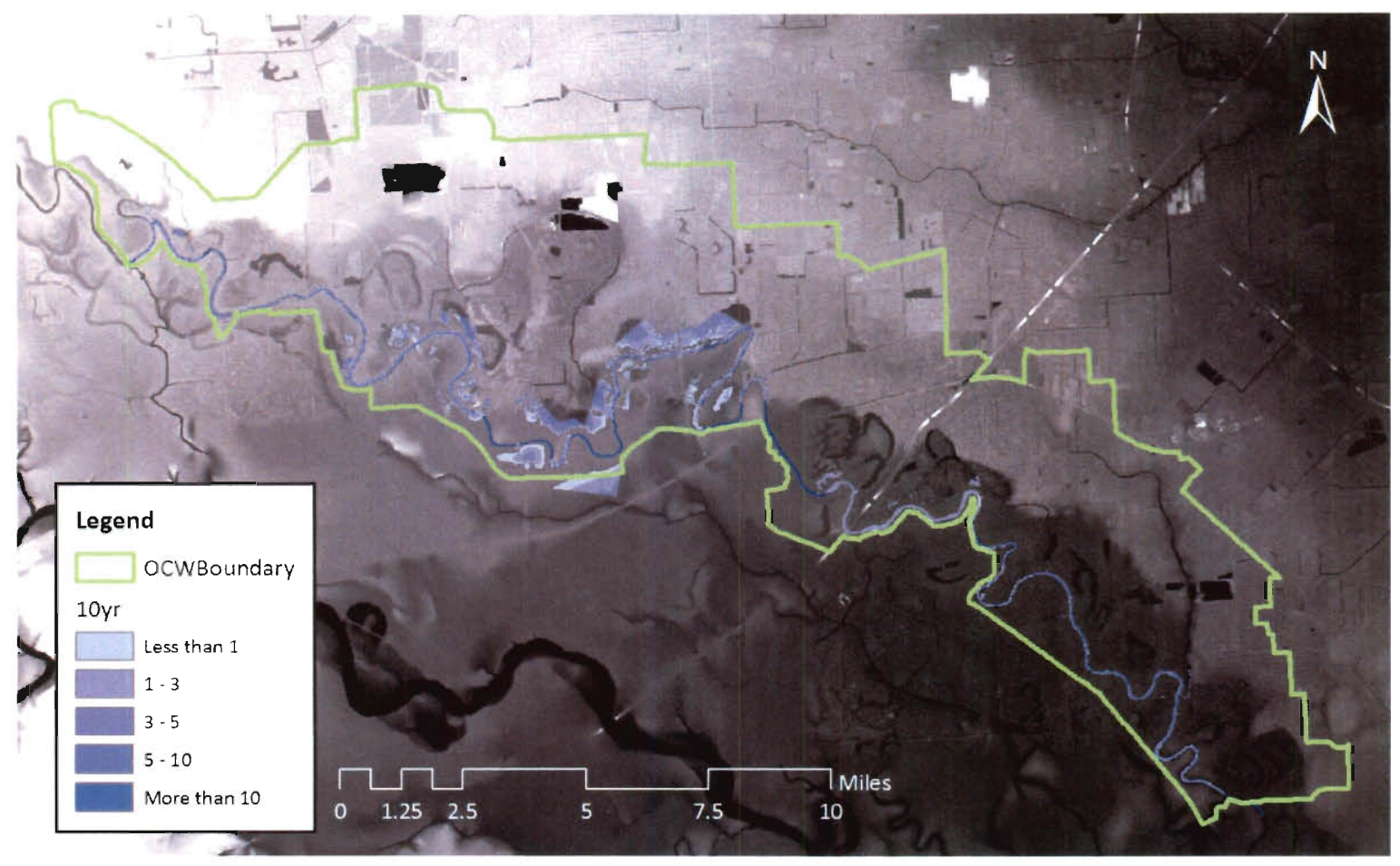

Figure 5.2: Calibrated10-year Floodplain Map of Oyster Creek

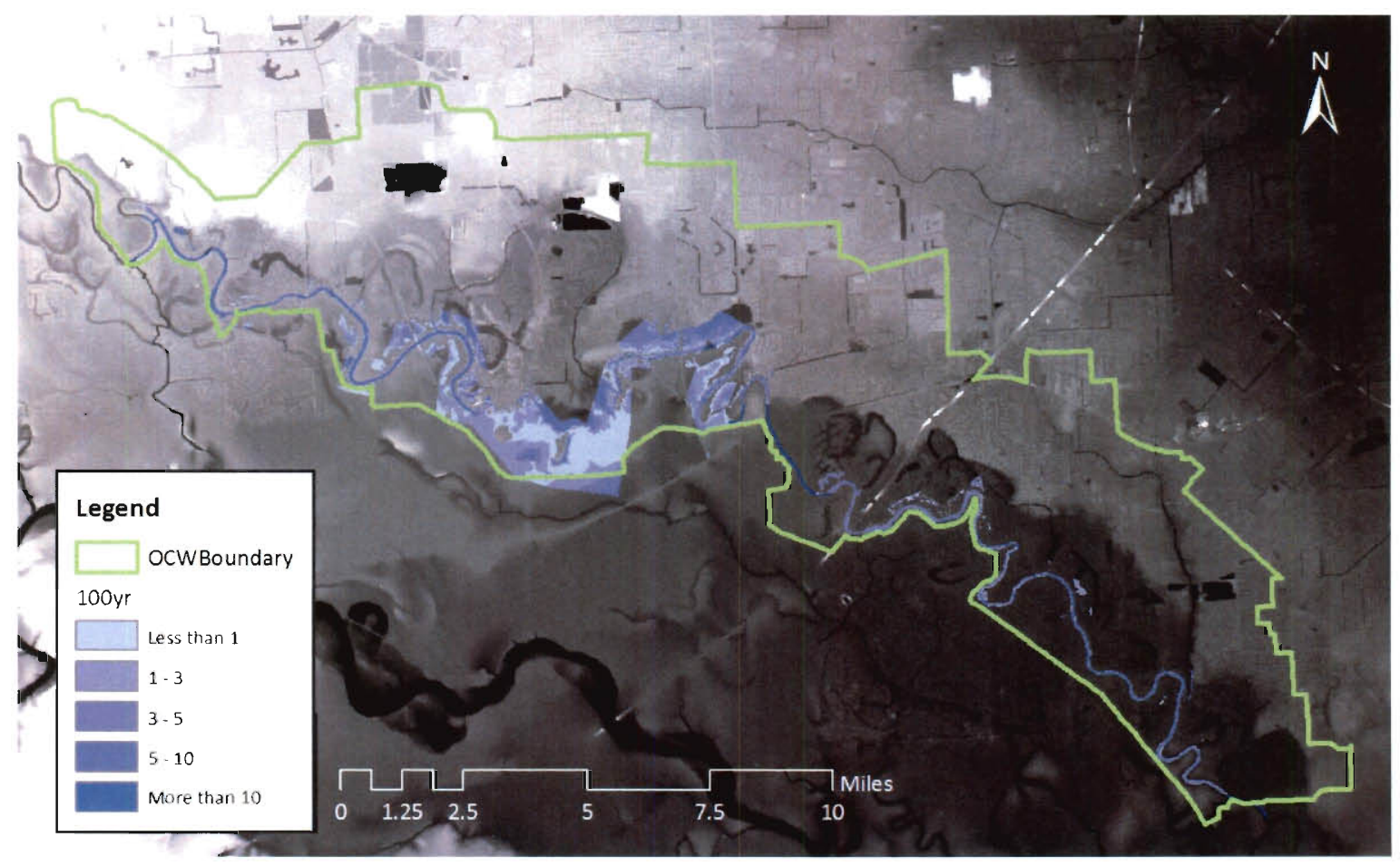

Figure 5.3: Calibrated 100-year Floodplain Map of Oyster Creek 
First of all, the generated floodplain maps are based on steady-state HEC-RAS models, where only peak flows instead of entire hydrographs are simulated. Since it is highly improbable that all locations in the watershed would experience peak flow rates at the same time, the resulting flood inundation levels would be higher than what they should be. The next factor that contributes to the unrealistic depiction of water levels is the inherent limitation of the hydraulic model itself. Since HEC-RAS is a onedimensional (1-D) hydraulic model, it does not take into account lateral flow. This means that water cannot flow beyond the extents of the defined channel cross sections in HECRAS. Finally, the other source of error in the floodplain map generation is the limited resolution of the elevation dataset used in this study. The DEM obtained from USGS has a 32 feet resolution, which is very likely to introduce some inaccuracies in depicting the elevation distribution throughout the watershed.

To remedy the first problem, conducting unsteady-state simulations in HEC-RAS that account for entire hydrographs instead of peak flows will depict the watershed's hydraulic response more accurately. For the second problem, one might attempt to increase the extents of the cross sections in HEC-RAS by conducting field surveys. Another solution is to use a 2-D hydraulic model such as the XP2D module of XPSWMM that has the capability to incorporate lateral flows. To address the third problem, a higher resolution elevation dataset (i.e. LiDAR with 1 meter resolution) should be c. All these improvements have not been implemented and would have to be addressed in future studies. In the meantime, although the steady-state floodplain maps are unlikely to provide accurate flood water levels, they are useful to identify the most flood-susceptible areas in the watershed. This may help city officials in determining 
critical areas for emergency or evacuation planning, traffic control, and other decisionmaking process.

\subsection{Floodplain Map Library (FPML)}

One potential future work in Sugar Land's FAS is to provide real-time visualizations of flood inundation as storms progress. Although HEC-RAS has the capability to delineate floodplains when flow rates are input at corresponding river stations, relying on it to create numerous floodplain maps in real-time during a storm event would be difficult due to its large computational load requirement and its inconsistency in data processing. To avoid this problem, Fang et al. (2008) have developed a method where the floodplain maps are created ahead of time and compiled in a database called the Floodplain Map Library (FPML). This method has been applied in the Rice-TMC FAS for the Brays Bayou Watershed and has generally shown great success in its implementation.

FPML consists of over a hundred pre-delineated floodplain maps based on various storm scenarios categorized by their rainfall totals, frequencies, durations, and spatial variations (Fang et al., 2008). The FPML has a unique map selection algorithm that approximates NEXRAD total rainfall for the past 24 hours during each cycle of the operation, then accumulates rainfall totals from the watershed, and compiles them into 3 , $6,9,12$, and 24 -hour totals. The rainfall totals are converted into rainfall intensity values, which are then used to select the most representative floodplain map based on the current rainfall conditions in the watershed for the next 1-2 hours. Following the same methodology, the FPML might also be applied in the Oyster Creek Watershed in the 
future to show real-time flooding levels in the watershed. In the meantime, the next chapter will discuss an alternative flood control option that only uses radar rainfall to provide simplified visualizations of flooding potential in the watershed, the Flood Warning Indicator (FWI). 


\section{Chapter 6: Flood Warning Indicator (FWI)}

\subsection{Motivation and Purpose}

The limited availability of recorded gauge data during storm events has proven to be the limiting factor in model calibration efforts. Ideally, an accurate real-time flood warning system requires calibration of radar rainfall with information recorded by a dense gauge network. This requirement is not a huge obstacle in big cities such as Houston, where it has the necessary resources to build and maintain an extensive gauge network. However, not every city or watershed has the ability to do the same.

Moreover, although a city or watershed may possess sufficient gauges for monitoring and calibration, there is no guarantee that they would be fully operational during severe storm events. Compared to radar, gauges are more prone to mechanical failures and data transmission problems. The unreliability of gauges is evident in the calibration process of Oyster Creek, where only two out of the six stream gauges (Gauges 4483 and 4153, Fig. 3.3) recorded both the April 2009 and May 2010 storms. In a larger storm (approximately 7 inches of total rainfall) that occurred on July 2010, the event was not recorded by the gauges entirely. Due to these considerations, this thesis introduces the radar-based Flood Warning Indicator (FWI), a flood warning tool that minimizes the dependence on a gauge network during storms. By only using radar rainfall, the FWI is able to portray potential flooding problems in specific areas within a watershed. The purpose of this tool is to serve as the first line of defense during storm events, especially for city officials to deploy personnel to the area of concern to verify and determine the extents of flooding. With this information, the city may then be able to plan for any necessary actions, such as evacuation planning and traffic control. 


\subsection{Characteristics}

One important characteristic of the FWI compared to other flood warning mechanisms is that it does not rely on floodplain maps to show flooding potential. Although floodplain maps are extremely useful to show areas of inundation within a watershed, huge amounts of data collection and processing times are required for their generation. For complex watersheds such as Oyster Creek, which has many manmade flood control structures such as dams and diversions; accurately modeling the hydrologic and hydraulic responses of the watershed becomes problematic. Manually-operated flood control devices such as flood gates and sluice gates also add to the complexities of modeling, since they may skew the model results. Hence, accurate models require full understanding of the standard operating procedures of these manually-operated devices in addition to knowledge of the numerous hydrologic parameters of the watershed.

The FWI, on the other hand, does not depend on these factors to work properly, since it only relies on accurate radar rainfall information during storm events. This reduces data requirements and processing times, making it an effective tool to provide useful flood warning information in a simplified, timely manner. One limitation of the FWI, however, is that it would not be able to provide detailed information regarding the extents and exact locations of flooding within the particular region in the watershed, since it was never intended for this purpose. Despite this limitation, the FWI tool is ideal to be applied in relatively small, suburban watersheds that do not experience large storms frequently or possess the necessary resources to build and maintain an extensive gauge network. 


\subsection{Methodology}

As mentioned previously, the FWI only uses real-time radar (NEXRAD) rainfall to show potential flooding problems. Radar rainfall is averaged for specific, pre-defined regions in the watershed. During a storm event, the rainfall amount that falls into the regions for a particular time interval is linked with a specific alert level. The city officials may then use this information to verify the extents of flooding in the region of concern. The following sections will discuss the development of FWI in more detail.

\subsubsection{Delineating FWI Regions}

The first step in formulating the FWI is to divide the Oyster Creek Watershed into 5 separate regions (see Fig. 6.1), based on sub-basins areal extents, land uses, population densities, and time to peak (refer to Appendix $\mathrm{C}$ to see the breakdown of each region with individual sub-basins). Each region covers approximately 9 square miles with 6-7 subbasins. Ideally, regions should not be too small to maintain its simplicity. Likewise, they should also not be too large in order to show sufficient detail.

\begin{tabular}{|c|c|}
\hline Region & Area (sq. mi.) \\
\hline 1 & 10.3 \\
\hline 2 & 8.5 \\
\hline 3 & 10.9 \\
\hline 4 & 6.9 \\
\hline 5 & 8.5 \\
\hline
\end{tabular}

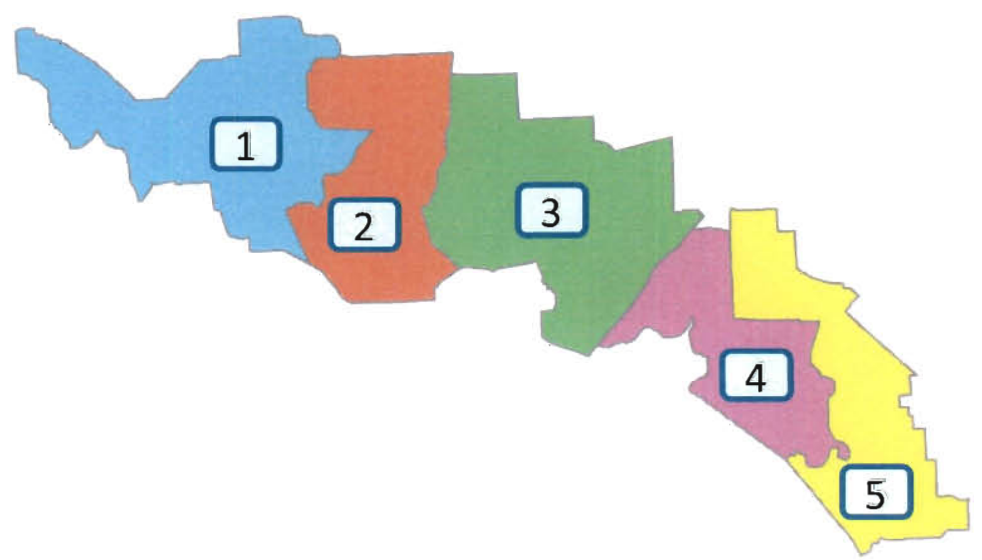

Figure 6.1: FWI Region Delineation and areal extents 
To test the performances of the delineated FWI regions, the patterns for both gridded radar rainfall distribution and the region-averaged radar rainfall data are compared to a storm that occurred in July 2010 (see figure below).
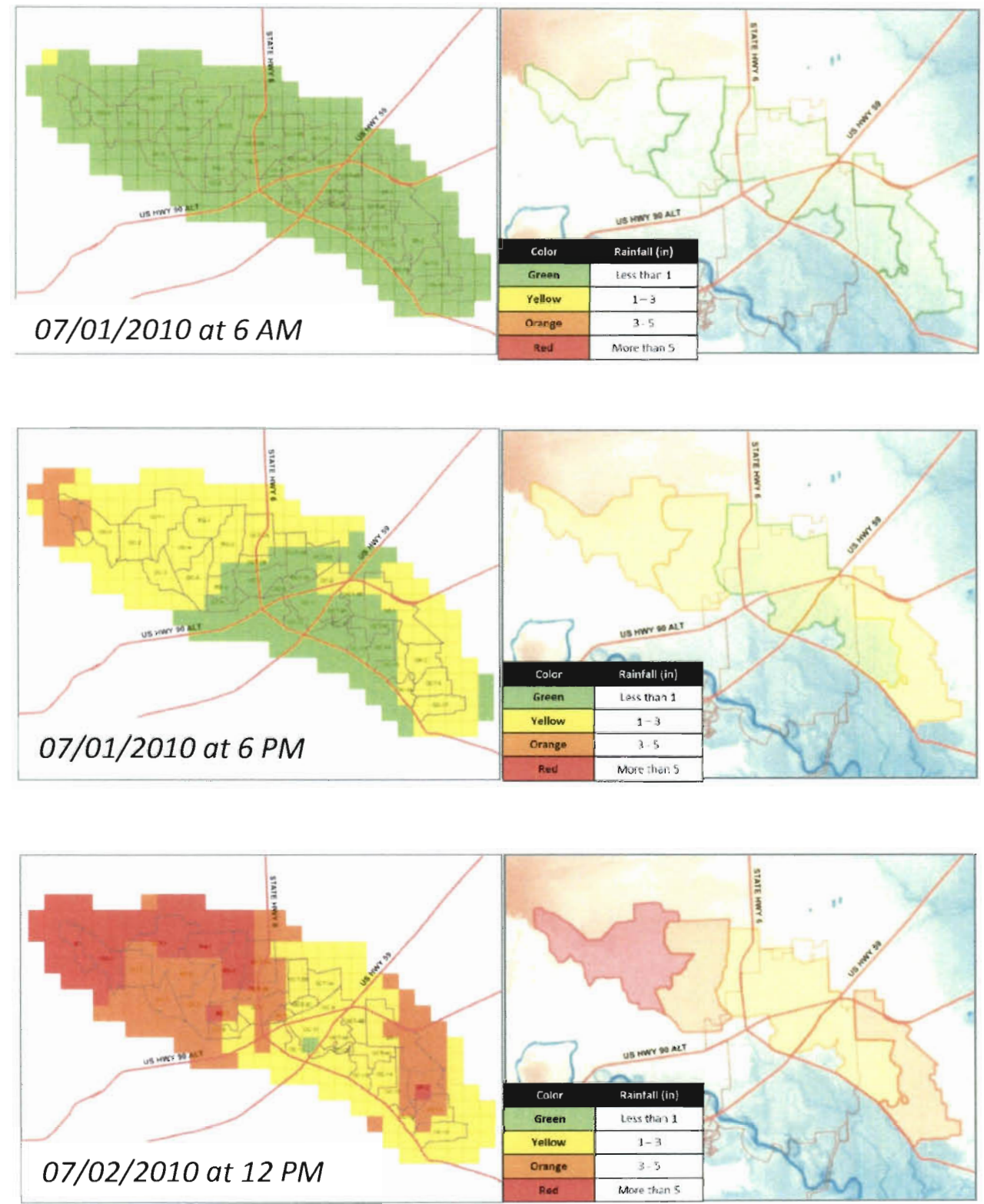

Figure 6.2: Total rainfall distribution comparison for July 2010 storm

(Note: Images on the left column are gridded radar rainfall. Images on the right column are FWI regionaveraged radar rainfall. Color indicates cumulative rainfall with green: less than I inch of rainfall; yellow: I-3 in; orange: $3-5$ in; and red: greater than $5 \mathrm{in}$.) 
This storm had a total rainfall amount of 7 inches which started in June 30, 2010 and ended in July 2, 2010. The comparison results from Fig. 6.2 show that the FWI regions generally corresponded well with the rainfall distribution patterns obtained from the gridded radar rainfall. Although not identical, the rainfall patterns of the FWI regions were comparable to the ones of the gridded radar rainfall. Having the FWI regions delineated, the next step in the FWI procedure is to perform historical rainfall analyses.

\subsubsection{Historical Rainfall Analysis}

To determine the threshold levels for FWI, detailed rainfall amount, intensity, and duration from various storms were analyzed and compiled in a database. The data for Fort Bend County (obtained from TxDOT, 2004) were used for this analysis.

$$
I=\frac{b}{\left(T_{d}+d\right)^{e}}
$$

Equation 6.1 denotes the rainfall intensity-duration frequency (IDF) relationship that is applicable to Fort Bend County, where $I$ indicated design rainfall intensity in in/hr.; $T_{d}$ is the time of concentration or duration of rainfall in minutes; $e, b$, and $d$ are coefficients for specific frequencies based on the National Weather Service Technical Paper 40 (NWS TP-40). The IDF coefficients used are listed on the following table:

\begin{tabular}{|ccccccc|}
\hline Coefficient & $\mathbf{5 0 \%}$ & $\mathbf{2 0 \%}$ & $\mathbf{1 0 \%}$ & $\mathbf{4 \%}$ & $\mathbf{2 \%}$ & $\mathbf{1 \%}$ \\
\hline e & 0.804 & 0.760 & 0.751 & 0.729 & 0.726 & 0.710 \\
b & 70 & 71 & 80 & 84 & 91 & 92 \\
d & 7.9 & 8.1 & 8.1 & 8.1 & 8.1 & 7.9 \\
\hline
\end{tabular}

Table 6.1: IDF coefficients for Fort Bend County, TX 
Based on equation (6.1), the rainfall intensities and frequencies are calculated (see Appendix D) and the resulting IDF curves are plotted in Fig. 6.3.

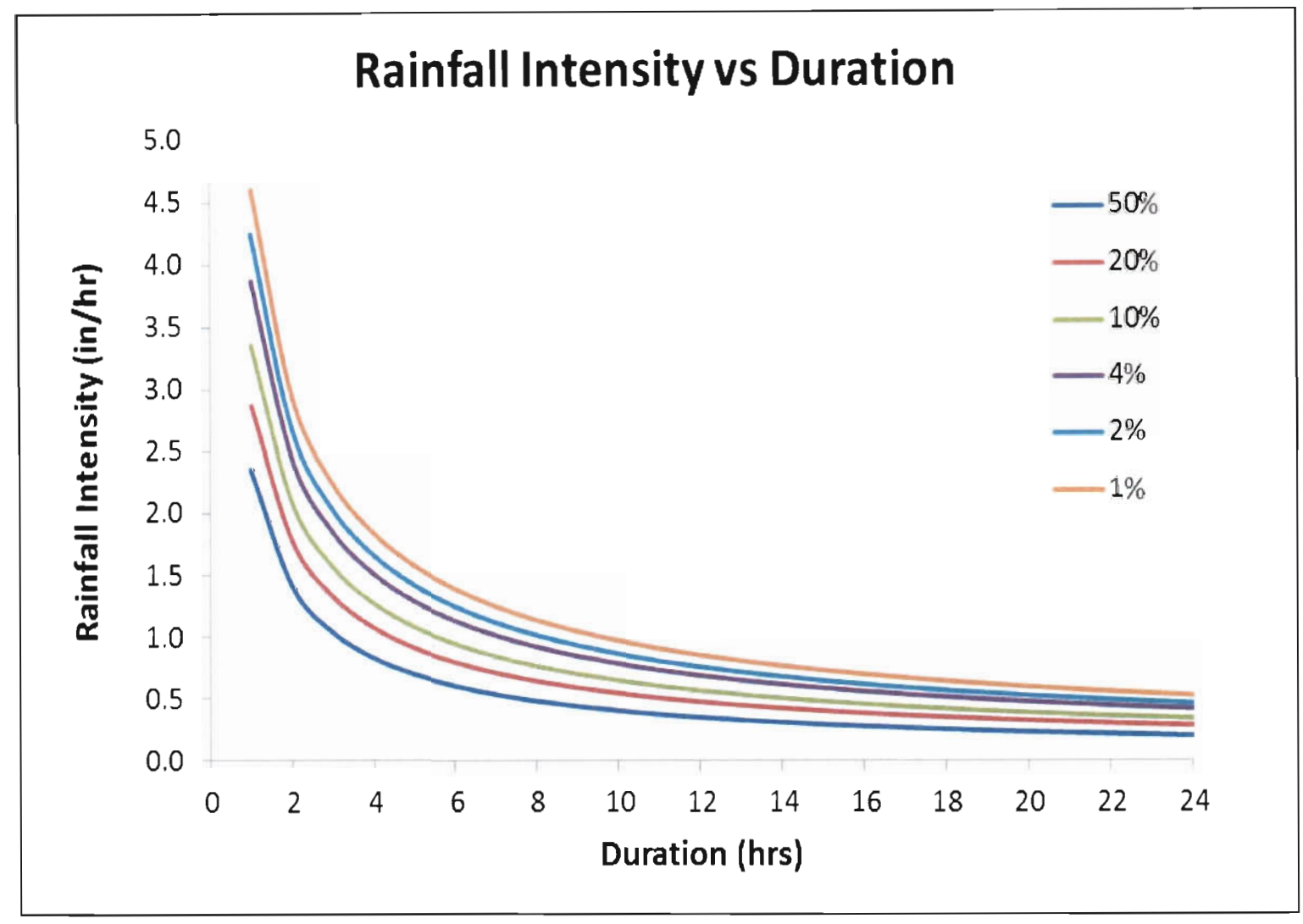

Figure 6.3: IDF Curves for Fort Bend County

Having the IDF curves, rainfall depth and duration for various rainfall frequencies are plotted on a logarithmic scale (see Figure 6.4). Several gauge and radar-recorded storms were also plotted on the same figure to see which frequencies these storms fit into. As one may notice, most of the recorded storms fall within the 50\% (2-year storm) category. The exception is TS Allison which falls just below the $2 \%$ (50-year storm) category. 


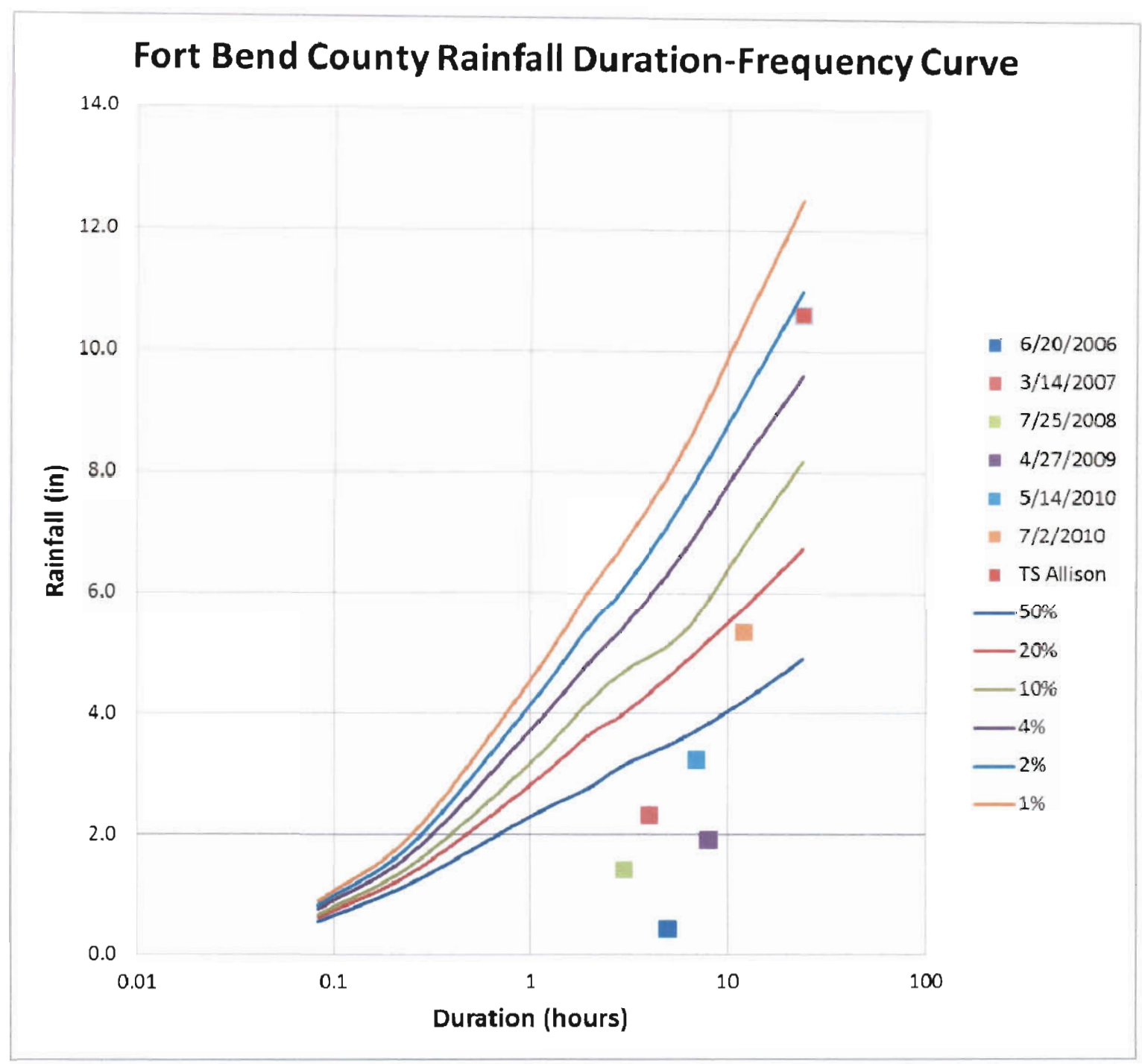

Fig. 6.4: Fort Bend County Rainfall Depth Duration-Frequency Curves

To further corroborate these findings, an analysis of the historical trend of maximum 24-hour rainfall at a particular gauge is conducted. This gauge is located at the Sugar Land Regional Airport, and the data were obtained from the National Data Climatic Center (NCDC). Data from 1946 to 2010 were analyzed and plotted in Figure 6.5 below: 


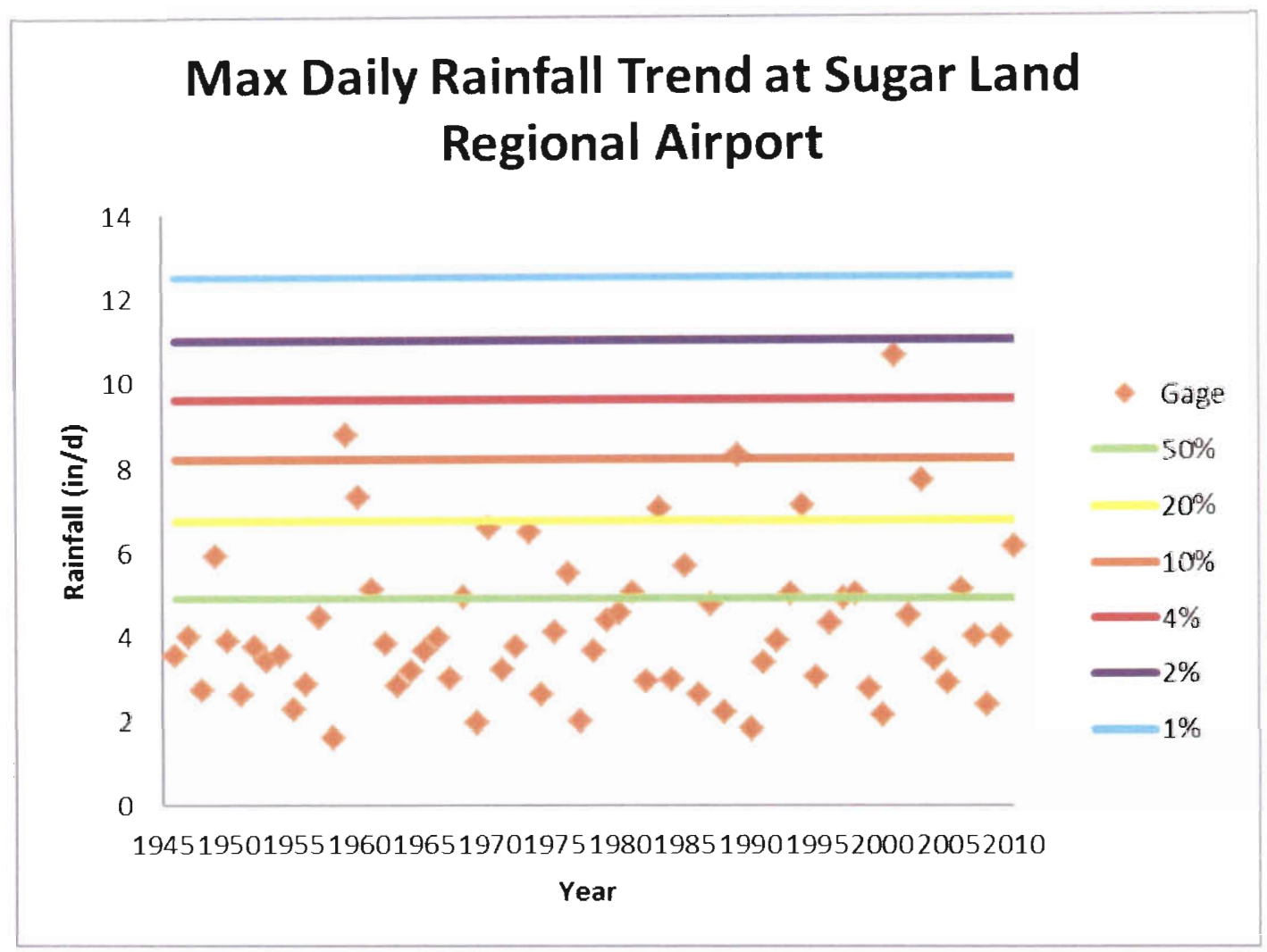

Fig.6.5: Historical max 24-hr rainfall at Sugar Land Regional Airport

The Fort Bend County 24-hr IDF storms were also plotted in the figure for comparison. The results showed that most of the storms $(\sim 79 \%)$ are within the 2-year category, $19 \%$ are 5 -year, $6 \%$ are 10 -year, and only $3 \%$ are 10 -year category storms. The results of the historical rainfall analyses are then compared with documented flooding occurrences of Fort Bend County, Texas. The comparison is necessary to establish a relationship between rainfall intensities and potential flooding hazards. According to the Flood Insurance Study of Fort Bend County conducted by FEMA in 2001, there were several notable flooding events caused by severe storms:

- The October 1994 floods were prompted by heavy rains moving across Burleson, Brazos, Grimes and Washington counties. The rains continued southward and 
affected Jackson, Wharton, Matagorda, Brazoria, and portions of Fort Bend County.

Total rainfall from the entire storm ranged from 10 to 20 inches.

- On October 17, 1998, a series of storms moved across the central and south regions of Texas, dropping up to 22 inches of rain in some areas. Sixty Texas counties $(24 \%)$ reported flooding during October 17-19. Thirty-six counties, including Fort Bend County, became eligible for federal and/or state assistance as a result of damages suffered from this storm system during this time period.

- Tropical Storm Allison was formed in the Gulf of Mexico on June 4, 2001 and hit the upper Texas coast soon afterwards. After moving northward through the state, it cycled back south and reentered the Gulf of Mexico before heading east to Louisiana. The storm brought heavy rainfall that caused severe flooding problems, especially in Houston, with recorded total rainfall exceeding 40 inches.

Based on the total rainfall amount and their durations, all these storms are in the 10-year return period category or higher. This implies that rainfall events with a 10-year return period or higher are very likely to cause flooding. Likewise, there are no recorded flooding occurrences for storms in the 2-year return period or less category. With this information, the relationship between rainfall (intensity, duration, and amount) and the likelihood of flooding can be established.

\subsubsection{Determining Threshold Levels}

From the historical rainfall analyses and comparison of flood occurrences, the threshold levels with their associated flooding potentials are formulated. FWI operates by 
following two procedures simultaneously: the rainfall intensity procedure and the rainfall total procedure.

\begin{tabular}{|c|c|c|}
\hline Alert Color & $\begin{array}{l}\text { Rainfall intensity } \\
\text { (in/15 min) }\end{array}$ & $\begin{array}{l}\text { Flooding } \\
\text { potential }\end{array}$ \\
\hline Green & $<1$ & Minimal \\
\hline Yellow & $1-1.5$ & Low \\
\hline Orange & $1.5-1.8$ & Moderate \\
\hline Red & $>1.8$ & High \\
\hline
\end{tabular}

Table 6.2: FWI threshold levels for the rainfall intensity procedure

In the rainfall intensity procedure (Table 6.2), the FWI will be updated in 15-

minute time intervals. When the rainfall intensity of a region reaches a certain threshold during that time interval, that region would be represented with the appropriate alert color. The alert colors show four distinct flood potentials, with green indicating minimal potential of flooding, yellow indicating a low probability of flooding, orange indicating moderate chance of flooding, and red indicating high possibility of flooding.

In the rainfall total procedure (see table 6.3), FWI accumulates hourly total rainfall as a storm progresses. When the rainfall totals of the regions reach a certain amount, they would also be assigned a specific alert level. In the operation of FWI, it is possible that following one procedure would result in an alert color that is different from that of the other procedure. If that is the case, then the "worse" alert color in either procedure takes precedence over the other.

As an example, a region may record rainfall intensities of $0.5,0.7,0.9$, and 0.6 inches in four consecutive 15-minute time intervals for total rainfall duration of 1 hour. In the rainfall intensity procedure, the associated alert level would be green. In the rainfall 
total procedure, however, the alert color would be yellow since the rainfall total at 1 -hr is 2.7 inches $(0.5+0.7+0.9+0.6=2.7$ inches $)$. Therefore, that particular region would be represented by a yellow alert level instead of green. When a particular region flashes a dangerous threat level, for instance orange or red, the city officials might be able to take preemptive measures, such as dispatching someone to that particular region of concern in order to verify the extents of flooding.

\begin{tabular}{|c|c|c|c|c|}
\hline \multirow{2}{*}{$\begin{array}{c}\text { Rainfall } \\
\text { Duration (hrs) }\end{array}$} & Green & Yellow & Orange & Red \\
\hline 1 & $<2.4$ & $2.4-2.9$ & $2.9-3.4$ & $>3.4$ \\
2 & $<2.8$ & $2.8-3.6$ & $3.6-4.2$ & $>4.2$ \\
3 & $<3.1$ & $3.1-4.0$ & $4.0-4.7$ & $>4.7$ \\
4 & $<3.3$ & $3.3-4.3$ & $4.3-5.1$ & $>5.1$ \\
5 & $<3.5$ & $3.5-4.6$ & $4.6-5.4$ & $>5.4$ \\
6 & $<3.7$ & $3.7-4.8$ & $4.8-5.7$ & $>5.7$ \\
7 & $<3.8$ & $3.8-5.0$ & $5.0-5.9$ & $>5.9$ \\
8 & $<3.8$ & $3.8-5.1$ & $5.1-6.2$ & $>6.2$ \\
9 & $<4.0$ & $4.0-5.3$ & $5.3-6.3$ & $>6.3$ \\
10 & $<4.0$ & $4.0-5.4$ & $5.4-6.5$ & $>6.5$ \\
11 & $<4.1$ & $4.1-5.6$ & $5.6-6.6$ & $>6.6$ \\
12 & $<4.2$ & $4.2-5.6$ & $5.6-6.8$ & $>6.8$ \\
13 & $<4.3$ & $4.3-5.9$ & $5.9-6.9$ & $>6.9$ \\
14 & $<4.3$ & $4.3-5.9$ & $5.9-7.1$ & $>7.1$ \\
15 & $<4.4$ & $4.4-6.0$ & $6.0-7.2$ & $>7.2$ \\
16 & $<4.5$ & $4.5-6.1$ & $6.1-7.4$ & $>7.4$ \\
17 & $<4.6$ & $4.6-6.1$ & $6.1-7.5$ & $>7.5$ \\
18 & $<4.6$ & $4.6-6.3$ & $6.3-7.6$ & $>7.6$ \\
19 & $<4.6$ & $4.6-6.4$ & $6.4-7.6$ & $>7.6$ \\
20 & $<4.6$ & $4.6-6.5$ & $6.5-7.8$ & $>7.8$ \\
21 & $<4.6$ & $4.6-6.5$ & $6.5-7.8$ & $>7.8$ \\
22 & $<4.8$ & $4.8-6.6$ & $6.6-7.9$ & $>7.9$ \\
23 & $<4.8$ & $4.8-6.7$ & $6.7-8.1$ & $>8.1$ \\
24 & $<4.8$ & $4.8-6.7$ & $6.7-8.2$ & $>8.2$ \\
\hline
\end{tabular}

Table 6.3: FWI threshold levels for the rainfall total procedure 


\subsection{FWI Application - July 2010 Storm}

To demonstrate how the FWI would perform in an actual storm, the July 2010 event is once again used. Figure 6.6 below shows the FWI regions with the associated alert levels as the storm progresses.
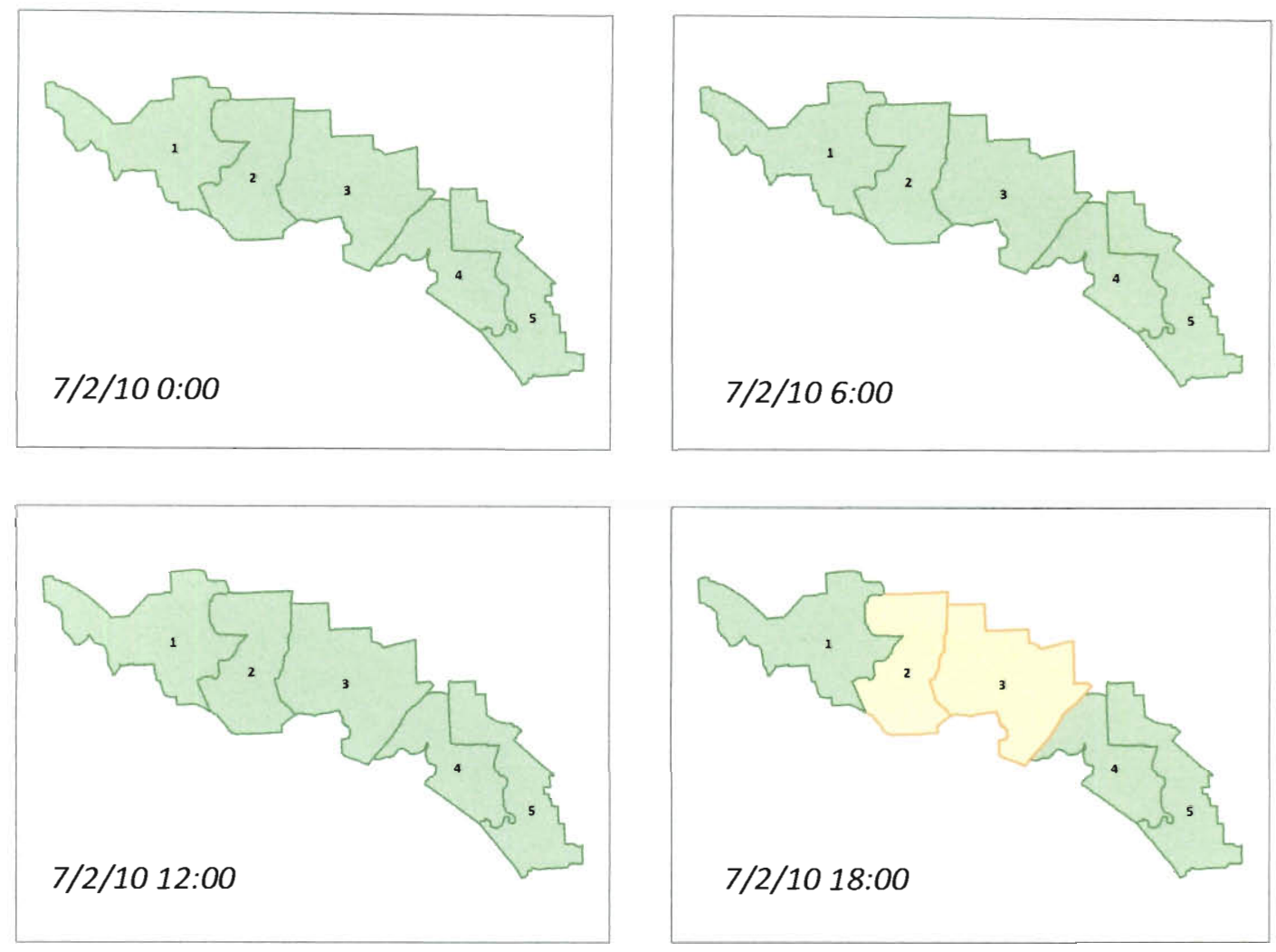

Fig.6.6: FWI regions during July 2010 storm

Table 6.4 shows the alert levels of each region as the July 2010 storm progressed. $D$ indicates the duration of the rainfall in hours, $I$ indicates the rainfall intensity in inches per 15 minute at that particular time, and $T$ represents the total rainfall amount in inches based on the rainfall duration, $D$. One might notice that at 6 PM on July 2, 2010, both regions 2 and 3 are represented with a "yellow" alert, indicating low possibilities of flooding, even though the rainfall intensities fall in the "green" alert category (see Table. 
6.3). As have been explained previously, the "more dangerous" alert level from one procedure will take precedence over the other; and in this case, the alert level from the total rainfall procedure falls into the "yellow" alert category, and is therefore displayed in the FWI. Emergency personnel may then use the displayed alert information to verify the extents of flooding at the region of concern, and plan for any ensuing actions.

\begin{tabular}{|c|c|c|c|c|}
\hline \multirow{2}{*}{ Date $\&$ time } & \multirow{2}{*}{ D (hrs) } & \multicolumn{3}{|c|}{ Region 1} \\
\hline & & I & $\mathbf{T}$ & Alert \\
\hline 7/2/10 0:00 & 0 & 0.026 & 0.0 & Green \\
\hline $7 / 2 / 106: 00$ & 6 & 0.006 & 0.1 & Green \\
\hline $7 / 2 / 1012: 00$ & 12 & 0.029 & 2.9 & Green \\
\hline $7 / 2 / 1018: 00$ & 18 & 0.002 & 4.1 & Green \\
\hline \multirow{2}{*}{ Date $\&$ time } & \multirow{2}{*}{ D (hrs) } & \multicolumn{3}{|c|}{ Region 2} \\
\hline & & I & $\mathrm{T}$ & Alert \\
\hline $7 / 2 / 100: 00$ & 0 & 0.028 & 0.0 & Green \\
\hline 7/2/10 6:00 & 6 & 0.012 & 0.1 & Green \\
\hline $7 / 2 / 1012: 00$ & 12 & 0.031 & 3.0 & Green \\
\hline $7 / 2 / 1018: 00$ & 18 & 0.001 & 5.6 & Yellow \\
\hline \multirow{2}{*}{ Date \& time } & \multirow{2}{*}{ D (hrs) } & \multicolumn{3}{|c|}{ Region 3} \\
\hline & & I & $T$ & Alert \\
\hline $7 / 2 / 100: 00$ & 0 & 0.034 & 0.0 & Green \\
\hline $7 / 2 / 106: 00$ & 6 & 0.017 & 0.1 & Green \\
\hline $7 / 2 / 1012: 00$ & 12 & 0.033 & 2.6 & Green \\
\hline $7 / 2 / 1018: 00$ & 18 & 0.001 & 5.3 & Yellow \\
\hline \multirow{2}{*}{ Date \& time } & \multirow{2}{*}{ D (hrs) } & \multicolumn{3}{|c|}{ Region 4} \\
\hline & & I & $\mathbf{T}$ & Alert \\
\hline $7 / 2 / 100: 00$ & 0 & 0.056 & 0.0 & Green \\
\hline $7 / 2 / 106: 00$ & 6 & 0.025 & 0.1 & Green \\
\hline $7 / 2 / 1012: 00$ & 12 & 0.082 & 2.5 & Green \\
\hline $7 / 2 / 1018: 00$ & 18 & 0.006 & 4.0 & Green \\
\hline \multirow{2}{*}{ Date \& time } & \multirow{2}{*}{ D (hrs) } & \multicolumn{3}{|c|}{ Region 5} \\
\hline & & I & $\mathrm{T}$ & Alert \\
\hline $7 / 2 / 100: 00$ & 0 & 0.052 & 0.0 & Green \\
\hline $7 / 2 / 106: 00$ & 6 & 0.048 & 0.1 & Green \\
\hline $7 / 2 / 1012: 00$ & 12 & 0.145 & 2.8 & Green \\
\hline $7 / 2 / 1018: 00$ & 18 & 0.014 & 4.1 & Green \\
\hline
\end{tabular}

Table 6.4: FWI alert levels during July 2010 storm 
With the demonstration of FWI, this thesis shows that an operational flood warning system is possible despite lacking gauge data. Although the performance of the FWI still needs to be confirmed and updated in future storms, it is apparent that this method has the potential to be applied in other cities or watersheds that do not necessarily possess the resources to build and maintain extensive gauge networks. 


\section{Chapter 7: Conclusions and Recommendations}

\subsection{Objective 1: Update and calibrate the hydrologic model of Oyster Creek Watershed}

Hydrologic models of the Oyster Creek Watershed both in HEC-HMS 3.3 and

HEC-1 were created. The HEC-HMS 3.3 model was used for model calibration, while the HEC-1 model was developed for real-time flood prediction. The HEC-HMS 3.3 model was successfully calibrated to two actual storms with similar total rainfall amounts of 2.5 inches that occurred in April 2009 and May 2010. By adjusting the Green and Ampt infiltration and the Clark UH transform parameters, the calibrated model showed improved match with the observed stream gauge data in terms of peak flows, time to peaks, and volumes when compared to the original model.

Although having shown improved performances compared to the original model, one should use the calibrated model with caution. Due to the model being calibrated to merely two relatively small storms, the calibrated model might not be applicable in other types of storms (i.e. storms with total rainfall greater than 2.5 inches). Therefore, the performance of the model needs to be confirmed in the future with varying rainfall amount and duration and the hydrologic parameters updated as necessary.

\subsection{Objective 2: Determine flood vulnerability of the watershed and assess the effectiveness of structural flood control options}

Both hydrologic analyses in HEC-HMS and steady-state hydraulic analyses in HEC-RAS were performed to assess the flood vulnerability of the Oyster Creek Watershed and to determine the effectiveness of various structural flood control scenarios. This thesis has shown that high flow locations in HEC-HMS did not 
necessarily correspond to water inundated areas identified by HEC-RAS. This is largely due to the varying hydrologic and hydraulic capacities along the main channel of Oyster Creek. The results of HEC-RAS showed that the watershed is most vulnerable between JOC-4 and JOC-10 (see Fig. 4.3).

To determine the effectiveness of structural flood control options, five different scenarios were considered and analyzed. These scenarios involved the use of diversions, detention ponds, and channel modifications that were simulated with a 100-year design storm. The assessment of these different scenarios resulted in some reduction in water levels between JOC-4 and JOC-10 (refer to Table 4.2). However, it was observed that the structural solutions did not provide any flood protection to locations directly downstream from JOC-10 (i.e. JOC 11 onwards). These results suggest that relying on structural flood control options alone might be uneconomical as well as insufficient to protect the watershed from future flood damages.

\subsection{Objective 3: Develop a framework for a real-time radar-based flood warning system for the City of Sugar Land}

This thesis has shown the framework for Sugar Land's Flood Alert System (FAS) that included real-time updates of radar rainfall inputs and hydrologic prediction in the form of an interactive website, http://ike.oystercreek.flood-alert.org. Radar rainfall inputs are delivered by Vieux and Associates, Inc. from Oklahoma to a remote server located in Houston, Texas. The rainfall inputs are used in real-time hydrologic prediction with the HEC-1 model of Oyster Creek Watershed. HEC-1 is chosen instead of HEC-HMS 3.3 due to its stability in scripting. The results of the hydrologic analyses are then displayed 
in the mentioned website that can be accessed by the city officials and emergency personnel.

Despite having the Sugar Land's FAS online, its performance still need to be tested in future storms and adjusted as necessary. Also, one future work in consideration is the development of the Floodplain Map Library (FPML) for the Oyster Creek Watershed. With the help of these maps, one might easily visualize the extents of flooding in real-time during storm events. The creation of these maps should be possible when the calibrated hydrologic model has been tested with larger storms and unsteadystate runs of the hydraulic model be performed to more realistically depict the conditions of the watershed.

\subsection{Objective 4: Develop and implement the radar-based Flood Warning Indicator (FWI) as a flood control option for areas that lack sufficient gauge networks}

This thesis also discussed a flood control alternative, the Flood Warning Indicator (FWI), for a city or watershed that lacks the required resources to build and maintain an extensive gauge network for flood monitoring and calibration. With radar rainfall, FWI is able to portray potential flooding problems in particular regions of the watershed. Although FWI does not show the extents of flooding in specific locations in the watershed, it provides simplified visualizations of flooding potentials that may aid city officials and emergency personnel to plan for any preventive actions. The performance of FWI still needs to be tested in future storms, the results of which may change the threshold alert levels as well as the region boundaries. Nevertheless, the introduction of FWI in this thesis shows the possibility of having an operational flood warning system in place despite lacking a gauge network. 


\section{References and Work Cited}

Ajami, N. K., H. Gupta, T. Wagener, and S. Sorooshian. 2004. Calibration of a semidistributed hydrologic model for streamflow estimation along a river system. Journal of Hydrology 298 (1-4):112-135.

Arnold, J. G., R. Srinivasan, R. S. Muttiah, and J. R. Williams. 1998. Large area hydrologic modeling and assessment - Part 1: Model development. Journal of the American Water Resources Association 34 (1):73-89.

Bates, P. D. 2004. Remote sensing and flood inundation modelling. Hydrological Processes 18 (13):2593-2597.

Bedient, P. B., A. Holder, J. A. Beneavides, and B. E. Vieux. 2003. Radar-based flood warning system applied to tropical storm allison. Journal of Hydrologic Engineering 8 (6):308-318.

Bedient, Philip B., Wayne C. Huber, and Baxter E. Vieux. 2008. Hydrology and Floodplain Analysis, 4th Edition. 4th ed. Upper Saddle River, NJ 07458: Prentice Hall.

Berne, A., G. Delrieu, J. D. Creutin, and C. Obled. 2004. Temporal and spatial resolution of rainfall measurements required for urban hydrology. Journal of Hydrology 299 (3-4):166-179.

Brandes, E. A., J. Vivekanandan, and J. W. Wilson. 1999. A comparison of radar reflectivity estimates of rainfall from collocated radars. Journal of Atmospheric and Oceanic Technology 16 (9):1264-1272.

Ciach, G. J., M. L. Morrissey, and W. F. Krajewski. 2000. Conditional bias in radar rainfall estimation. Journal of Applied Meteorology 39 (11):1941-1946.

Correia, F. N., M. D. Saraiva, F. N. Da Silva, and I. Ramos. 1999. Floodplain management in urban developing areas. Part I. Urban growth scenarios and landuse controls. Water Resources Management 13 (1):1-21.

Delrieu, G., I. Braud, A. Berne, M. Borga, B. Boudevillain, F. Fabry, J. Freer, E. Gaume, E. Nakakita, A. Seed, P. Tabary, and R. Uijlenhoet. 2009. Weather radar and hydrology Preface. Advances in Water Resources 32 (7):969-974.

Dutta, D., S. Herath, and K. Musiake. 2000. Flood inundation simulation in a river basin using a physically based distributed hydrologic model. Hydrological Processes 14 (3):497-519. 
Fang, Z., P. B. Bedient, J. Benavides, and A. L. Zimmer. 2008. Enhanced radar-based flood alert system and FloodPlain Map Library. Journal of Hydrologic Engineering 13 (10):926-938.

FBCDD. 1999. Fort Bend County Drainage Criteria Manual. Fort Bend, TX.

Federal Emergency Management Agency (FEMA). 2006a. $<$ http://www.fema.gov/hazard/flood/index.shtm>.

Freer, J., K. Beven, and B. Ambroise. 1996. Bayesian estimation of uncertainty in runoff prediction and the value of data: An application of the GLUE approach. Water Resources Research 32 (7):2161-2173.

Gurnell, A., and D. Montgomery. 1998. Preface: Hydrological applications of GIS. Hydrological Processes 12 (6):821-822.

HEC. 1998. HEC-1 Flood Hydrograph Package, User's Manual. Hydrologic Engineering Center, Davis, CA.

HEC. 2000. Hydrologic Modeling System HEC-HMS User's Manual, Version 2.

Hydrologic Engineering Center, Davis, CA.

HEC. 2006. Hydrologic Modeling System HEC-HMS User's Manual. Hydrologic Engineering Center, Davis, CA.

HEC. 2002. River Analysis System HEC-RAS User's Manual. Hydrologic Engineering Center, Davis, CA.

Hoblit, B., B. Vieux, A. Holder, and P. Bedient. 1999. Predicting with precision. Civil Engineering 69 (11):40-43.

James, W. P., C. G. Robinson, and J. F. Bell. 1993. Radar-Assisted Real-Time Flood Forecasting. Journal of Water Resources Planning and Management-Asce 119 (1):32-44.

Knebl, M. R., Z. L. Yang, K. Hutchison, and D. R. Maidment. 2005. Regional scale flood modeling using NEXRAD rainfall, GIS, and HEC-HMS/RAS: a case study for the San Antonio River Basin Summer 2002 storm event. Journal of Environmental Management 75 (4):325-336.

Krajewski, W. F., and J. A. Smith. 2002. Radar hydrology: rainfall estimation. Advances in Water Resources 25 (8-12):1387-1394.

Krajewski, W. F., G. Villarini, and J. A. Smith. 2010. RADAR-RAINFALL UNCERTAINTIES Where are We after Thirty Years of Effort? Bulletin of the American Meteorological Society 91 (1):87. 
Mason, D. C., D. M. Cobby, M. S. Horritt, and P. D. Bates. 2003. Floodplain friction parameterization in two-dimensional river flood models using vegetation heights derived from airborne scanning laser altimetry. Hydrological Processes 17 (9):1711-1732.

Neary, V. S., E. Habib, and M. Fleming. 2004. Hydrologic modeling with NEXRAD precipitation in middle Tennessee. Journal of Hydrologic Engineering 9 (5):339349.

Ogden, F. L., J. Garbrecht, P. A. DeBarry, and L. E. Johnson. 2001. GIS and distributed watershed models. II: Modules, interfaces and models. Journal of Hydrologic Engineering 6 (6):515-523.

Seo, D. J., and J. P. Breidenbach. 2002. Real-time correction of spatially nonuniform bias in radar rainfall data using rain gauge measurements. Journal of Hydrometeorology 3 (2):93-111.

Sharif, H. O., L. Sparks, A. A. Hassan, J. Zeitler, and H. J. Xie. 2010. Application of a Distributed Hydrologic Model to the November 17, 2004, Flood of Bull Creek Watershed, Austin, Texas. Journal of Hydrologic Engineering 15 (8):651-657.

USACE, United States Army Corps of Engineers. 2010. National Flood Risk Management Program Newsletter Vol 3. No. 2: Focusing on Nonstructural flood risk management alternatives.

USEOP, U.S. Executive Office of the President. Interagency Floodplain Management Review Committee. 1994. Sharing the Challenge: Floodplain Management into the $21^{\text {st }}$ Century. Prepared for the Administration Floodplain Management Task Force by Gerald E. Galloway. U.S. Government Printing Office, Washington, D.C.

Vieux, B. E., and P. B. Bedient. 2004. Assessing urban hydrologic prediction accuracy through event reconstruction. Journal of Hydrology 299 (3-4):217-236.

Vieux, B. E., J. H. Park, and B. Kang. 2009. Distributed Hydrologic Prediction: Sensitivity to Accuracy of Initial Soil Moisture Conditions and Radar Rainfall Input. Journal of Hydrologic Engineering 14 (7):671-689.

Villarini, G., J. A. Smith, M. L. Baeck, P. Sturdevant-Rees, and W. F. Krajewski. 2010. Radar analyses of extreme rainfall and flooding in urban drainage basins. Journal of Hydrology 381 (3-4):266-286.

Vivekanandan, J., D. N. Yates, and E. A. Brandes. 1999. The influence of terrain on rainfall estimates from radar reflectivity and specific propagation phase observations. Journal of Atmospheric and Oceanic Technology 16 (7):837-845. 
Whiteaker, T. L., O. Robayo, D. R. Maidment, and D. Obenour. 2006. From a NEXRAD rainfall map to a flood inundation map. Journal of Hydrologic Engineering 11 (1):37-45.

Wilson, J. W., and E. A. Brandes. 1979. Radar Measurement of Rainfall - Summary. Bulletin of the American Meteorological Society 60 (9):1048-1058. 


\section{Appendices}

Appendix A: Calibrated Clark UH Parameters for Oyster Creek in HEC-HMS 3.3 ..... 79

Appendix B1: 10-year peak flow comparisons of HEC-1 and HMS 3.3 .................... 80

Appendix B2: 100-year peak flow comparisons of HEC-1 and HMS 3.3 ................... 81

Appendix C: Breakdown of FWI regions with their associating sub-basins................ 82

Appendix D: Fort Bend County's rainfall intensities, durations, and frequencies ......... 83

Appendix E: Fort Bend County's rainfall totals, durations, and frequencies................ 84

Appendix F: HEC-1 scripts of Oyster Creek Watershed for real-time hydrologic

forecasting. 
Appendix A: Calibrated Clark UH Parameters for Oyster Creek in HEC-HMS 3.3

\begin{tabular}{|c|c|c|c|c|}
\hline \multirow{2}{*}{$\begin{array}{c}\text { Sub- } \\
\text { basin }\end{array}$} & \multicolumn{2}{|c|}{ Original } & \multicolumn{2}{c|}{ Calibrated } \\
\cline { 2 - 5 } JC & TC & R & TC & R \\
\hline OC-1 & 4.45 & 8.04 & 1.95 & 20.10 \\
\hline OC-10 & 0.59 & 2.96 & 0.59 & 7.40 \\
\hline OC-11 & 1.62 & 8.43 & 1.62 & 21.08 \\
\hline OC-12 & 3.47 & 8.69 & 3.47 & 21.73 \\
\hline OC-13 & 2.21 & 4.32 & 2.21 & 10.80 \\
\hline OC-14 & 0.9 & 3.9 & 0.90 & 9.75 \\
\hline OC-15 & 1.96 & 3.36 & 1.96 & 8.40 \\
\hline OC-16 & 1.22 & 2.84 & 1.22 & 7.10 \\
\hline OC-17 & 2 & 5.49 & 2.00 & 13.73 \\
\hline OC-2 & 3.16 & 8.67 & 1.58 & 21.68 \\
\hline OC-3 & 6.67 & 11.01 & 3.34 & 27.53 \\
\hline OC-4 & 3.2 & 6.59 & 1.60 & 16.48 \\
\hline OC-5 & 3.16 & 13.79 & 1.58 & 34.48 \\
\hline OC-6 & 6.75 & 12.39 & 3.38 & 30.98 \\
\hline OC-7A & 4.72 & 10.85 & 2.36 & 27.13 \\
\hline OC-7B & 5.76 & 10.4 & 2.88 & 26.00 \\
\hline OC-8 & 2.47 & 6.16 & 2.47 & 15.40 \\
\hline OC-9 & 2.96 & 4.92 & 2.96 & 12.30 \\
\hline OCT-1 & 2.22 & 8.63 & 1.11 & 21.58 \\
\hline OCT-2A & 1.17 & 3.95 & 1.17 & 9.88 \\
\hline OCT-2B & 1.72 & 6.86 & 1.72 & 17.15 \\
\hline OCT-3A & 1.19 & 3.48 & 1.19 & 8.70 \\
\hline OCT-3B & 0.69 & 3.81 & 0.69 & 9.53 \\
\hline OCT-3C & 2.25 & 4.39 & 2.25 & 10.98 \\
\hline OCT-4A & 2.99 & 8.95 & 2.99 & 22.38 \\
\hline OCT-4B & 1.51 & 3.25 & 1.51 & 8.13 \\
\hline OCT-4C & 1.51 & 2.99 & 1.51 & 7.48 \\
\hline OCT-5 & 0.81 & 1.93 & 0.81 & 4.83 \\
\hline RG-1 & 2.04 & 4.59 & 1.02 & 11.48 \\
\hline RG-2 & 2.59 & 6.04 & 1.30 & 15.10 \\
\hline RG-3 & 2.52 & 5.14 & 1.26 & 12.85 \\
\hline SR-1 & 3.36 & 4.21 & 3.36 & 10.53 \\
\hline SR-2 & 1.43 & 2.28 & 1.43 & 5.70 \\
\hline
\end{tabular}


Appendix B1: 10-year peak flow comparisons of HEC-1 and HMS 3.3

\begin{tabular}{|ccccc|}
\hline Subbasin & HEC-1 & HMS & Difference (cfs) & Difference (\%) \\
\hline JOC-1 & 238 & 246.3 & 8.3 & 3.4 \\
\hline JOC-2 & 495 & 512.8 & 17.8 & 3.5 \\
\hline JOC-3 & 541 & 559.5 & 18.5 & 3.3 \\
\hline JOC-4 & 665 & 683.2 & 18.2 & 2.7 \\
\hline JOC-5 & 725 & 744.8 & 19.8 & 2.7 \\
\hline JOC-6 & 1025 & 1052.2 & 27.2 & 2.6 \\
\hline JOC-7A & 1078 & 1109.1 & 31.1 & 2.8 \\
\hline JOC-7 & 1149 & 1181.4 & 32.4 & 2.7 \\
\hline JOC-8 & 1132 & 1163.6 & 31.6 & 2.7 \\
\hline JOC-9 & 1226 & 1260.4 & 34.4 & 2.7 \\
\hline JOC-10 & 1388 & 1416.7 & 28.7 & 2.0 \\
\hline JOC-11 & 547 & 552.4 & 5.4 & 1.0 \\
\hline JOC-12 & 667 & 676.2 & 9.2 & 1.4 \\
\hline JOC-13 & 681 & 690.2 & 9.2 & 1.3 \\
\hline JOC-14 & 994 & 1012.5 & 18.5 & 1.8 \\
\hline JOC-15 & 1095 & 1116.2 & 21.2 & 1.9 \\
\hline JOC-16 & 1596 & 1640.4 & 44.4 & 2.7 \\
\hline JOC-17 & 1812 & 1857.5 & 45.5 & 2.4 \\
\hline JOC-18 & 2046 & 2096.8 & 50.8 & 2.4 \\
\hline
\end{tabular}


Appendix B2: 100-year peak flow comparisons of HEC-1 and HMS 3.3

\begin{tabular}{|ccccc|}
\hline Subbasin & HEC-1 & HMS & Difference (cfs) & Difference (\%) \\
\hline JOC-1 & 437 & 443 & 6 & 1.4 \\
\hline JOC-2 & 935 & 947.5 & 12.5 & 1.3 \\
\hline JOC-3 & 1041 & 1055.3 & 14.3 & 1.4 \\
\hline JOC-4 & 1282 & 1300.9 & 18.9 & 1.5 \\
\hline JOC-5 & 1359 & 1375.9 & 16.9 & 1.2 \\
\hline JOC-6 & 1877 & 1899.5 & 22.5 & 1.2 \\
\hline JOC-7A & 2008 & 2027.4 & 19.4 & 1.0 \\
\hline JOC-7 & 2137 & 2158 & 21 & 1.0 \\
\hline JOC-8 & 2051 & 2070.8 & 19.8 & 1.0 \\
\hline JOC-9 & 2209 & 2230.1 & 21.1 & 0.9 \\
\hline JOC-10 & 2365 & 2390.4 & 25.4 & 1.1 \\
\hline JOC-11 & 775 & 779.1 & 4.1 & 0.5 \\
\hline JOC-12 & 1005 & 1011.6 & 6.6 & 0.7 \\
\hline JOC-13 & 1038 & 1045.4 & 7.4 & 0.7 \\
\hline JOC-14 & 1706 & 1720.6 & 14.6 & 0.8 \\
\hline JOC-15 & 1928 & 1944.7 & 16.7 & 0.9 \\
\hline JOC-16 & 3055 & 3085.9 & 30.9 & 1.0 \\
\hline JOC-17 & 3337 & 3373.5 & 36.5 & 1.1 \\
\hline JOC-18 & 3630 & 3669.1 & 39.1 & 1.1 \\
\hline
\end{tabular}


Appendix C: Breakdown of FWI regions with their associating sub-basins

\begin{tabular}{|c|c|c|}
\hline Region & Sub-basins & Area (sq.mi) \\
\hline \multirow[t]{7}{*}{1} & $\mathrm{JC}$ & 1.19 \\
\hline & OC-1 & 1.84 \\
\hline & $O C-2$ & 1.62 \\
\hline & OC-3 & 1.43 \\
\hline & OC-4 & 1.84 \\
\hline & OCT-1 & 2.35 \\
\hline & Total & 10.27 \\
\hline \multirow[t]{6}{*}{2} & OC-5 & 1.94 \\
\hline & OC-6 & 0.62 \\
\hline & RG-1 & 1.9 \\
\hline & RG-2 & 2.89 \\
\hline & RG-3 & 1.15 \\
\hline & Total & 8.5 \\
\hline \multirow[t]{11}{*}{3} & OC-7 & 1.23 \\
\hline & OC- 8 & 0.42 \\
\hline & OC-9 & 1.18 \\
\hline & OC-10 & 0.54 \\
\hline & OC-11 & 1.35 \\
\hline & OCT-2A & 1.59 \\
\hline & OCT-2B & 1.45 \\
\hline & OCT-3A & 1.25 \\
\hline & OCT-3B & 1.22 \\
\hline & OCT-3C & 0.71 \\
\hline & Total & 10.94 \\
\hline \multirow[t]{8}{*}{4} & OC-12 & 0.46 \\
\hline & OC-13 & 0.82 \\
\hline & OC-14 & 1.12 \\
\hline & OC-15 & 1.4 \\
\hline & OCT-4A & 1.24 \\
\hline & OCT-4B & 0.95 \\
\hline & OCT-4C & 0.9 \\
\hline & Total & 6.89 \\
\hline \multirow[t]{6}{*}{5} & OC-16 & 0.64 \\
\hline & OC-17 & 1.43 \\
\hline & OCT-5 & 1.33 \\
\hline & SR-1 & 3.61 \\
\hline & SR-2 & 1.44 \\
\hline & Total & 8.45 \\
\hline
\end{tabular}


Appendix D: Fort Bend County's rainfall intensities, durations, and frequencies

\begin{tabular}{|c|c|c|c|c|c|c|}
\hline \multirow{2}{*}{$\begin{array}{c}\text { Duration } \\
\text { (hr) }\end{array}$} & \multicolumn{7}{|c|}{ Intensity (in/hr) } \\
\cline { 2 - 7 } & $\mathbf{5 0 \%}$ & $\mathbf{2 0 \%}$ & $\mathbf{1 0 \%}$ & $\mathbf{4 \%}$ & $\mathbf{2 \%}$ & $\mathbf{1 \%}$ \\
\hline 1 & 2.36 & 2.87 & 3.36 & 3.87 & 4.25 & 4.60 \\
3 & 1.42 & 1.78 & 2.09 & 2.44 & 2.69 & 2.94 \\
4 & 1.04 & 1.33 & 1.57 & 1.85 & 2.03 & 2.24 \\
5 & 0.83 & 1.07 & 1.27 & 1.51 & 1.66 & 1.84 \\
6 & 0.70 & 0.91 & 1.08 & 1.29 & 1.42 & 1.57 \\
7 & 0.61 & 0.80 & 0.95 & 1.13 & 1.25 & 1.39 \\
8 & 0.54 & 0.71 & 0.84 & 1.01 & 1.12 & 1.25 \\
9 & 0.48 & 0.64 & 0.77 & 0.92 & 1.02 & 1.14 \\
10 & 0.44 & 0.59 & 0.70 & 0.85 & 0.93 & 1.05 \\
11 & 0.40 & 0.54 & 0.65 & 0.78 & 0.87 & 0.97 \\
12 & 0.37 & 0.51 & 0.60 & 0.73 & 0.81 & 0.91 \\
13 & 0.35 & 0.47 & 0.57 & 0.69 & 0.76 & 0.85 \\
14 & 0.33 & 0.45 & 0.53 & 0.65 & 0.72 & 0.81 \\
15 & 0.31 & 0.42 & 0.51 & 0.62 & 0.68 & 0.77 \\
16 & 0.29 & 0.40 & 0.48 & 0.59 & 0.65 & 0.73 \\
17 & 0.28 & 0.38 & 0.46 & 0.56 & 0.62 & 0.70 \\
18 & 0.27 & 0.36 & 0.44 & 0.54 & 0.59 & 0.67 \\
19 & 0.25 & 0.35 & 0.42 & 0.51 & 0.57 & 0.64 \\
20 & 0.24 & 0.34 & 0.40 & 0.49 & 0.55 & 0.62 \\
21 & 0.23 & 0.32 & 0.39 & 0.48 & 0.53 & 0.60 \\
22 & 0.22 & 0.31 & 0.37 & 0.46 & 0.51 & 0.58 \\
23 & 0.22 & 0.30 & 0.36 & 0.44 & 0.49 & 0.56 \\
24 & 0.21 & 0.29 & 0.35 & 0.43 & 0.48 & 0.54 \\
& 0.20 & 0.28 & 0.34 & 0.42 & 0.46 & 0.52 \\
\hline
\end{tabular}


Appendix E: Fort Bend County's rainfall totals, durations, and frequencies

\begin{tabular}{|c|c|c|c|c|c|c|}
\hline \multirow{2}{*}{$\begin{array}{c}\text { Duration } \\
\text { (hr) }\end{array}$} & \multicolumn{7}{|c|}{ Rainfall Totals (in) } \\
\cline { 2 - 7 } & $\mathbf{5 0 \%}$ & $\mathbf{2 0 \%}$ & $\mathbf{1 0 \%}$ & $\mathbf{4 \%}$ & $\mathbf{2 \%}$ & $\mathbf{1 \%}$ \\
\hline 1 & 2.4 & 2.9 & 3.4 & 3.9 & 4.3 & 4.6 \\
3 & 2.8 & 3.6 & 4.2 & 4.9 & 5.4 & 5.9 \\
4 & 3.1 & 4.0 & 4.7 & 5.6 & 6.1 & 6.7 \\
4 & 3.3 & 4.3 & 5.1 & 6.0 & 6.6 & 7.4 \\
5 & 3.5 & 4.6 & 5.4 & 6.5 & 7.1 & 7.9 \\
6 & 3.7 & 4.8 & 5.7 & 6.8 & 7.5 & 8.3 \\
7 & 3.8 & 5.0 & 5.9 & 7.1 & 7.8 & 8.8 \\
8 & 3.8 & 5.1 & 6.2 & 7.4 & 8.2 & 9.1 \\
9 & 4.0 & 5.3 & 6.3 & 7.7 & 8.4 & 9.5 \\
10 & 4.0 & 5.4 & 6.5 & 7.8 & 8.7 & 9.7 \\
11 & 4.1 & 5.6 & 6.6 & 8.0 & 8.9 & 10.0 \\
12 & 4.2 & 5.6 & 6.8 & 8.3 & 9.1 & 10.2 \\
13 & 4.3 & 5.9 & 6.9 & 8.5 & 9.4 & 10.5 \\
14 & 4.3 & 5.9 & 7.1 & 8.7 & 9.5 & 10.8 \\
15 & 4.4 & 6.0 & 7.2 & 8.9 & 9.8 & 11.0 \\
16 & 4.5 & 6.1 & 7.4 & 9.0 & 9.9 & 11.2 \\
17 & 4.6 & 6.1 & 7.5 & 9.2 & 10.0 & 11.4 \\
18 & 4.5 & 6.3 & 7.6 & 9.2 & 10.3 & 11.5 \\
19 & 4.6 & 6.5 & 7.6 & 9.3 & 10.5 & 11.8 \\
20 & 4.6 & 6.4 & 7.8 & 9.6 & 10.6 & 12.0 \\
21 & 4.6 & 6.5 & 7.8 & 9.7 & 10.7 & 12.2 \\
22 & 4.8 & 6.6 & 7.9 & 9.7 & 10.8 & 12.3 \\
23 & 4.8 & 6.7 & 8.1 & 9.9 & 11.0 & 12.4 \\
24 & 4.8 & 6.7 & 8.2 & 10.1 & 11.0 & 12.5 \\
\hline
\end{tabular}




\section{Appendix F: HEC-1 scripts of Oyster Creek Watershed for real-time hydrologic forecasting}

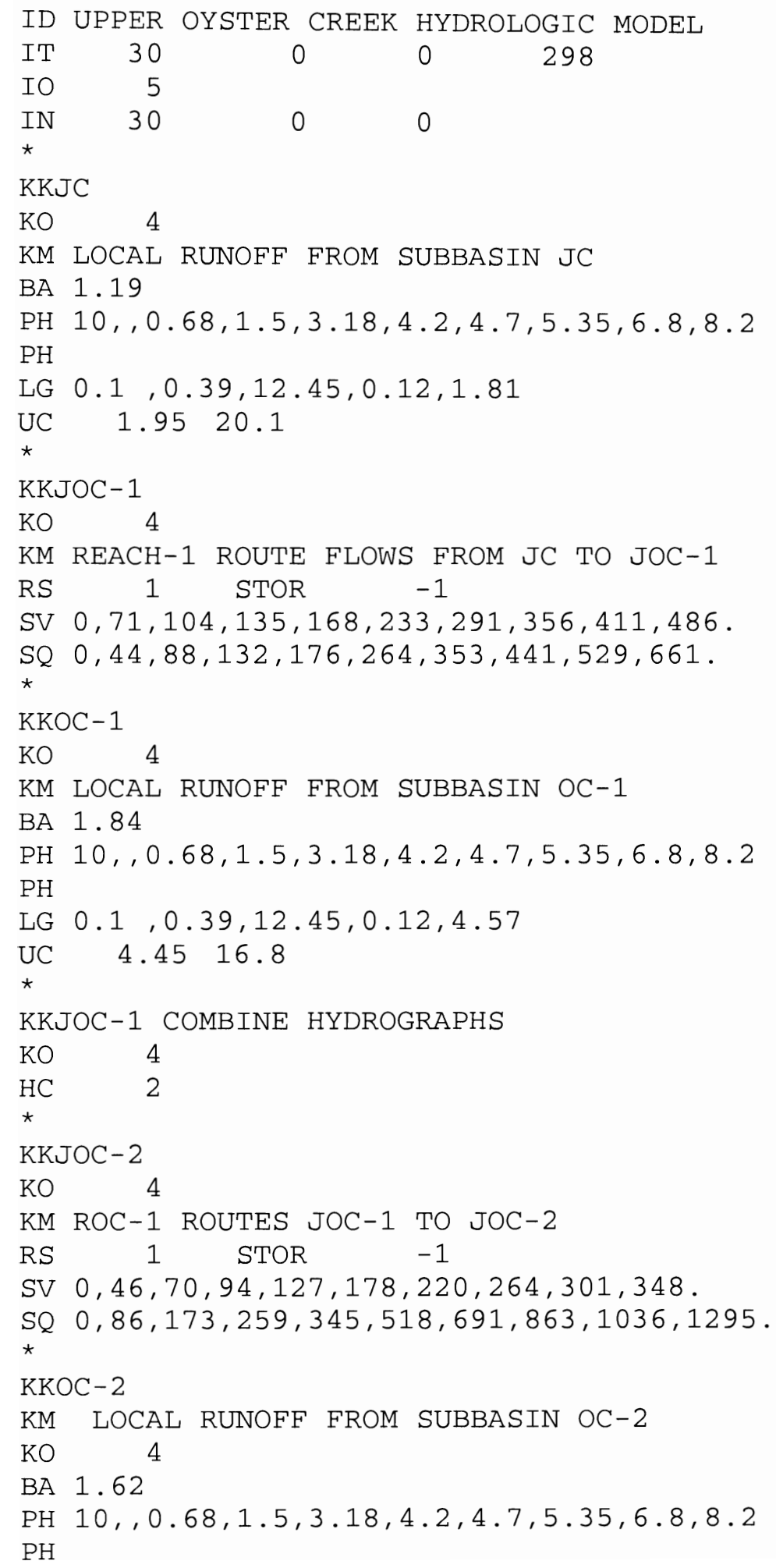









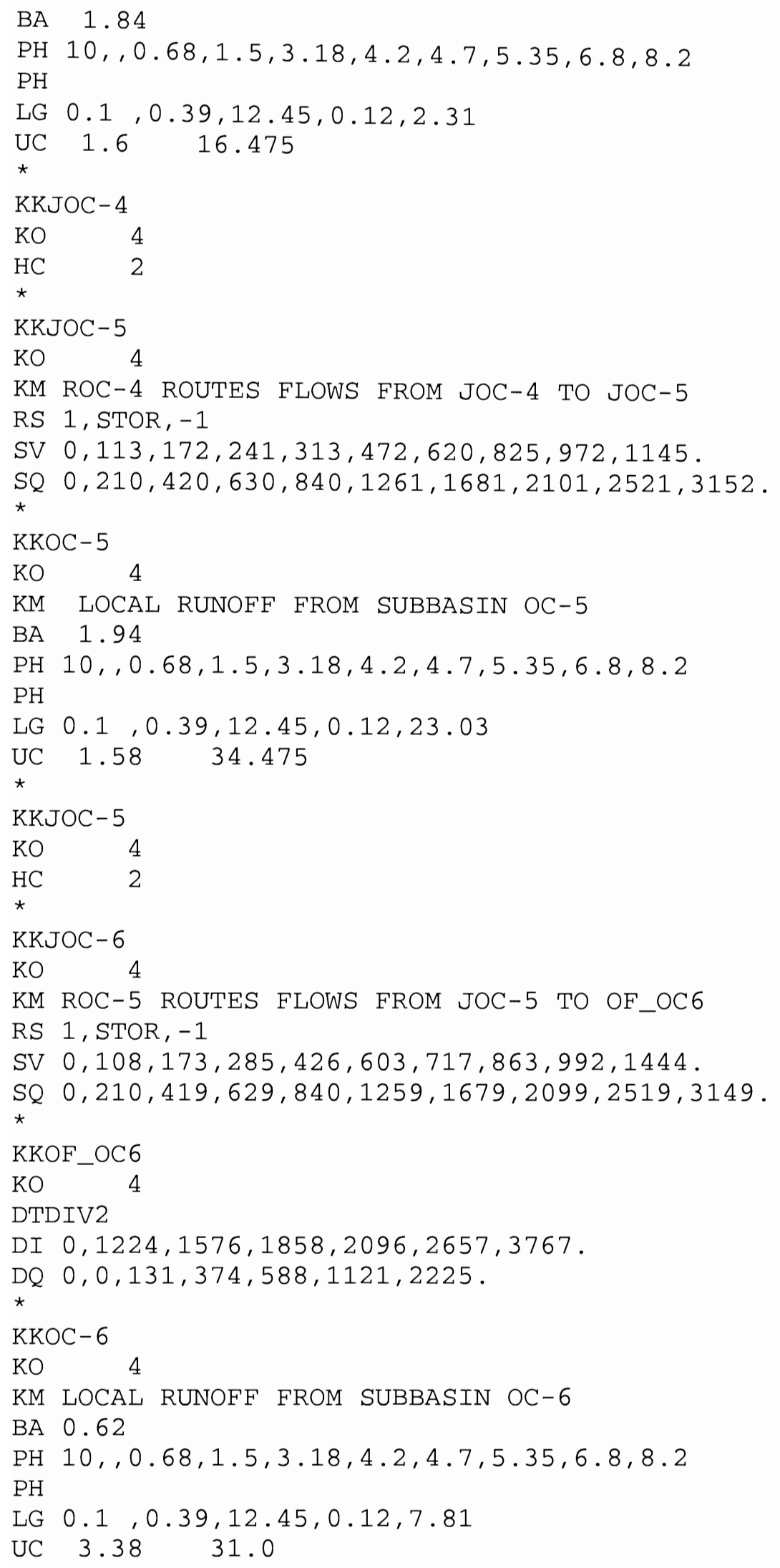




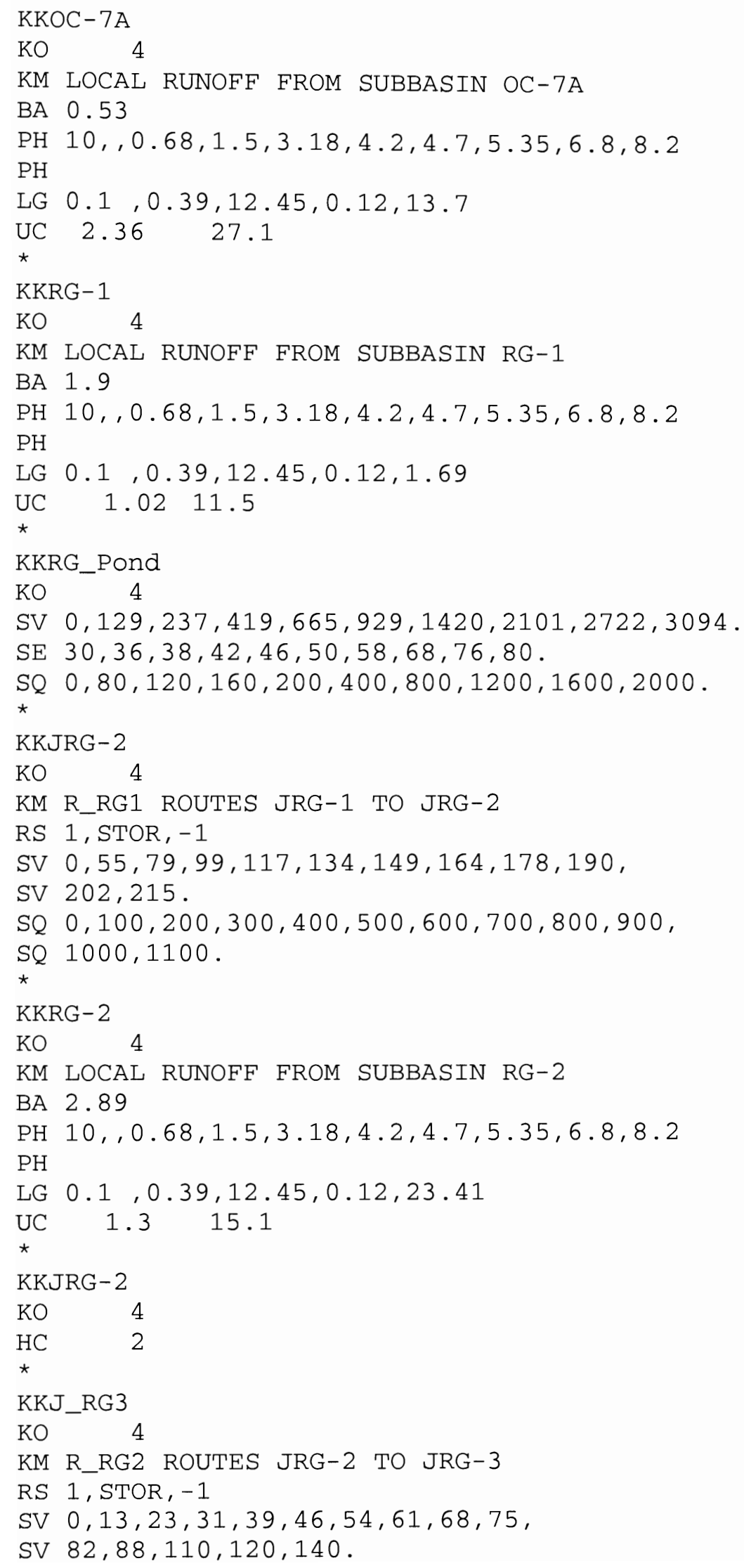




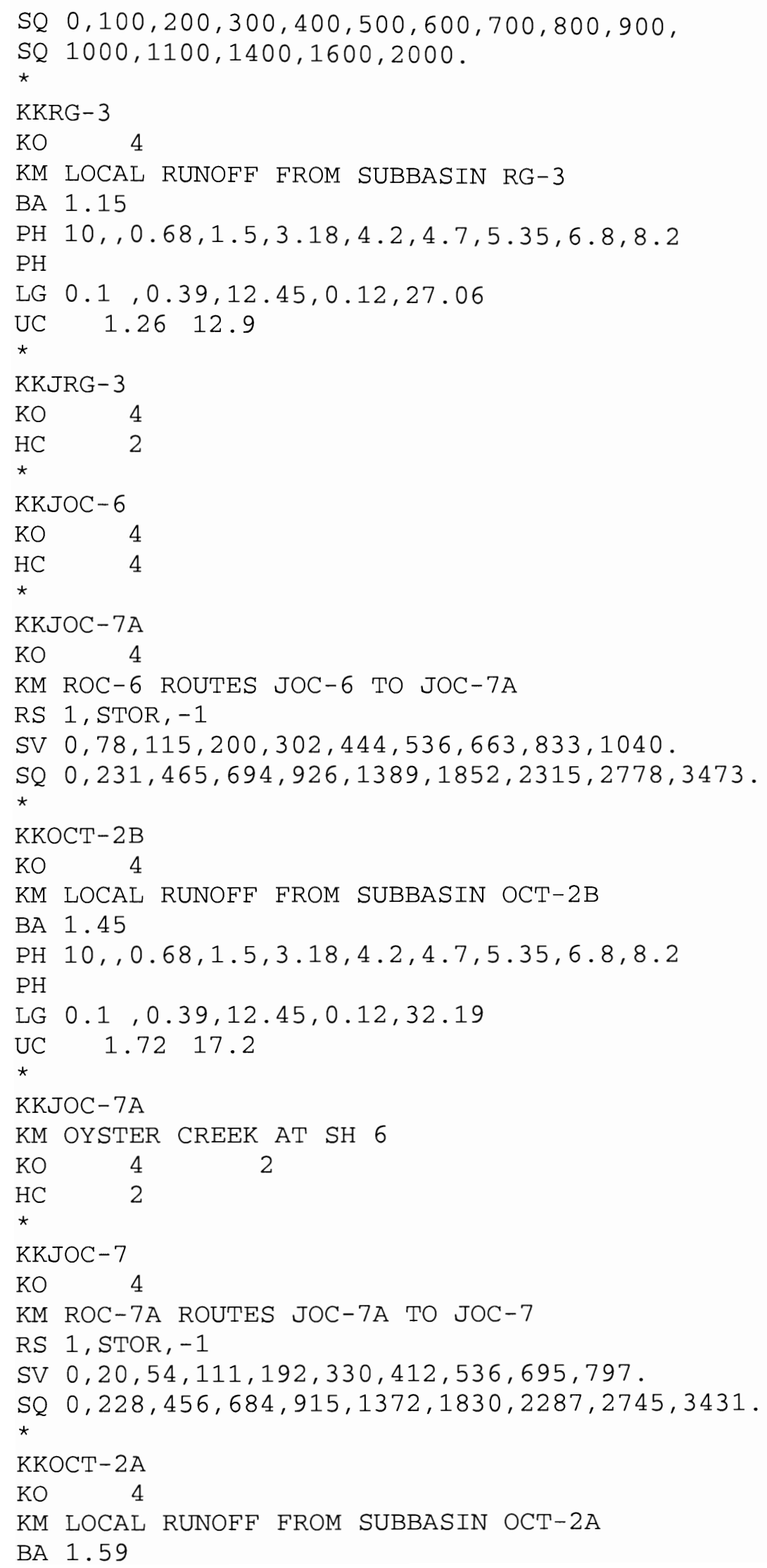




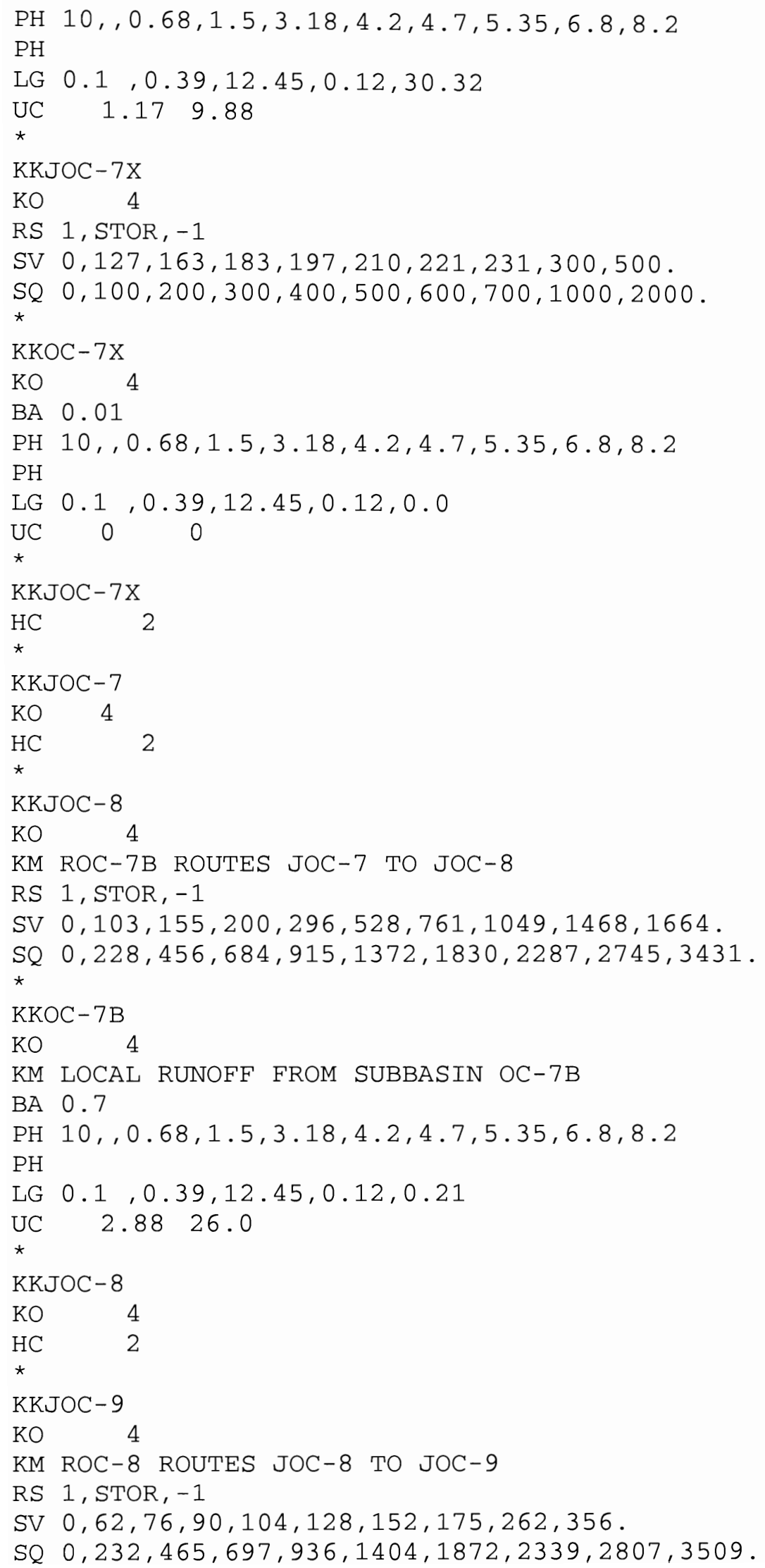




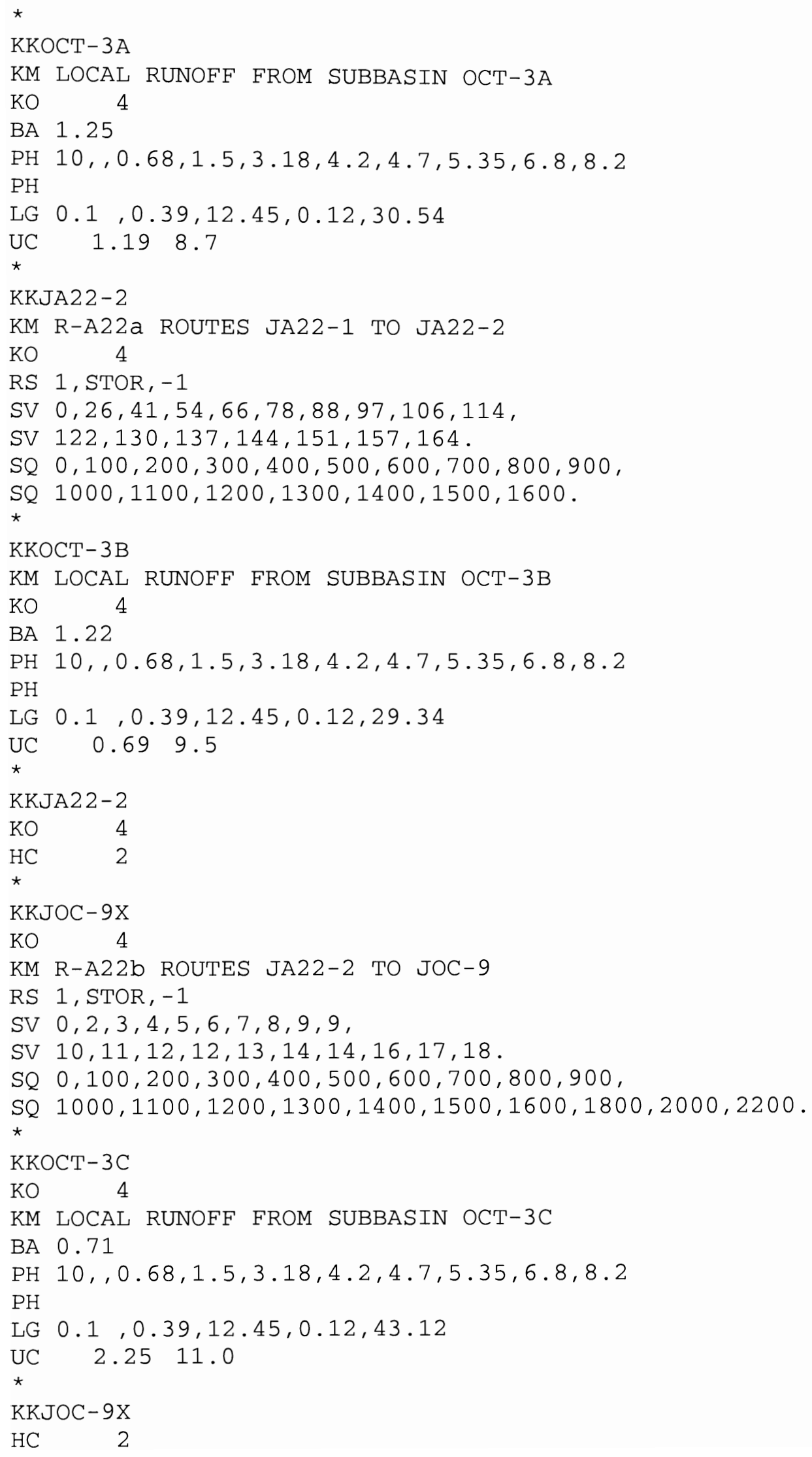




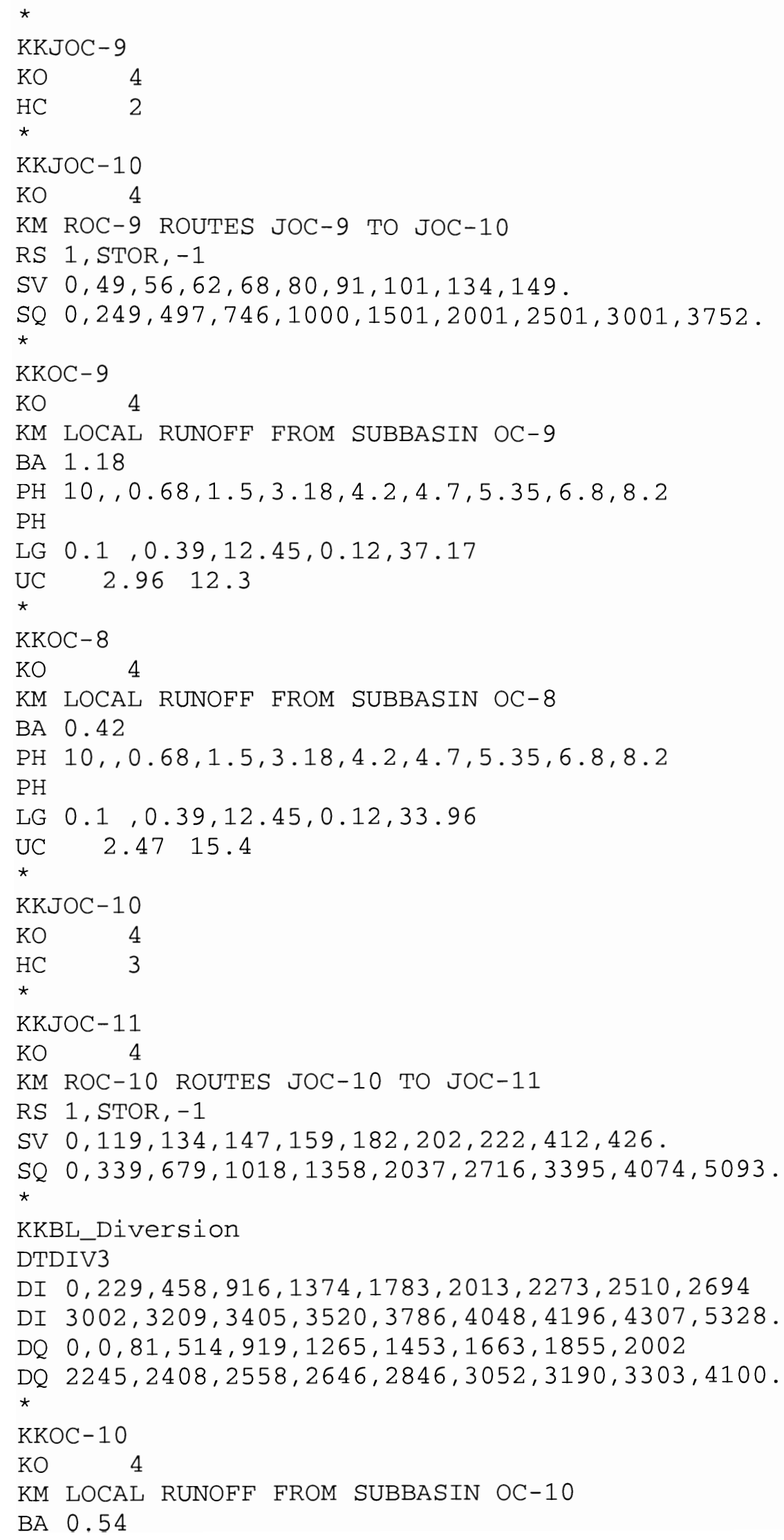




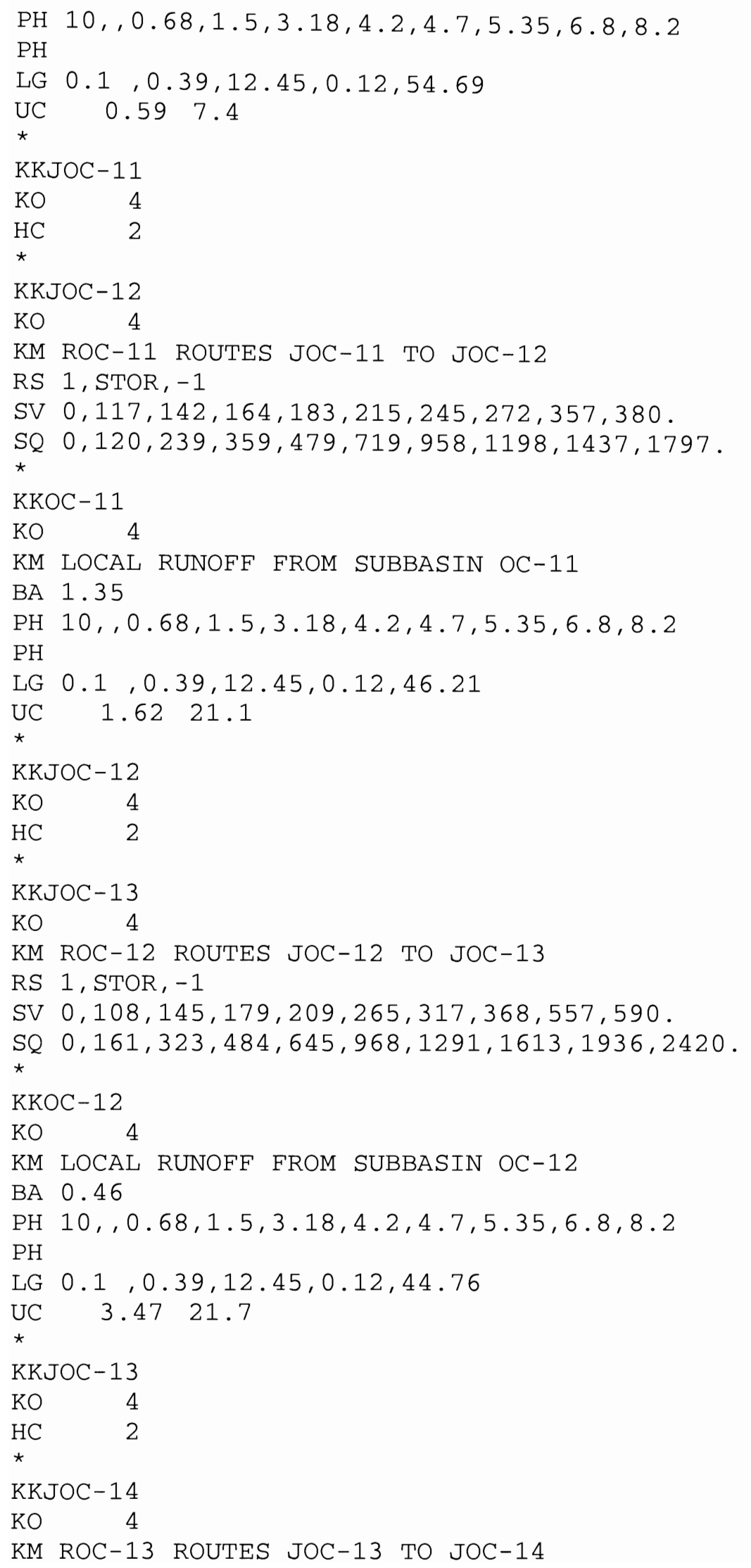




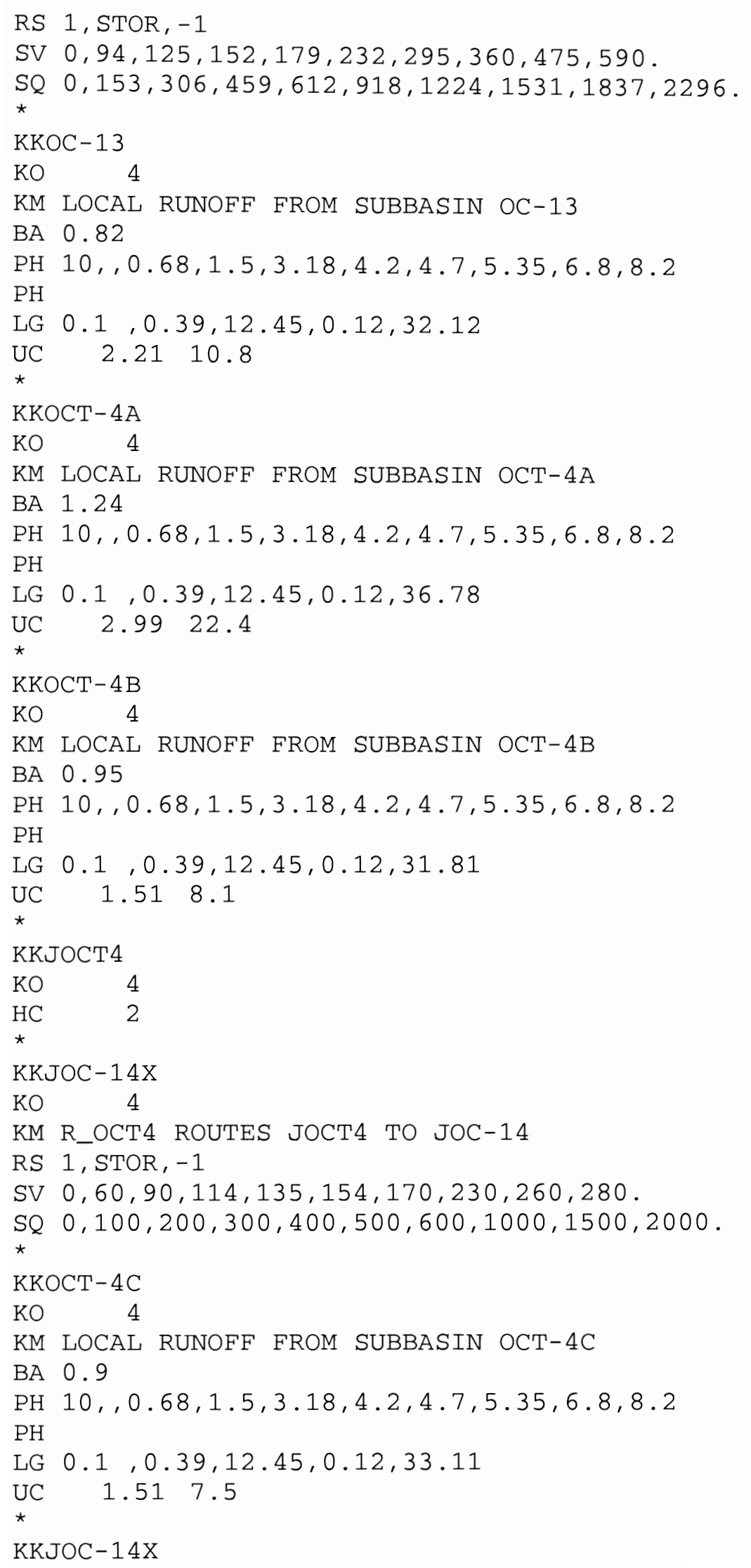




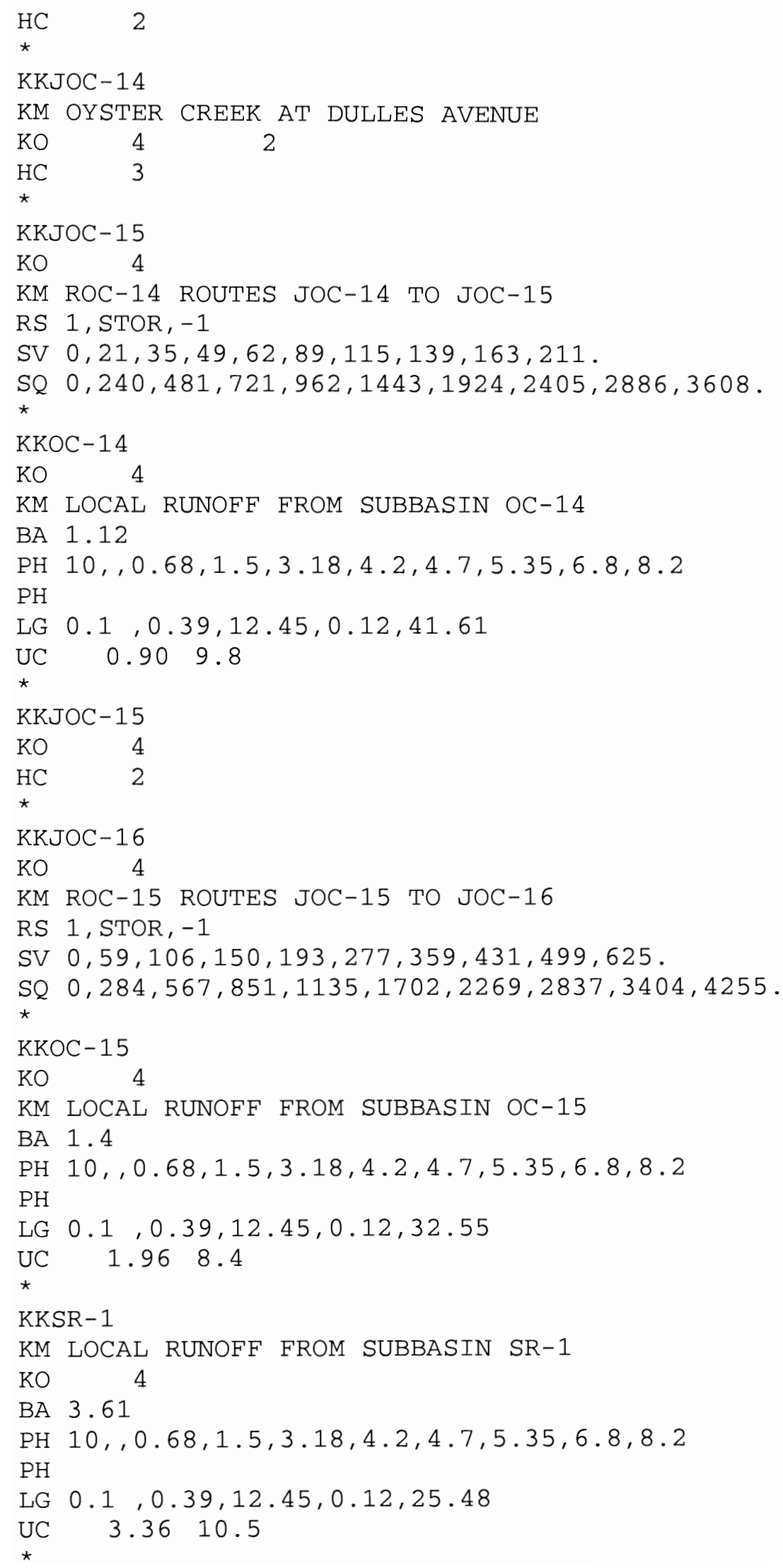




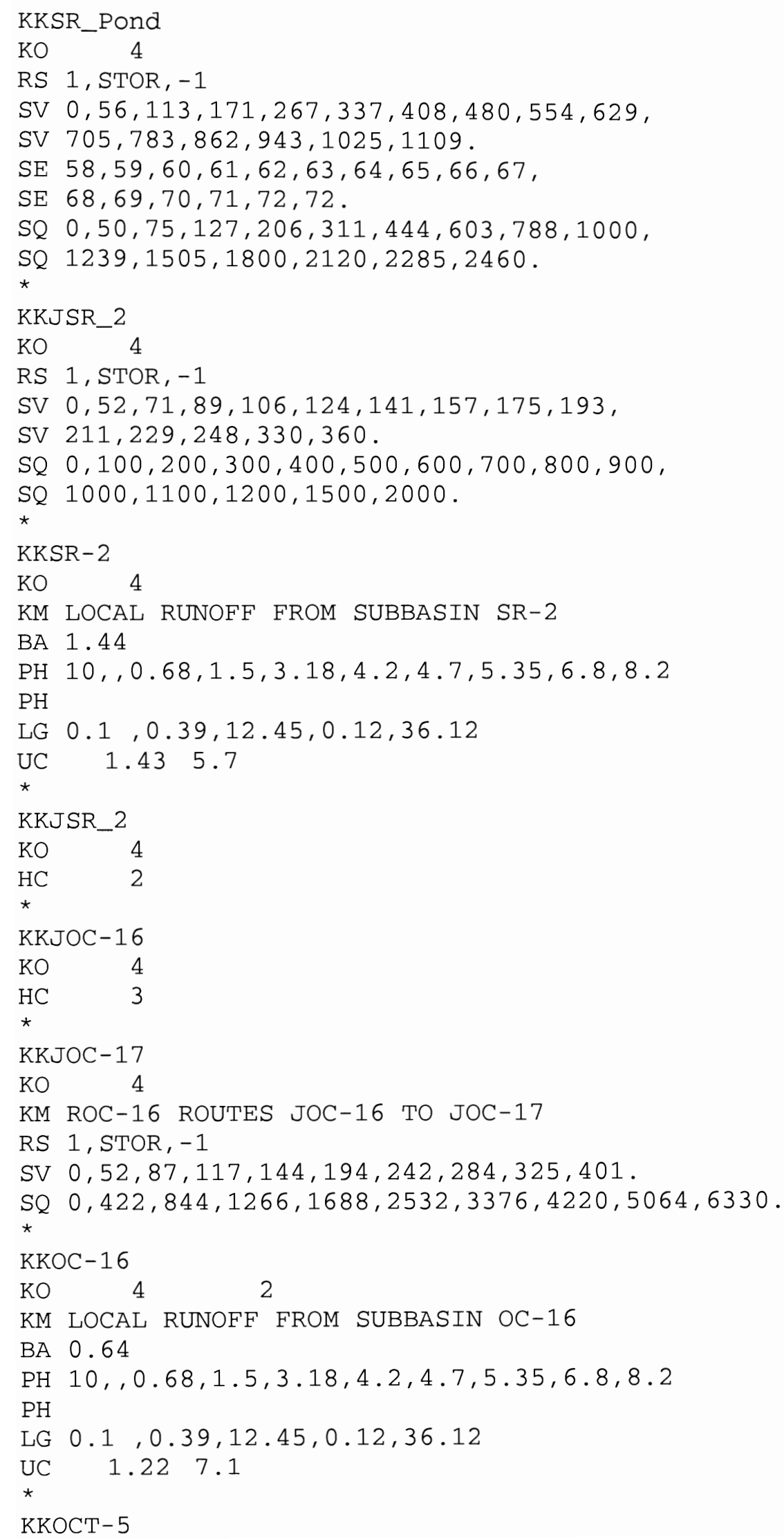




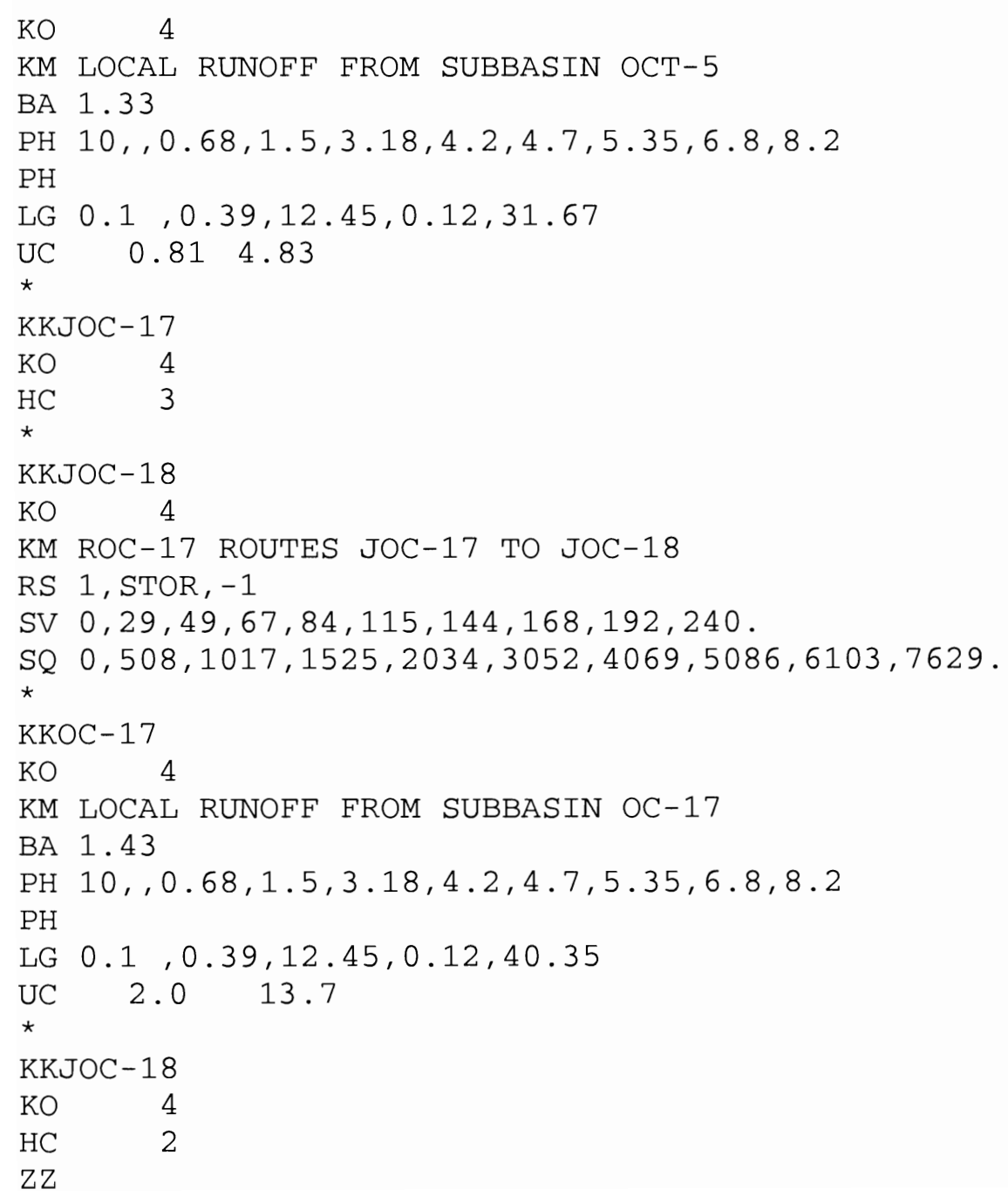

